\title{
Solution processed perovskite incorporated tandem photovoltaics: developments, manufacturing, and challenges
}

\author{
K. D. G. I. Jayawardena*, S. M. Silva, R. K. Misra \\ Advanced Technology Institute, Department of Electrical and Electronic Engineering, \\ University of Surrey, Guildford, Surrey, GU2 7XH, United Kingdom. \\ *Corresponding author e-mail: i.jayawardena@surrey.ac.uk
}

\begin{abstract}
Photovoltaics based on organic-inorganic as well as all inorganic semiconducting perovskites have emerged as a high performing concept at a lower cost. Intense research carried out in this regard over the last decade has resulted in single junction power conversion efficiencies that now exceed $25 \%$. Furthermore, combining wide-bandgap perovskites in combination with other narrow-bandgap absorbers have enabled efficiencies exceeding $24 \%$ in combination with both perovskite as well as other narrow-bandgap absorbers such as silicon. Such tandem architectures provide the possibility of increasing power conversion efficiency with either a little increase in cost or even at a lower cost. In this review, we discuss emerging tandem concepts that incorporate perovskites in at least one sub-cell and can also be printed on roll-toroll manufacturing lines. Initially, we discuss the progress in the field of perovskite/silicon tandem architectures followed by a discussion on perovskite/copper indium gallium selenide tandem devices. Then, recent progress in all-perovskite tandem devices is discussed. This is then followed by developments combining perovskites and organic bulk heterojunction absorbers. Subsequently, we discuss roll-to-roll and sheet-to-sheet printing techniques that can be used for scaled-up manufacturing of the above tandem concepts, which is then followed by reported work on perovskites that have utilised these printing techniques. Finally, we discuss prospects and future directions focusing on material stability and eliminating toxic solvents that are typically used in lab-scale perovskite solar cell fabrication processes and less well investigated applications such as for energy harvesting in space.
\end{abstract}




\section{Introduction}

Generation of energy through renewable sources and through sustainable means is one of the most important challenges humanity will have to overcome in the next few decades ${ }^{1}$. Among the key technologies that can enable renewable energy generation, photovoltaic (PV) energy harvesting is gaining momentum as a major contributor. Currently, photovoltaic modules based on silicon stands by-and-far, the widely deployed PV technology. However, there is still the need towards developing PV technologies that enables high efficiencies at low increase in cost. Furthermore, technologies at lower costs compared to the current technologies with low specific power output ${ }^{2}$ also open new market opportunities for non-grid based applications such as in building integrated photovoltaics ${ }^{3}$ etc.

Perovskite solar cells (PSCs), a thin film solar technology based on solution processable precursors, has rapidly emerged as both a competing, as well as supporting technology for $\mathrm{Si}$ PVs. Based on the $\mathrm{ABX}_{3}$ formula (Fig. 1(a)), there have been a number of compositions for perovskites reported with the A-site consisting of either an organic cation such as methylammonium ${ }^{4}\left(\mathrm{MA}=\mathrm{CH}_{3} \mathrm{NH}_{3}{ }^{+}\right)$, formamidinium ${ }^{5}\left(\mathrm{FA}=\mathrm{CH}\left(\mathrm{NH}_{2}\right)_{2}{ }^{+}\right)$, or an inorganic cation such as cesium ${ }^{6}\left(\mathrm{Cs}^{+}\right)$or a combination of these $\mathrm{e}^{7,8}$, the B-site consisting of lead $\left(\mathrm{Pb}^{2+}\right)^{7}$ or tin $\left(\mathrm{Sn}^{2+}\right)^{9}$ or a mixture of these $\mathrm{e}^{10-12}$ and the $\mathrm{X}$-site consisting of halides; iodide $\left(\mathrm{I}^{-}\right)$, bromide $\left(\mathrm{Br}^{-}\right)$, chloride $\left(\mathrm{Cl}^{-}\right)^{13}$ or a combination of these $\mathrm{e}^{4,7,14}$. Since its first demonstration as a photovoltaic material in 2009, the power conversion efficiency (PCE) of PSCs has seen a rapid increase from below $4 \%{ }^{15}$ to $25.2 \%^{16}$. Such impressive performances have been enabled due to promising characteristics such as high optical absorption coefficients, long carrier diffusion lengths exceeding $1 \mu^{17}$, excellent defect tolerance ${ }^{18}$ as well as low exciton binding energies ${ }^{19}$. Recent efforts have also seen developments in pathways for improved device stability ${ }^{20,21}$. However, the performance of single junction PSCs are limited by the Shockley Queisser limit of $\sim 33 \% \%^{22}$. A potential route towards bypassing this limit is through the formation of tandem architectures which is enabled by the bandgap $\left(E_{G}\right)$ tunability ${ }^{23}$ of perovskite absorbers through compositional engineering of the halides ${ }^{14}$, or the B-site ${ }^{12}$ enabling the formation of both wide bandgap and narrow bandgap absorber fabrication (Fig. 1(b) and (c)). This in turn has resulted in impressive developments not only in perovskite/Si tandem architectures with PCEs exceeding 29\% (certified) ${ }^{16}$, other perovskite incorporated tandem devices with efficiencies approaching $25 \%{ }^{12,16,24}$. 
As highlighted above, one of the key attractions of PSCs has been their solution processability. This can potentially enable high-throughput production based on roll-to-roll (R2R) and sheetto-sheet (S2S) fabrication methodologies based low cost, high throughput printing techniques such as slot die coating, ink jet printing, spray coating, doctor blading. In fact, there are ongoing industrially driven research and development activities towards the realization of printed perovskite solar technologies from companies such as Panasonic ${ }^{25}$, Saule Technologies ${ }^{26}$, and more recently, Swift Solar $^{27}$ to name a few.

With the developments in large area printed single junction perovskites, it is timely and important to consider the possibility of incorporation of such printed perovskite layers to manufacture tandem architectures. While the tandem device architectures can result in an increase in cost, this is often argued to be offset by the potentially higher PCEs possible. In fact, the possibility of developing low cost tandem architectures based on printed technologies was a key goal for organic photovoltaic (OPV) technologies towards realizing low cost renewable energy generation. ${ }^{28,29}$ With the advent of perovskites it is evident that the possibilities for such all printed tandem technologies have also dramatically enhanced. Some of the possible combinations in this regards include PSC (wide $E_{G}$ )/silicon (narrow $E_{G}$ ) or PSC (wide $E_{G}$ )/copper indium gallium selenide (CIGS, narrow $E_{G}$ ) for semi-printable approaches or PSC (wide $E_{G}$ )/PSC (narrow $E_{G}$ ) or PSC(wide $E_{G}$ )/OPV (low $E_{G}$ ) or even organic photovoltaics (OPV, wide $E_{G}$ )/PSC (low $E_{G}$ ) combinations for all-printed approached.

This review is structured as follows (Fig. 1(d)): initially, we will discuss the benefits of tandem architectures. This will be followed by developments in perovskite incorporated 2-terminal (2T) tandem technologies. Initially, we discuss recent developments in perovskite/silicon and perovskite CIGS tandem devices. This is followed by a discussion on potentially all-solution processable $2 \mathrm{~T}$ which includes all-perovskite tandem architectures, perovskite-OPV tandem architectures and, other emerging systems such as those based on quantum dots. We then discuss developments made in $\mathrm{R} 2 \mathrm{R}$ and $\mathrm{S} 2 \mathrm{~S}$ printing techniques for printing perovskite absorbers. Finally, we outline the current challenges and future directions that can enable such printed, perovskite incorporated tandem architectures to be realized. 
a

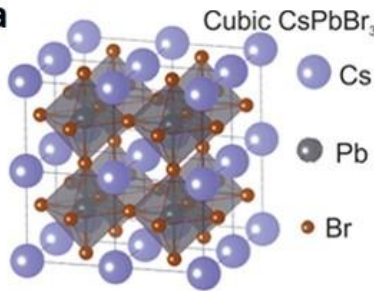

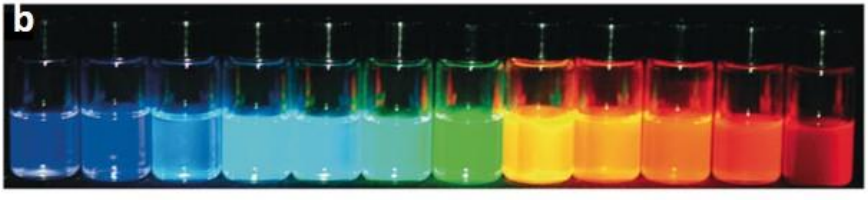

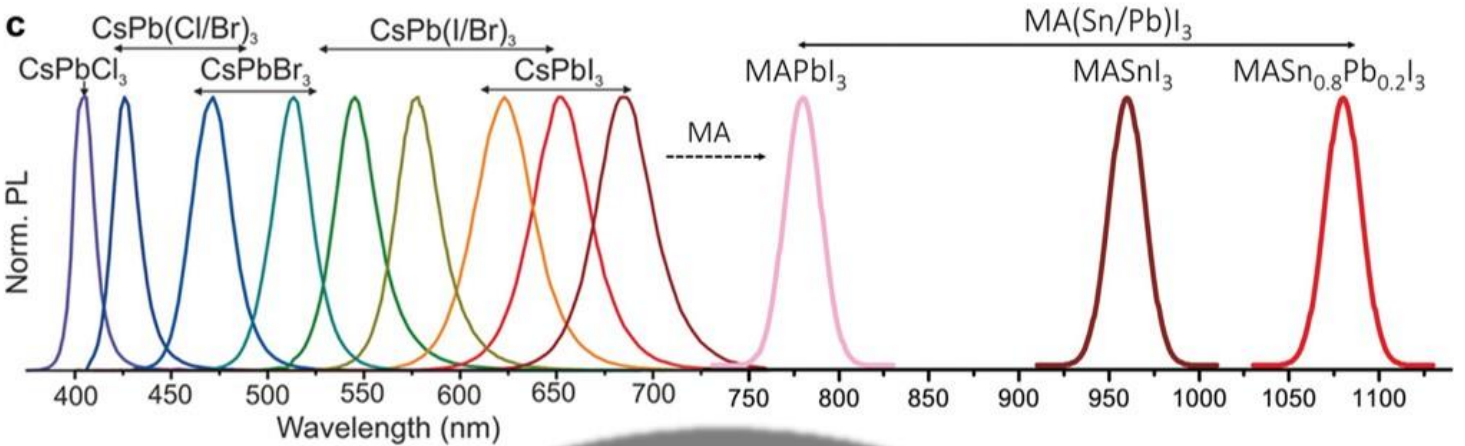

d

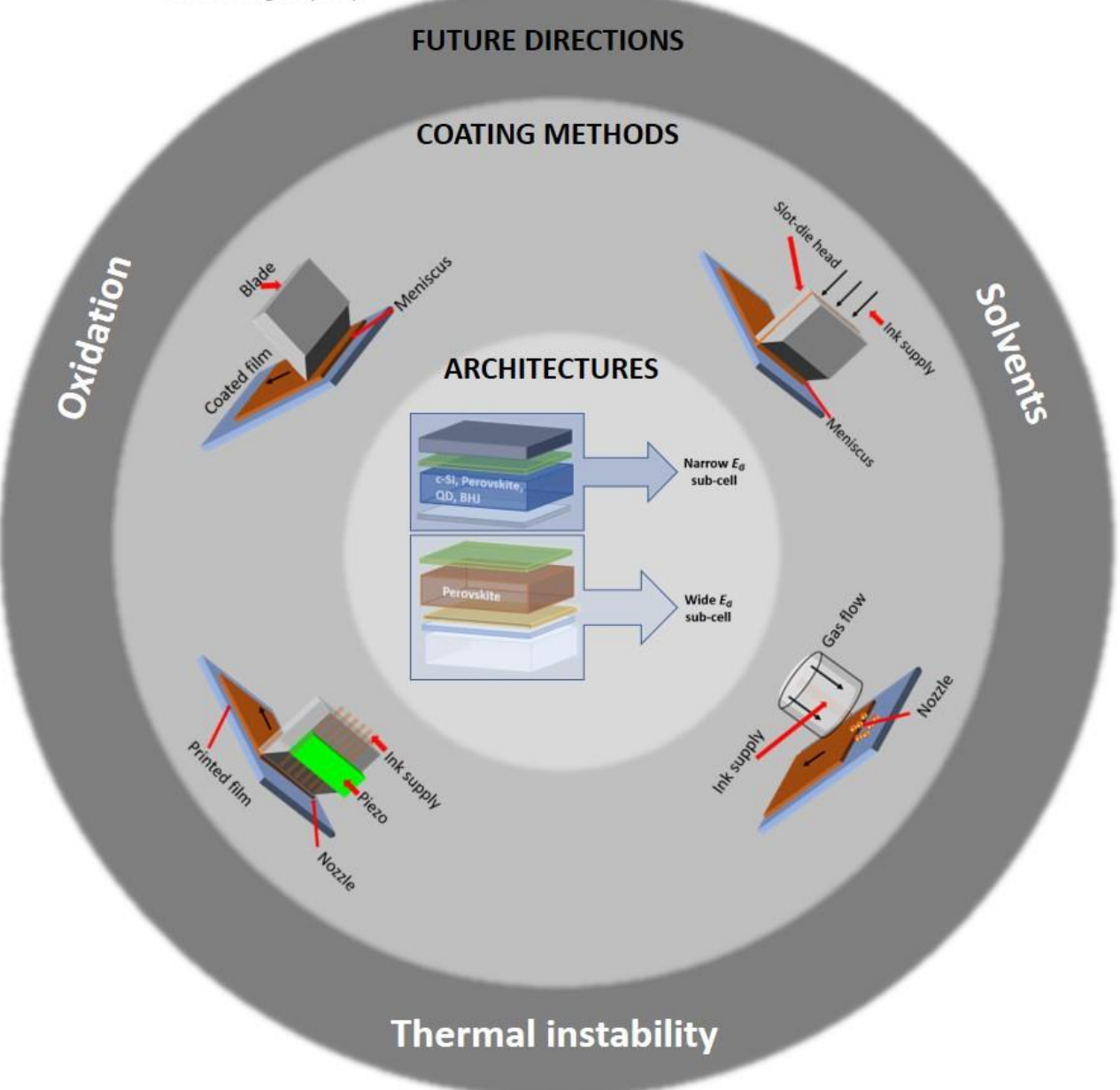

Fig. 1 (a) The arrangement of ions under the $\mathrm{ABX}_{3}$ crystal structure for a perovskite. (b) Example of bandgap tunability of perovskites. ${ }^{30}$ Here the $\mathrm{X}$-site $\left(\mathrm{Cl}^{-}, \mathrm{Br}^{-}, \mathrm{I}^{-}\right)$composition is varied in $\mathrm{CsPbX}_{3}$ quantum dots. Reprinted with permission from Ref. 30. Copyright (2015) American Chemical Society. (c) Bandgap tunability of perovskites shown here through variation of the B-site and X-site. ${ }^{23}$ Reproduced from Ref. 23 with permission from Wiley-VCH. (d) The overall structure of this review discussing the material combinations, printing methods and challenges, prospects. 


\section{2T tandem technologies}

One of the principle bottle necks of a single junction technology is the thermalization losses ${ }^{31}$ ((Fig. 2(a)) due to the absorption of photons with energies higher than the $E_{G}$, which restricts the maximum possible cell voltage to $\left(E_{G}-0.3\right) / \mathrm{e} \mathrm{V}$ where $e$ is the electronic charge and the $0.3 \mathrm{eV}$ term is due to fundamental thermodynamic losses ${ }^{32,33}$. One potential route towards bypassing this limit is thorough combining sub-cells in a series connection ${ }^{31}$ (Fig. 2(b)) where the photocurrent generated in each cell is matched or balanced to minimize losses. This has infact resulted in III-V multijunction cells consisting of six junctions with PCEs exceeding $39 \%$.

The theoretical maximum for all PV devices is estimated based on the detailed balance limit principle $^{32}$. For single junction devices, this often results in a theoretically possible maximum of $33 \%$ for a single junction cell which is increased to $46 \%$ for a 2 T 2 -junction (2J) (Fig. 2(c)) architecture. This can be further increased up to $52 \%$ for a triple junction (3J) architecture, and up to $68 \%$ for an infinite number of junctions ${ }^{34}$. With regards to perovskites incorporated in tandem architectures, Hörantner et al. ${ }^{35}$ estimated the impact of fabrication of all perovskite tandem architectures based on 2T-2J concept by combining absorbers with $E_{G} \mathrm{~S}$ of $0.9-1.35$ $\mathrm{eV} \& 1.5-2.0 \mathrm{eV}$ which was shown to enable PCEs of $\sim 32 \%$ while a $2 \mathrm{~T}-3 \mathrm{~J}$ scheme combining sub-cells with $E_{G}$ of $1.22 \mathrm{eV}, 1.50-1.90 \mathrm{eV} \& 1.90-2.30 \mathrm{eV}$ was shown to enable PCEs of $33.1 \%$ (Fig. 2(e)-(f)). It was noted that the appropriate matching of $E_{B G} \mathrm{~S}$ is crucial in obtaining the best PCE. In terms of combining perovskites with absorbers based on other semiconductors (e.g. OPVs), it is noted that appropriate losses that are over and above the losses typically observed for crystalline systems should also be also taken into consideration. For example, in OPVs, the fundamental voltage loss for a large portion of its early development was identified to be at $0.6 \mathrm{~V}$ due to the energy level alignments required for exciton dissociation. However with the recent resurgence in the field in development of new donor and acceptor systems, this loss has been reduced ${ }^{36}$, thereby enabling the previously identified target of $15 \%{ }^{29}$ for $2 \mathrm{~T}-2 \mathrm{~J}$ architecture to be surpassed ${ }^{37}$.

Beyond the benefit of minimizing thermalization losses, the use of multijunction concepts can also enable the balancing of optical absorption with efficient charge extraction. For example, while increasing the thickness of an absorber is beneficial to enable a higher generation of carriers, this may not be matched with the diffusion lengths of the absorber material. Therefore, the stacking of the same absorber to form multijunction architectures is also seen as a favorable 
route towards minimizing losses ${ }^{38}$. This has been implemented in both OPVs and as well as in all-perovskite architectures.

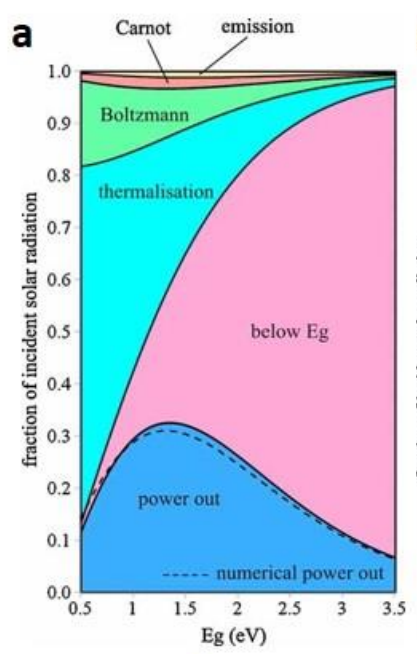

d
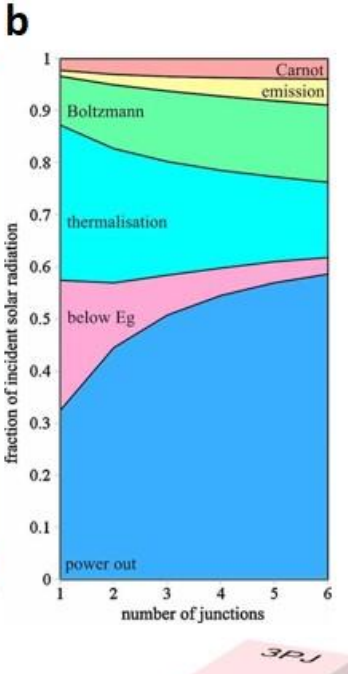

C
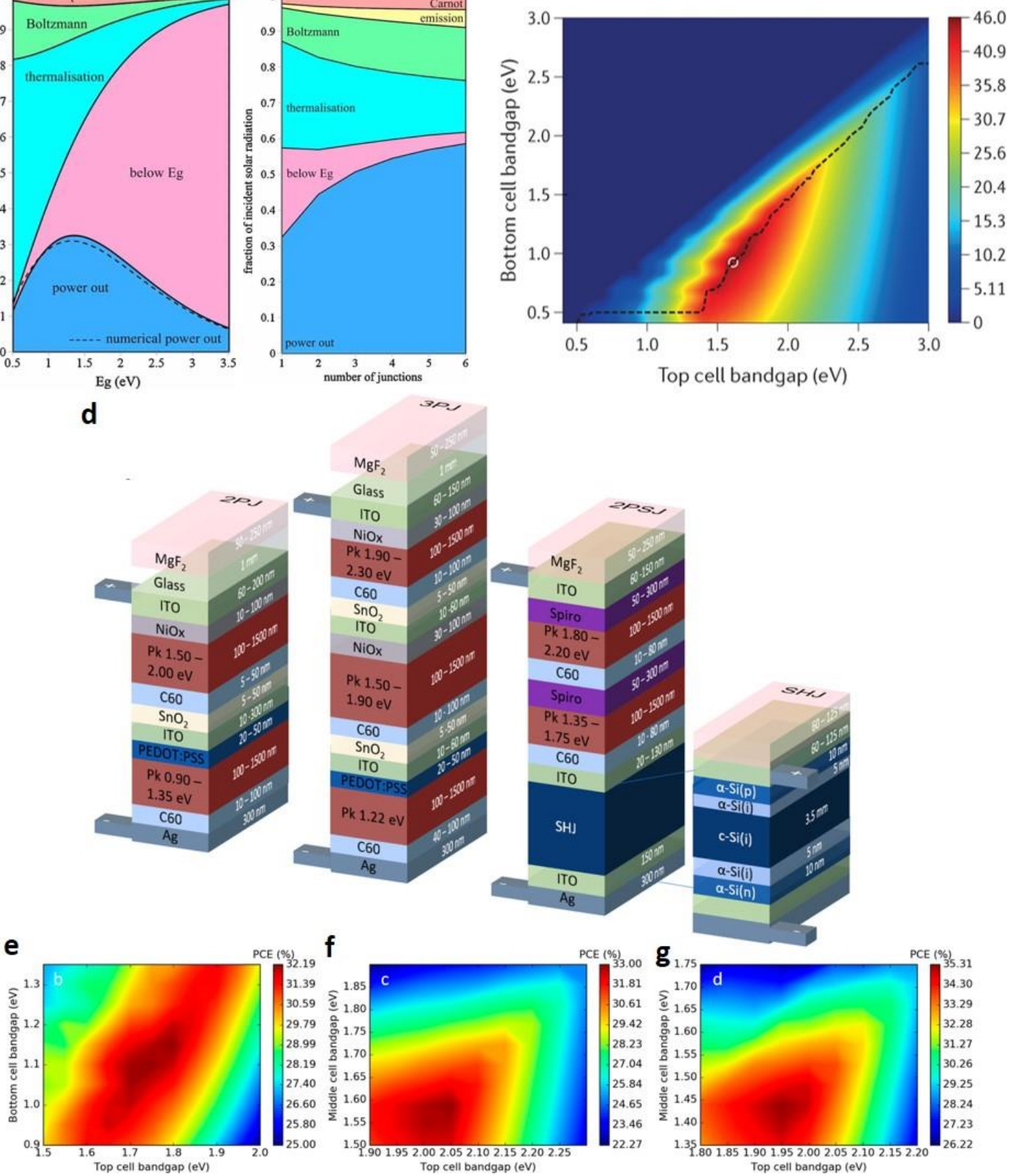
PCE ( $($ (s) $), f$
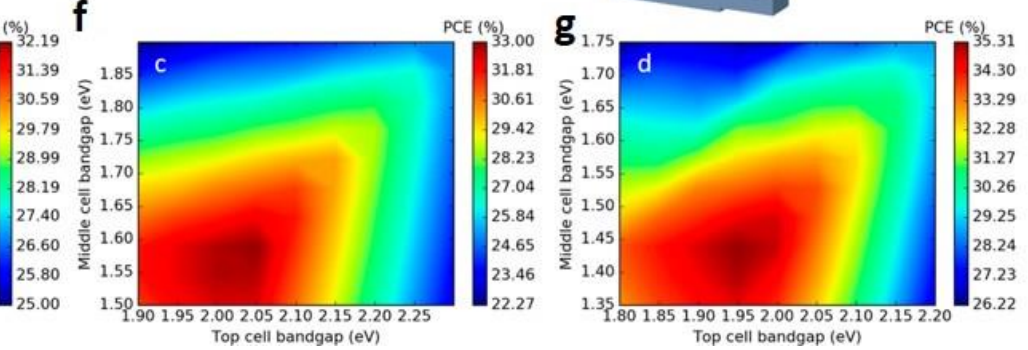

Fig. 2 Contribution of different loss mechanisms under (a) varying absorber $E_{G}$ and (b) number of junctions in a tandem architecture. ${ }^{31}$ Reproduced from Ref. 31 with permission from Wiley-VCH. (c) The predicted theoretically possible PCE for different combinations of top and bottom cell bandgaps. ${ }^{34}$ The white circle indicates the maximum PCE. Reproduced from Ref. 34 with permission from Springer Nature. (d) Potential multijunction cell combinations who's estimated PCEs are given in (e) for 2T$2 \mathrm{~J}$ tandems combining absorbers with $E_{G} \mathrm{~S}$ of $0.9-1.35 \mathrm{eV} \& 1.5-2.0 \mathrm{eV}$, (f) for 2T-3J devices with absorber $E_{G}$ of $1.22 \mathrm{eV}$ combined with 2 absorbers possessing $E_{G}$ in the $1.50-1.90 \mathrm{eV}$ range \& $(\mathrm{g}$ ) for absorber $E_{G}$ of $1.22 \mathrm{eV}$ combined with 2 absorbers possessing $1.90-2.30 \mathrm{eV} .{ }^{35}$ Reprinted with permission from Ref 35. Copyright (2017) American Chemical Society. 


\section{Perovskite incorporated tandem concepts}

We now proceed to discuss tandem technologies that have been reported based on the incorporation of a perovskite absorber.

\section{a) Perovskite/silicon tandem photovoltaics}

From the photovoltaic technologies that have been studied and developed so far, crystalline silicon (c-Si) has been the most successful in terms of commercial implementation. Consisting of a low $E_{G}$ of $1.1 \mathrm{eV}$, high PCEs exceeding $23 \%$ over large areas, non-toxicity and excellent stability, c-Si has been the benchmark for all emerging single junction PV technologies. ${ }^{16}$ As the efficiency of single junction cells approaches the theoretical limit for this material ${ }^{39}$, there have been significant efforts to identify an appropriate wide $E_{\mathrm{G}}$ absorber to form tandem architectures. Among the technologies that enable the formation of wide $E_{\mathrm{G}}$ sub-cells, perovskites have so far been the most promising due the bandgap tunability over $1.6-1.8 \mathrm{eV}$ through compositional engineering, low processing costs, and high efficiency. ${ }^{40,41}$ As a result, an industrial demonstrator with a PCE of $28 \%$ based on a 2T perovskite/silicon tandem cell has been reported by Oxford PV which was recently exceeded by a $2 \mathrm{~T}$ perovskite/silicon architecture with a PCE of $29.2 \% .{ }^{16}$ The latter is the first demonstrator where the efficiency of a single junction c-Si cell has been exceeded based on the incorporation of a printable wide $E_{G}$ cell. In terms of the c-Si cell, both homojunction and heterojunction architectures have been used in conjunction with a perovskite sub-cell. Si heterojunction technology (SHT) offers improved device performance and cost advanatges, ${ }^{42}$ although the former, which accounts for $>80 \%$ of the market share for photovoltaics ${ }^{43}$ enables processing at higher temperatures, enabling compatibility with the mesoporous perovskite architecture ${ }^{44}$.In the following sections, we will first discuss developments based on homojunction Si technologies followed by developments using SHT. A summary of reported device performances is given in Table 1.

The first reported work on a $2 \mathrm{~T}$ perovskite/silicon based on a silicon homojunction architecture was by Mailoa et al. ${ }^{45}$ The perovskite absorber used was based on the $\mathrm{MAPbI}_{3}$ composition which was identified to possess an $E_{G}$ of $1.61 \mathrm{eV}$. Utilizing a mesoscopic architecture for the perovskite cell in combination with a c-Si cell resulted in a PCE of 13.7\%. The low PCE observed were attributed to several issues including the use of a non-textured surface for fabrication of the perovskite sub-cell and lack of passivation. Indeed, the use of non-textured surface has been a favoured approach for a majority of developments in perovskite/silicon tandem architectures due to difficulties in achieving conformable perovskite coatings on 
textured surfaces. However, we note recent reports that identify routes towards the deposition of perovskites on textured surfaces. ${ }^{46,47}$ Following the above work, Werner et al. reported ${ }^{48}$ a tandem architecture comprising of a high temperature processed mesoscopic perovskite subcell together with a c-Si cell. A PCE of $16 \%$ was achieved, which is higher than that reported by Mailoa et al. ${ }^{45}$ This was enabled by incorporation of passivation strategies for the silicon sub-cell and also the use of better optimized recombination layers. Silicon oxide $\left(\mathrm{SiO}_{\mathrm{x}}\right)$ was used as a passivation layer on both surfaces of the $n$-type silicon wafer which enabled a higher $V_{O C}$ to be achieved compared to Mailoa et al. ${ }^{45}$ The hole-collecting emitter (through boron implantation), as well as the local contact and back surface field (BFS) formation (through phosphorous implantation) was formed through laser patterning. Improvements in PCE were also driven by optimization of the recombination layer thicknesses. This was also noted to influence the optical interference pattern in the Si cell which occurs due to the refractive index mismatch between compact titanium oxide $\left(\mathrm{c}-\mathrm{TiO}_{2}\right)$ electron transport layer in the perovskite sub-cell and the zinc tin oxide (ZTO) recombination layer. As noted above, the optimization of the optical coupling due to the influence of each layer used in tandem architectures is another key point for PCE gains. Further improvements in the PCE for the above work was noted to be limited by the interfacial resistance which limited the fill factor $(F F)$ of the device. A significant improvement for perovskite/silicon tandems incorporating a mesoscopic perovskite sub-cell was reported by $\mathrm{Wu}$ et $\mathrm{al}^{49}$ where a PCE of $22.5 \%$ was obtained. The authors incorporated several notable improvements. Firstly, passivation of front and rear surface was carried out which also enabled optimization of the optical coupling. An alumina $\left(\mathrm{Al}_{2} \mathrm{O}_{3}\right)$ /silicon nitride $\left(\mathrm{SiN}_{\mathrm{x}}\right)$ bilayer was used on the front surface for better matching of refractive indices and suppression of reflection losses while the rear $\mathrm{SiN}_{\mathrm{x}}$ layer enhanced light trapping (and as a result, the current). To minimize resistive losses due to the contact resistance between the indium tin oxide (ITO) recombination layer and the boron emitter, a factor which restricted the performance in the cells developed by Werner et al. ${ }^{48}$, an array of $\mathrm{Cr} / \mathrm{Pd} / \mathrm{Ag}$ metal stacks was used for the contact openings. The authors also used a quadruple cation composition $^{50}$ of the form $\mathrm{Cs}_{0.07} \mathrm{Rb}_{0.03} \mathrm{FA}_{0.765} \mathrm{MA}_{0.135} \mathrm{PbI}_{2.55} \mathrm{Br}_{0.45}$ which when processed with vacuum flash assisted solution process (VASP) as reported by $\mathrm{Bi}$ et al. ${ }^{51}$ improved reproducibility.

In most of the above reports, the use of a relatively high conductivity metal oxide recombination contact has been a common factor. Zheng et al. ${ }^{52}$ demonstrated a tandem device based on a planer $\mathrm{MAPbI}_{3}$ cell where such a recombination contact was removed. The resulting 
devices demonstrated steady-state PCEs of $20.5 \%$ over $4 \mathrm{~cm}^{2}$ and $17.1 \%$ over $16 \mathrm{~cm}^{2}$. In place of the widely used $\mathrm{TiO}_{2}$ electron extraction contact for the perovskite, tin oxide $\left(\mathrm{SnO}_{2}\right)$ based on a colloidal solution was used, enabling compatibility with printed manufacturing routes. Rear texturing of bottom silicon cell enabled improved light trapping while the use of a metal grid together with the top ITO transparent contact also minimized sheet resistance losses, thereby improving device $F F$. Shen et al. ${ }^{43}$ developed a similar concept where c- $\mathrm{TiO}_{2}$ deposited using atomic layer deposition (ALD) on both homojunction as well as passivating contact heterojunction cells. Together with a $\mathrm{Cs}_{0.05} \mathrm{Rb}_{0.05} \mathrm{FA}_{0.765} \mathrm{MA}_{0.135} \mathrm{PbI}_{2.55} \mathrm{Br}_{0.45}$ leading to stabilised PCEs of $22.8 \%$ and $24.1 \%$ respectively (Fig. 3(a) and (b)).

One of the limitations perovskite incorporated tandem architectures has been the parasitic absorption losses due to 2,2',7,7'-Tetrakis[N,N-di(4-methoxyphenyl)amino]-9,9'spirobifluorene (Spiro-OMeTAD), the most widely used hole transport layer in PSCs. To mitigate this issue, Zheng et al. ${ }^{53}$ used textured polydimethylsiloxane (PDMS) film that incorporated a down-shifting phosphor $(\mathrm{Ba}, \mathrm{Sr})_{2} \mathrm{SiO}_{4}: \mathrm{Eu}^{2+}$ in front of monolithic perovskite/silicon tandem. The phosphor converted near UV light to visible light, thereby bypassing parasitic absorption losses in Spiro-OMeTAD. Based on the above approach, a further improved PCE of $23.1 \%$ on $4 \mathrm{~cm}^{2}$ cell with a high $F F$ of $81 \%$ was reported (Fig. 3(c)).

In the above reports, $n$-type silicon was widely adopted. However, c-Si cells based on $p$-type Si account for a large market share. ${ }^{54}$ Therefore, in this regard, it would be advantageous to develop perovskite/silicon tandem architectures based on $p$-type Si wafers. In this regard, Kim et al. ${ }^{55}$ reported design rules for planar monolithic perovskite/ $p$-type Si Tandem solar cells based on controlling of the thickness and $E_{G}$ of the perovskite absorber as well as the selection of an appropriate hole transport layer. Using a double cation $\left(\mathrm{FAPbI}_{3}\right)_{0.8}\left(\mathrm{MAPbBr}_{3}\right)_{0.2}$ composition, a PCE of $21.19 \%$ was achieved.

The first perovskite/silicon tandem architecture based on the SHT concept was reported in 2015 by Albrecht et al. ${ }^{56}$. The authors reported the use of atomic layer deposited $\mathrm{SnO}_{2}$ to form the electron extraction contact, enabling a stabilized PCE of $18.1 \%$ to be achieved together with high $V_{O C}$ of $1.78 \mathrm{~V}$. The use of ALD for the $\mathrm{SnO}_{2}$ continues to be the preferred route for the formation of a metal oxide electron extraction layer in a majority of perovskite based tandem cells to-date. Almost immediately following the above work, Werner et al. ${ }^{57}$ reported a perovskite/silicon tandem cell with an improved PCE in excess of $21 \%$. The most notable feature of the work was the incorporation of an indium zinc oxide (IZO) window as the 
recombination layer together with solution processed polyethyleneimine (ethoxylated) (PEIE)/phenyl-C61-butyric-acid-methyl-ester $\left(\mathrm{PC}_{61} \mathrm{BM}\right)$ bilayer for electron extraction from the perovskite sub-cell which facilitates low temperature processing. The authors also employed a two-step fabrication process for the $\mathrm{MAPbI}_{3}$ perovskite absorber with MAI being solution deposited on thermally evapourated $\mathrm{PbI}_{2}$, a route that shows promise for perovskite deposition on textured surfaces. ${ }^{46}$ Through optimization of the IZO thickness, they achieved a stable PCE of $21.2 \%$ over an aperture area of $0.17 \mathrm{~cm}^{2}$ and $19.2 \%$ over an aperture area of 1.22 $\mathrm{cm}^{2}$. One of the key issues in the above work by Werner et al. ${ }^{57}$ was the limited near infrared response of the Si sub-cell due to the non-textured cell used. This was reduced in a subsequent study by Werner et al. ${ }^{58}$ where a PCE of $20.5 \%$ was reported for an area of $1.43 \mathrm{~cm}^{2}$. The rearside texturing on the bottom cell led to an enhancement of the photocurrent response of the $\mathrm{Si}$ sub-cell in the near-infrared region. Zhue et al. ${ }^{59}$ demonstrated the possibility of obtaining high efficiencies following careful optimization of the top $\mathrm{MoO}_{3}$ buffer layer and ITO transparent electrode stack. Through careful tuning of the thickness and the deposition conditions to reduce optical and electrical losses, they achieved a further improved PCE of $22.8 \%$.

While most of the above reports for SHT based work used $\mathrm{MAPbI}_{3}$ as the absorber, this has a lower $E_{G}$ than is typically desired for tandem architectures. Based on this, Fan et al. ${ }^{60}$ investigated the impact of $E_{G}$ tuning in mixed A-site cation compositions by the use of mixed halides (iodine and bromine). In their work, $\mathrm{MA}_{0.37} \mathrm{FA}_{0.48} \mathrm{Cs}_{0.15} \mathrm{PbI}_{2.01} \mathrm{Br}_{0.99}$ with an $E_{G}$ of 1.69 $\mathrm{eV}$ was identified to be optimum. they fabricated monolithic perovskite tandem solar cell with the steady state PCE of $18 \%$. Qiu et al. ${ }^{61}$ followed a similar approach and identified $\mathrm{MA}_{0.38} \mathrm{FA}_{0.50} \mathrm{Cs}_{0.12} \mathrm{PbI}_{2.04} \mathrm{Br}_{0.96}$ as possessing the optimum $E_{G}$ of $1.69 \mathrm{eV}$ for perovskite/silicon tandem solar cells. Through further optimization of the $\mathrm{SnO}_{2}$ electron transport layer thickness, the authors achieved a steady state PCE of $20.6 \%$, similar to Fan et al. ${ }^{60}$

One of the key concerns in the above perovskite compositions has been the use of methylammonium which typically regarded to introduce device instabilities under heating. ${ }^{62}$ This has led to the development of compositions consisting Cs and FA. ${ }^{8,14}$ Based on this, Bush et al. ${ }^{63}$ developed $\mathrm{Cs}_{0.17} \mathrm{FA}_{0.83} \mathrm{PbI}_{0.83} \mathrm{Br}_{0.17}$ based perovskite/silicon tandem cells with a PCE of $23.6 \%$ over $1 \mathrm{~cm}^{2}$ featuring rear textured SHJ. A $\mathrm{SnO}_{2} / \mathrm{ZTO}$ deposited using ALD/pulsedchemical vapour deposition enabled a hole blocking window layer with lower parasitic absorption. The photocurrent losses in the infrared region was reduced by using a $\mathrm{Si}$ nanoparticle incorporated rear reflector which allowed appropriate refractive index matching. Bush et al. ${ }^{64}$ later reported further improvements in PCE through reduction of the optical losses 
that was present in their previous work. ${ }^{63}$ This was achieved by optimizing the perovskite composition to achieve a wider $E_{G}$, reducing front reflection losses by thinning of the ITO electrode and introduction of metal fingers to minimize sheet resistance losses due to the thinner ITO layer, and the incorporation of a polydimethylsiloxane (PDMS) stamp with random, pyramidal texture to further reduce front side reflection losses. They achieved $25 \%$ efficiency on a $1 \mathrm{~cm}^{2}$ cell.

In addition to its use in the rear electrode, nanocrystalline $\mathrm{Si}$ (nc-Si) has also been used in the recombination layer. For example, Sahli et al. ${ }^{65}$ who utilized a hydrogenated nanocrystalline $\mathrm{Si}(\mathrm{nc}-\mathrm{Si}: \mathrm{H})$ layer, deposited by plasma-enhanced chemical vapor deposition (PECVD) at low temperature, as recombination junction. This led to a decrease in the parasitic absorption and reflection losses leading to PCEs of $22 \%, 21.2 \%$ and $18 \%$ for active areas of $0.25,1.43$ and $12.96 \mathrm{~cm}^{2}$. Sahli et al. ${ }^{46}$ used a similar concept on the first perovskite/silicon tandem architecture where the perovskite was deposited on a textured silicon bottom cell (Fig. 3(d) (f)). For this purpose, a hybrid two-step deposition method combining sequential coevaporation of $\mathrm{PbI}_{2}$ and $\mathrm{CsBr}_{2}$ and spin coating of $\mathrm{FABr}$ and $\mathrm{FAI}$ mixture to form the conformal perovskite absorber layer. A certified steady-state PCE of $25.2 \%$ over an aperture area of 1.419 $\mathrm{cm}^{2}$ was achieved based on the above architecture and processing. Nogay et al. ${ }^{54}$ adopted a similar approach with a $p$-type, textured Si based bottom cell by where a steady-state PCE of $25.1 \%$ and a reverse scan PCE of $25.4 \%$ was achieved for devices with an active area of 1.42 $\mathrm{cm}^{2}$.

Other than nanocrystalline Si layers, optimized hydrogenated nanocrystalline silicon oxide (nc$\left.\mathrm{SiO}_{\mathrm{x}}: \mathrm{H}\right)$ layers ${ }^{66}$ have also been reported as a suitable interlayer. Ren et al ${ }^{67}$ improved the near infrared response of SHJ solar cells by using wide band gap and low refractive index

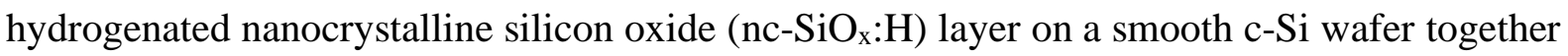
with an $n$-type back surface field (BSF) layer resulting in a PCE of $20.1 \%$. Mazzarella et al. ${ }^{68}$ also reported monolithic perovskite/silicon cell which employed a nc-SiOx:H as the interlayer between the silicon and perovskite sub-cells. An increased bottom cell current density due to reduction in reflection losses as a result of the nc-SiOx:H enabled a certified PCE of $25.2 \%$ (stabilized). The use of $\mathrm{nc}-\mathrm{SiO} x: \mathrm{H}$ together with the incorporation of a textured light management (LM) foil on the front-side of a tandem solar cell processed on a planar front-side wafer consisting of and textured back-side was reported by Jošt et al. ${ }^{69}$ The resulting improvement in optical management led to an increase in PCE from $23.4 \%$ to $25.5 \%$ for tandems consisting of perovskites with $\mathrm{Cs}_{0.05}\left(\mathrm{FA}_{0.83} \mathrm{MA}_{0.17}\right)_{0.95} \mathrm{~Pb}_{1.1}\left(\mathrm{I}_{0.83} \mathrm{Br}_{0.17}\right)_{3}$. Hou et al. ${ }^{70}$ 
utilized a nc-SiO $: \mathrm{H}$ layer which together with a PDMS as an antireflective foil resulted in improvement in PCE from $19.38 \%$ to $21.93 \%$.

Processing of the perovskite layer is another key aspect that drives high performing perovskite/silicon tandem PVs. Zhu et al. $^{71}$ reported the importance of optimization of dimethylformamide (DMF) and dimethyl sulfoxide (DMSO) as means of optimizing the properties of the perovskite layer, which in turn impacts the light absorption and transmission within a tandem device structure. This approach was demonstrated for both FACs based and FAMACs based perovskite compositions, with the latter resulting in a PCE of $22.8 \%$. Other than solvent engineering, the incorporation of additives is now rapidly becoming a preferred approach towards grain engineering and modification of morphology in perovskite absorbers. For example, Chen et al. ${ }^{72}$ incorporated methyl ammonium chloride $(\mathrm{MACl})$ and $\mathrm{MAH}_{2} \mathrm{PO}_{2}$ into the perovskite precursor. These additives were shown to modify the crystallization process, resulting in PCE of $25.4 \%$ for perovskite/silicon tandem devices. More recently, Xu et al. ${ }^{13}$ reported the incorporation of chlorine into a FACs based perovskite composition as means maintaining an $E_{G}$ of $1.67 \mathrm{eV}$ (suitable for tandem architectures), while reducing the bromine content. While high bromine loadings enable wider bandgaps to be achieved, this often results in light induced halide segregation ${ }^{73}$, leading to solar cell performance drift. Based on the above approach, the authors reported an impressive PCE of $27 \%$ efficiency over $1 \mathrm{~cm}^{2}$. However, it is noted that the excess chloride was added to the perovskite precursor in the form of $\mathrm{MAPbCl}_{3}$ and as of present, the role of the excess MA on the above device characteristics remains unclear. Mitigation of halide segregation has also been reported to be possible through solvent posttreatment. For example, Hou et al. ${ }^{47}$ reported a PCE of $25.7 \%$ efficiency via post treatment of the perovskite film with 1-butanethiol (Fig. 3(g) and (i)). The resulting self-limiting passivation layer formed on rough and micrometer thick perovskite surfaces was reported to increase carrier diffusion length while mitigating phase segregation. More importantly, this work also reported the first example of an entirely solution processed perovskite layer on a textured $\mathrm{Si}$ surface (Fig. 3(h)). The shunting of devices which is usually anticipated when solution processed layers are deposited on textured surfaces with high peak-to-trough dimensions was avoided through the use of thick perovskite layers. Approaches to passivate of grain boundary recombination in tandem solar cells have also followed trends utilized in perovskite single junction cells. In this regard, Kim et al. ${ }^{74}$ reported the grain boundary passivation of a $1.68 \mathrm{eV}$ perovskite absorber through the incorporation of phenethylammonium (PEA)-based two- 
dimensional (2D) additives together with a thiocyanate (SCN) which enabled a PCE of $26.7 \%$ to be achieved (Fig. $3(\mathrm{j})-(\mathrm{m})$ ).

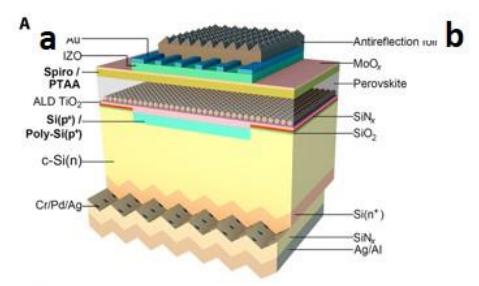

d
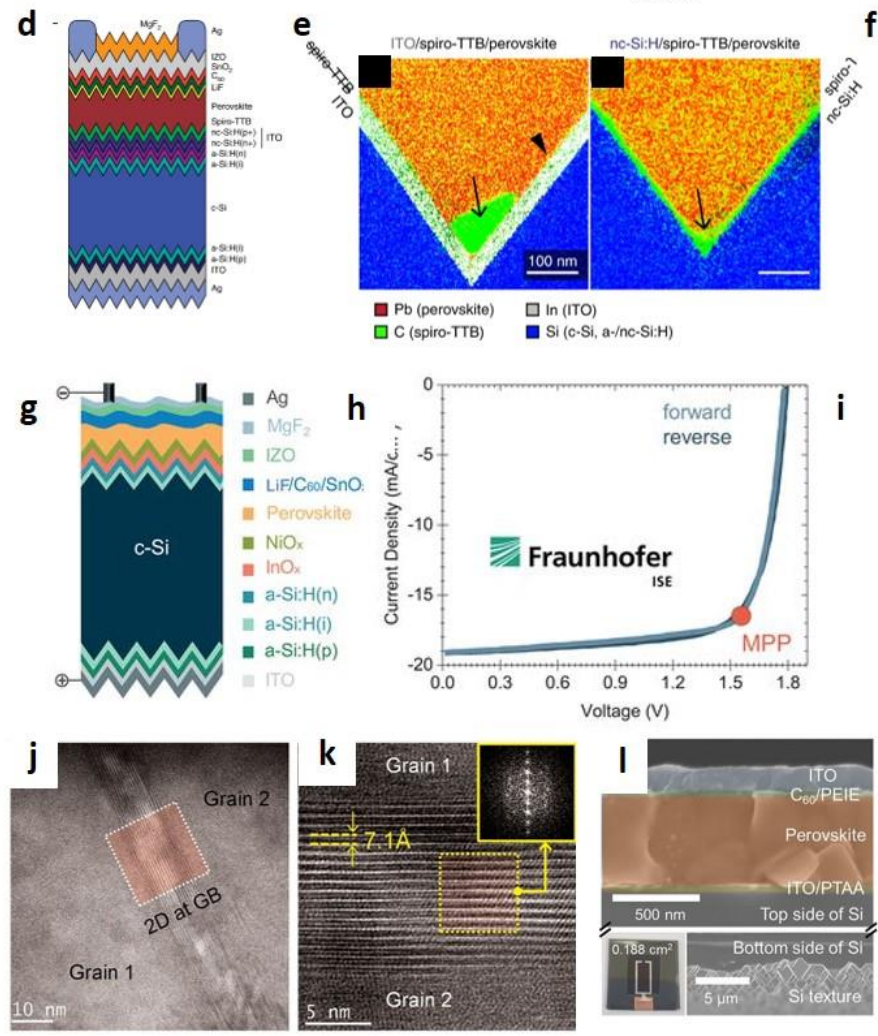

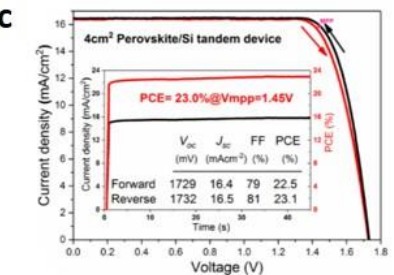

f
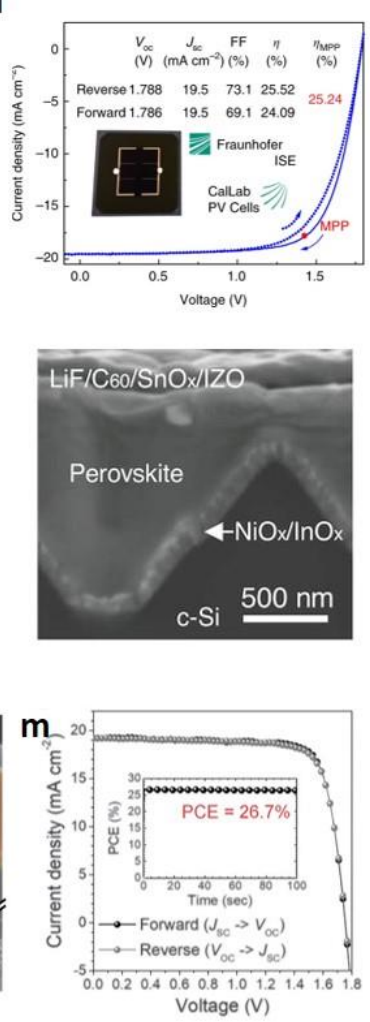

Fig. 3 (a) Schematic of the device architecture and (b) $J-V$ characteristics of perovskite/silicon tandem cell that utilizes an in-situ built recombination layer. ${ }^{43}$ Reproduced from Ref. 43 under the Creative Commons Attribution Non-Commercial License 4.0 (CC BY-NC). (c) The $J$ - $V$ characteristics of $4 \mathrm{~cm}^{2}$ perovskite/silicon tandem $\mathrm{PV}$ as reported by Zheng et al. ${ }^{53}$ incorporating the down-shifting phosphor $(\mathrm{Ba}, \mathrm{Sr})_{2} \mathrm{SiO}_{4}: \mathrm{Eu}^{2+}$ within a PDMS antireflection layer. Reprinted with permission from Ref 53. Copyright (2017) American Chemical Society. (d) Schematic of device architecture of the first reported perovskite/tandem architecture where the perovskite is deposited on a textured surface through combined thermal evaporation and spin-coating process, (e) cross sectional EDX image indicating accumulation of Spiro-TTB on an ITO recombination junction (when annealed) as opposed to a more uniform coating when deposited on $\mathrm{nc}-\mathrm{Si}: \mathrm{H}$, and (d) the $J-V$ characteristics for the certified device. ${ }^{46}$ Reproduced from Ref. 46 with permission from Springer Nature. (g) Device schematic, (h) $J-V$ characteristics for the certified device and (i) cross sectional image of perovskite/silicon tandem device where the perovskite was solution processed on a textured silicon surface ${ }^{47}$ From Ref. 47 . Reprinted with permission from AAAS. (j) and (k) TEM images indicating the formatting of a $2 \mathrm{D}$ phase at the grain boundary for PEA $\left(\mathrm{I}_{0.25} \mathrm{SCN}_{0.75}\right)$ incorporated perovskites as reported by Kim et al. ${ }^{74}$ The inset in (k) shows the fast Fourier Transform pattern of the 2D perovskite. (1) Cross sectional image and (m) $J$ $V$ characteristics of perovskite/silicon tandem devices from Ref. 74. From Ref. 74. Reprinted with permission from AAAS. 
Table 1. Summary of performance characteristics for perovskite/silicon tandem photovoltaics. SPO indicates stabilised power output. Note: *Mask area> active area

\begin{tabular}{|c|c|c|c|c|c|c|}
\hline Year & Configuration & $V_{o c}(\mathrm{~V})$ & $\begin{array}{c}J_{s c} \\
\left(\mathrm{mAcm}^{-2}\right)\end{array}$ & $\boldsymbol{F F}$ & $\begin{array}{l}\text { PCE (\%) } \\
\text { (SPO(\%)) }\end{array}$ & Ref \\
\hline 2015 & $\begin{array}{r}\text { Metal/n++ Si BSF/n-type Si (Base)/p }{ }^{++} \mathrm{Si}\left(\text { Emitter) } / \mathrm{n}^{++} \mathrm{Si} \mathrm{TJ} / \mathrm{c}-\right. \\
\mathrm{TiO}_{2} / \mathrm{mp}-\mathrm{TiO}_{2} / \mathrm{MAPbl}_{3} / \text { Spiro-OMeTAD } / \mathrm{Ag} \mathrm{NW} / \mathrm{LiF}\end{array}$ & 1.58 & 11.5 & 75 & - (13.7) & 45 \\
\hline 2015 & 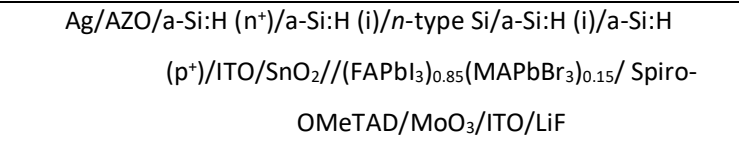 & 1.785 & 14 & 77.3 & 19.1 (18.1) & 56 \\
\hline 2015 & $\begin{array}{c}\text { Ag/ITO/a-Si (n)/a-Si (i)/n-type Si/a-Si (i)/a-Si } \\
\text { (p)/IZO/PC } 61 \text { BM/PEIE/MAPbl } 3 / \text { Spiro- } \\
\text { OMeTAD/MoO } / \text { ITO/IO:H }\end{array}$ & 1.692 & 15.8 & 79.9 & $21.4(21.2)$ & 57 \\
\hline 2016 & $\begin{array}{c}\mathrm{Al} / \mathrm{BSF} / n \text {-type } \mathrm{Si}\left(\text { Base)/p }{ }^{++} \mathrm{Si} \text { (Emitter)/ZTO/ c-TiO } / \mathrm{mp}-\right. \\
\mathrm{TiO}_{2} / \mathrm{MAPbl}_{3} / \text { Spiro-OMeTAD/MoO } / \text { IO:H/ITO }\end{array}$ & 1.643 & 15.3 & 64.8 & $16.3(16)$ & 48 \\
\hline 2016 & 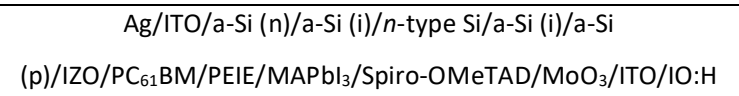 & 1.717 & 16.4 & 73.1 & 20.6 (20.5) & 58 \\
\hline 2017 & 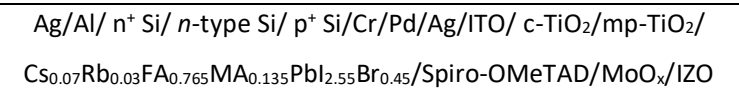 & 1.75 & 17.6 & 73.8 & $22.8(22.5)$ & 49 \\
\hline 2017 & $\begin{array}{c}\text { Al/ITO/a-Si (n)/a-Si (i)/ n-type Si/a-Si (i)/a-Si } \\
\text { (p)/ITO/SnO } / \mathrm{MAPbl}_{3} / \mathrm{Spiro-OMeTAD} / \mathrm{MoO}_{3} / \mathrm{ITO}\end{array}$ & 1.687 & 15.62 & 68 & $18(-)$ & 59 \\
\hline 2017 & $\begin{array}{c}\mathrm{Ag} / \mathrm{a}-\mathrm{Si}\left(\mathrm{n}^{+}\right) / n \text {-type Si/a-Si }\left(\mathrm{p}^{+}\right) / \mathrm{ITO} / \mathrm{SnO}_{2} / \\
\mathrm{MA}_{0.37} \mathrm{FA}_{0.48} \mathrm{Cs}_{0.15} \mathrm{Pbl}_{2.01} \mathrm{Br}_{0.99} / \text { Spiro-OMeTAD/MoOx/ITO }\end{array}$ & 1.703 & 15.25 & 79.22 & $20.57(18)$ & 60 \\
\hline 2017 & $\begin{array}{c}\mathrm{Ag} / \mathrm{Si} \mathrm{NP} / \mathrm{ITO} / \mathrm{a}-\mathrm{Si}\left(\mathrm{p}^{+}\right) / \mathrm{a}-\mathrm{Si}(\mathrm{i}) / n \text {-type Si/a-Si (i)/a-Si } \\
\left(\mathrm{n}^{+}\right) / \mathrm{ITO} / \mathrm{NiO} / \\
\mathrm{FA}_{0.83} \mathrm{CS}_{0.17} \mathrm{~Pb}\left(\mathrm{l}_{0.83} \mathrm{Br}_{0.17}\right) / \mathrm{LiF} / \mathrm{PC}_{61} \mathrm{BM}_{\mathrm{SnO}} / \mathrm{ZTO} / \mathrm{ITO} / \mathrm{LiF}\end{array}$ & 1.65 & 18.1 & 79 & $23.6(23.6)$ & 63 \\
\hline 2017 & $\begin{array}{c}\text { Ag/TCO/a-Si:H (n+)/a-Si:H (i)/n-type Si/a-Si:H (i)/a-Si:H }\left(p^{+}\right) / n c-S i \\
\left(p^{+}\right) / \text {nc-Si }\left(n^{+}\right) / \mathrm{C}_{60} / \mathrm{Cs}_{0.19} \mathrm{FA}_{0.81} \mathrm{Pbl}_{3} / \text { Spiro- } \\
\text { OMeTAD/MoO }{ }_{3} / \mathrm{IZO}_{\mathrm{MgF}}\end{array}$ & 1.751 & 16.8 & 77.5 & $22.8(22)$ & 65 \\
\hline 2018 & $\begin{array}{c}\mathrm{Ti} / \mathrm{Pd} / \mathrm{Ag} / \mathrm{n}^{++} \mathrm{Si} / n \text {-type } \mathrm{Si} / \mathrm{p}^{++} \mathrm{Si} \text { (Emitter)/SnO } 2 / \mathrm{MAPBI}_{3} / \mathrm{Spiro-} \\
\mathrm{OMeTAD} / \mathrm{MoO}_{3} / \mathrm{ITO} / \mathrm{Ag} \text { busbar/PDMS AR foil }\end{array}$ & 1.676 & 16.1 & 78 & $21(20.5)$ & 52 \\
\hline 2018 & $\begin{array}{c}\mathrm{Ag} / \mathrm{a}-\mathrm{Si}(\mathrm{n}) / \mathrm{a}-\mathrm{Si}(\mathrm{i}) / \mathrm{n} \text {-type Si/a-Si (i)/a-Si} \\
\text { (p)/IZO/PC }{ }_{61} \mathrm{BM} / \mathrm{PEIE} / \mathrm{MAPbl}_{3} / \mathrm{Spiro-OMeTAD} / \mathrm{MoO}_{3} / \mathrm{ITO} /\end{array}$ & 1.655 & 16.5 & 81.1 & $\begin{array}{l}22.22 \\
(20.6)\end{array}$ & 61 \\
\hline 2018 & 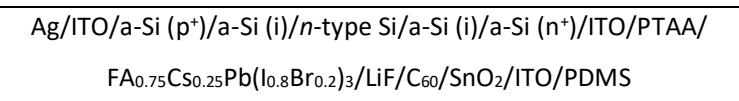 & 1.77 & 18.4 & 77 & $25(-)$ & 64 \\
\hline 2018 & 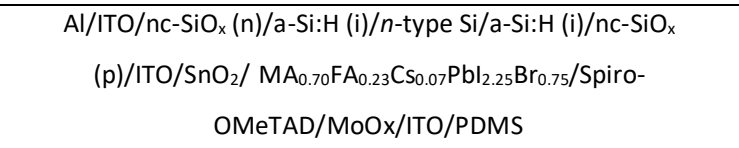 & 1.75 & 16.89 & 74.18 & $21.93(-)$ & 70 \\
\hline 2018 & 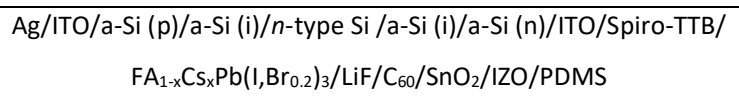 & 1.788 & 19.5 & 73.1 & 25.52 & 46 \\
\hline 2018 & 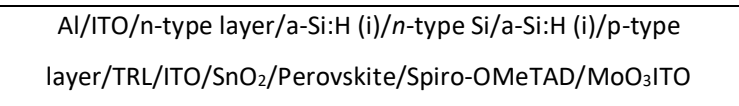 & 1.71 & 15.87 & 74 & $20.1(-)$ & 67 \\
\hline 2018 & $\begin{array}{l}\text { Ag/ZnO:Al/a-Si:H (p)/a-Si:H (i)/n-type Si/a-Si:H (i)/nc- } \\
\qquad \text { SiO }_{x}: \mathrm{H} / \mathrm{ITO} / \mathrm{PTAA} / \\
\mathrm{Cs}_{0.05}\left(\mathrm{FA}_{0.83} \mathrm{MA}_{0.17}\right)_{0.95} \mathrm{~Pb}\left(\mathrm{I}_{0.83} \mathrm{Br}_{0.17}\right)_{3} / \mathrm{C}_{60} / \mathrm{SnO}_{2} / \mathrm{IZO} / \mathrm{ML} \text { foil }\end{array}$ & $\begin{array}{c}1.76 \\
1.76^{*}\end{array}$ & $\begin{array}{c}18.5 \\
19.4^{*}\end{array}$ & $\begin{array}{l}78.5 \\
77 *\end{array}$ & $\begin{array}{c}25.2 \\
26.5(26.5)^{*}\end{array}$ & 69 \\
\hline
\end{tabular}




\begin{tabular}{|c|c|c|c|c|c|c|}
\hline 2018 & 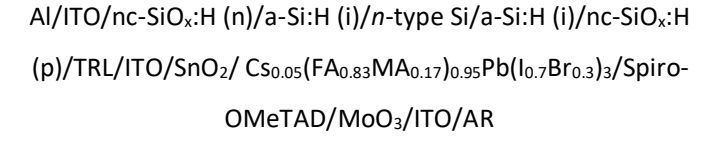 & 1.71 & 15.46 & 73 & $19.3(-)$ & 71 \\
\hline \multirow{2}{*}{2018} & 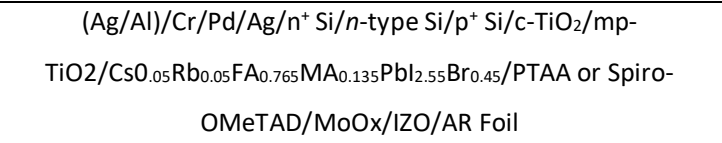 & 1.763 & 17.8 & 78.1 & $24.5(24.1)$ & \multirow{2}{*}{43} \\
\hline & $\begin{array}{c}(\mathrm{Ag} / \mathrm{Al}) / \mathrm{Cr} / \mathrm{Pd} / \mathrm{Ag} / \mathrm{n}^{+} \mathrm{Si} / \mathrm{n} \text {-type Si/SiO } / \mathrm{a}-\mathrm{Si}(\mathrm{p}) / \mathrm{c}-\mathrm{TiO}_{2} / \mathrm{mp}- \\
\mathrm{TiO} 2 / \mathrm{CsO}_{0.05} \mathrm{Rb}_{0.05} \mathrm{FA}_{0.765} \mathrm{MA}_{0.135} \mathrm{Pbl}_{2.55} \mathrm{Br}_{0.45} / \mathrm{PTAA} \text { or Spiro- } \\
\text { OMeTAD/MoOx/IZO/AR Foil }\end{array}$ & 1.703 & 17.2 & 79.2 & $23.2(22.8)$ & \\
\hline 2019 & $\begin{array}{c}\mathrm{Ti} / \mathrm{Pd} / \mathrm{Ag} / \mathrm{n}^{++} \mathrm{Si} / n \text {-type } \mathrm{Si} / \mathrm{p}^{++} \mathrm{Si}(\mathrm{Emitter}) / \mathrm{SnO}_{2} / \mathrm{MAPBI}_{3} / \mathrm{Spiro}- \\
\text { OMeTAD } / \mathrm{MoO}_{3} / \mathrm{ITO} / \mathrm{Ag} \text { busbar} / \mathrm{PDMS} \text { AR foil with } \\
(\mathrm{Ba}, \mathrm{Sr})_{2} \mathrm{SiO}_{4}: \mathrm{Eu}^{2+}\end{array}$ & 1.732 & 16.5 & 81 & $23.1(23)$ & 53 \\
\hline 2019 & $\begin{array}{c}\mathrm{Ag} / \mathrm{Al} \text {-BSF } / p \text {-type } \mathrm{Si} / \mathrm{n}^{+} \mathrm{Si} \\
\left(\text { Emitter)//TO/PTAA} /\left(\mathrm{FAPb}_{3}\right)_{0.85}\left(\mathrm{MAPbBr}_{3}\right)_{0.15} / \mathrm{PC}_{61} \mathrm{BM} / \mathrm{ZnO}\right. \\
\mathrm{NP} / \mathrm{IZO} / \mathrm{LiF}\end{array}$ & 1.645 & 16.12 & 79.92 & $\begin{array}{l}21.19 \\
(21.1)\end{array}$ & 55 \\
\hline 2019 & 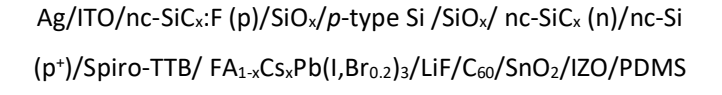 & 1.741 & 19.5 & 74.7 & $\begin{array}{l}25.41 \\
(25.1)\end{array}$ & 54 \\
\hline 2019 & $\begin{array}{c}\text { Ag/AZO/a-Si (p)/a-Si (i)/n-type Si/a-Si (i)/nc-SiO }{ }_{x} \\
\text { (n)/ITO/PTAA/Cs } 0.05\left(\mathrm{FA}_{0.83} \mathrm{MA}_{0.17}\right)_{0.95} \mathrm{~Pb}\left(\mathrm{l}_{0.83} \mathrm{Br}_{0.17}\right)_{3} \\
/ \mathrm{C}_{60} / \mathrm{SnO}_{2} / \mathrm{IZO} / \mathrm{LiF}\end{array}$ & 1.78 & 17.81 & 78.64 & $\begin{array}{c}24.95 \\
(24.97)\end{array}$ & 66 \\
\hline 2019 & $\begin{array}{l}\text { Ag/AZO/a-Si:H (p)/a-Si:H (i)/n-type Si/a-Si:H (i)/ITO/poly-TPD/ } \\
\text { Cso.05 }\left(\mathrm{FA}_{0.83} \mathrm{MA}_{0.17}\right)_{0.95} \mathrm{~Pb}\left(\mathrm{l}_{0.83} \mathrm{Br}_{0.17}\right)_{3} / \mathrm{ETL} / \text { Buffer layer/ITO/ARC }\end{array}$ & 1.7919 & 19.02 & 74.6 & $25.43(-)$ & 68 \\
\hline 2019 & $\begin{array}{l}\left.\text { Ag/ITO/a-Si:H ( } \mathrm{p}^{+}\right) / \mathrm{a}-\mathrm{Si}: \mathrm{H}(\mathrm{i}) / \mathrm{n} \text {-type Si/a-Si:H }\left(\mathrm{n}^{+}\right) / \mathrm{ITO} / \mathrm{PTAA} / \\
\mathrm{Cs}_{0.15}\left(\mathrm{FA}_{0.83} \mathrm{MA}_{0.17}\right)_{0.85} \mathrm{~Pb}\left(\mathrm{I}_{0.8} \mathrm{Br}_{0.2}\right)_{3} / \mathrm{ICBA} / \mathrm{C}_{60} / \mathrm{SnO}_{2} / \mathrm{IZO} / \mathrm{MgF}_{2}\end{array}$ & 1.8 & 17.8 & 79.4 & $25.4(-)$ & 72 \\
\hline 2020 & $\begin{array}{c}\mathrm{Ag} / \mathrm{ITO} / \mathrm{a}-\mathrm{Si}: \mathrm{H}(\mathrm{p}) / \mathrm{a}-\mathrm{Si}: \mathrm{H}(\mathrm{i}) / n \text {-type Si/a-Si:H (n)/ITO/NiO }{ }_{x} / \text { poly- } \\
\text { TPD/PFN/ FA }{ }_{0.75} \mathrm{Cs}_{0.25} \mathrm{~Pb}\left(\mathrm{lo}_{0.85} \mathrm{Br}_{0.15}\right)_{3}+\mathrm{MAPbCl}_{3} \\
\text { /LiF/C } 60 / \mathrm{SnO}_{2} / \mathrm{ITO} / \mathrm{PDMS}\end{array}$ & 1.886 & 19.12 & 75.3 & $\begin{array}{c}27.13 \\
(27.04)\end{array}$ & 13 \\
\hline 2020 & $\begin{array}{l}\text { Ag/ITO/a-Si:H (p)/a-Si:H (i)/n-type Si/a-Si:H (n)/IOx/ } \mathrm{NiO}_{x} / \text { poly- }^{-} \\
\text {TPD/ Cs } s_{0.05} \mathrm{FA}_{0.8} \mathrm{MA}_{0.15} \mathrm{Pbl}_{2.25} \mathrm{Br}_{0.75} / \mathrm{LiF} / \mathrm{C}_{60} / \mathrm{SnO}_{2} / \mathrm{IZO} / \mathrm{MgF}_{2}\end{array}$ & 1.7805 & 19.07 & 75.36 & $\begin{array}{l}25.59 \\
(25.7)\end{array}$ & 47 \\
\hline 2020 & $\begin{array}{l}\text { Ag/ITO/a-Si:H (p)/a-Si:H (i)/n-type Si/a-Si:H (n)/ITO/PTAA/ } \\
\mathrm{CS}_{0.15} \mathrm{FA}_{0.65} \mathrm{MA}_{0.20} \mathrm{~Pb}\left(\mathrm{l}_{0.8} \mathrm{Br}_{0.2}\right)_{3}+\mathrm{PEAl}_{0.25} \mathrm{SCN}_{0.75} / \mathrm{C}_{60} / \mathrm{PEIE} / \mathrm{ITO}\end{array}$ & 1.765 & 19.2 & 79.2 & (26.7) & 74 \\
\hline
\end{tabular}

\section{b) Perovskite/CIGS tandem photovoltaics}

Among the emerging thin film photovoltaic technologies, I-III-VI type compound semiconductors consisting of copper, indium, gallium, sulphur and selenium are of significant interest. Consisting of a chalcopyrite crystalline structure, this technology displays a number of key advantages including high energy yield, low temperature coefficient of power loss, low sensitivity to shadowing (i.e. good performance under low illumination intensities as well as short energy payback times ${ }^{75}$. Presently, CIGS PVs have achieved a certified Power Conversion Efficiency (PCE) of $23.35 \pm 0.5 \%$ over areas of $1.043 \mathrm{~cm}^{2}$ for lab scale devices while a certified PCE of $19.2 \pm 0.5 \%$ over an aperture area of $841 \mathrm{~cm}^{2} .76$ 
One of the important optoelectronic properties of CIGS is the tunability of its $E_{G}{ }^{77}$, with $E_{G}$ in the range of $1.1-1.2 \mathrm{eV}$ being the most widely developed. As a result, this allows the possibility of developing tandem solar cells when combined with absorbers with $E_{G}$ in the range of $1.7-1.8 \mathrm{eV}$ as allowed by perovskites. ${ }^{14}$ Despite this, there has been very little activity in developing $2 \mathrm{~T}$ perovskite/CIGS tandem architectures as evident from the following discussion (related device performances given in Table 2).

The first example of a $2 \mathrm{~T}$ perovskite/CIGS tandem device was reported by Todorov et al. ${ }^{78}$ The authors evaluated the impact of both $\mathrm{MAPbI}_{3}$ and $\mathrm{MAPbBr}_{3}$ as the perovskite on the overall tandem performance. As the perovskite was observed to degrade when deposited on $\mathrm{ZnO}$ and annealed at $60^{\circ} \mathrm{C}$, the usage of an i-ZnO layer on the CIGS sub-cell was avoided. Furthermore, the perovskite sub-cell processing temperature was kept below $120^{\circ} \mathrm{C}$ to avoid the degradation of the CIGS sub-cell due to the interdiffusion that takes place at the cadmium sulfide (CdS)/CIGS interface. While the CIGS sub-cell on its own demonstrated a PCE of $11.6 \%$, the authors noted a drop in the PCE to $4.6 \%$ with a $J_{s c}$ of $16 \mathrm{mAcm}^{-2}$ when shadowed using an $\mathrm{MAPbI}_{3}$ sub-cell. On the other hand, a higher PCE of $7.7 \%$ with a $J_{s c}$ of $25 \mathrm{mAcm}^{-2}$ for the CIGS sub-cell was observed when shadowed with $\mathrm{MAPbBr}_{3}$. Based on the above, the authors developed a perovskite with an $E_{G}$ of $1.72 \mathrm{eV}$ for the $2 \mathrm{~T}$ tandem architecture. The perovskite was fabricated based on a vapour based halide exchange process where the existing halide was replaced by $\mathrm{MABr}$ vapour. Test devices formed using a 10-15 $\mathrm{nm}$ thick Al layer as the transparent conducting electrode (with $50 \%$ transmission) resulted in a PCE of $\sim 8 \%$. The authors pointed out a number of issues in this structure including the high resistance of the perovskite sub-cell, the high ideality factor of the overall tandem cell and the low optical transmission of the Al. Replacing the $\mathrm{Al}$ with a thin layer of $\mathrm{Ca}$ enabled a higher optical transmission of $70-80 \%$ which led to a PCE of $10.98 \%$.

The next example of a $2 \mathrm{~T}$ perovskite/silicon tandem devices was reported in 2018, possibly due to the difficulty in the fabrication of the perovskite cell on the highly textured CIGS which typically demonstrates a high $\sigma_{R M S}$ of $\sim 50-200 \mu \mathrm{m} .{ }^{79}$ In their work reported in 2018, Han et al., ${ }^{80}$ utilised a boron doped $\mathrm{ZnO}$ (BZO) layer on top of the CIGS cell which minimised the $\sigma_{R M S}$ to $\sim 60 \mathrm{~nm}$. However, this still possessed features with a height of $\sim 250 \mathrm{~nm}$. In order to address this, the authors deposited a thick layer of ITO which was then polished using a chemical-mechanical polishing (CMP) method (Fig. 4(a)) which reduced the height of the maximum vertical features observed to $\sim 40 \mathrm{~nm}$. However, the thickness of the ITO was such that the CMP processing did not polish the BZO layer. As BZO has a work function of $\sim 4 \mathrm{eV}$ 
in comparison to the PTAA hole transport layer (work function of $-5.1 \mathrm{eV}$ ) used in this work, the use of an ITO layer reduced the barrier potential for holes, thereby enabling a more effective recombination junction to be formed. Following the CMP process, the CIGS cell was reported to show a slight decrease in $J_{s c}$ to $34.34 \mathrm{mAcm}^{-2}$ from an initial value of $37.10 \mathrm{mAcm}^{-2}$ for the unpolished cell. This was attributed to the parasitic absorption due to the ITO over the wavelength region of $400-500 \mathrm{~nm}$ range (the parasitic absorption of ITO does not affect the absorption over longer wavelengths). The $F F$ was also reported to decrease from $74.7 \%$ (unpolished) to $72.4 \%$ (polished), which was attributed to the higher sheet resistance $\left(R_{\text {sheet }}\right)$ of the polished ITO. As a result, the CMP polishing process resulted in a decrease of the PCE to $16.76 \%$ from an initial value of $18.73 \%$ for the unpolished cell. The authors also noted a $J_{s c}$ loss of $1.386 \mathrm{mAcm}^{-2}$ over the wavelength range of $750-1250 \mathrm{~nm}$ for the CIGS cell. For the perovskite sub-cell, the authors employed a $\mathrm{Cs}_{0.09} \mathrm{FA}_{0.77} \mathrm{MA}_{0.14} \mathrm{PbI}_{2.58} \mathrm{Br}_{0.42}$ (with $E_{G}$ of 1.59 $\mathrm{eV})$ as the absorber. In order to mitigate the detrimental influence of the prevailing surface roughness of the polished ITO, the authors optimized the thickness of the PTAA layer in combination with dopants. Following the above, the authors reported the fabrication of a $2 \mathrm{~T}$ tandem cell where a certified PCE of $22.43 \%$ was achieved over a cell area of $0.042 \mathrm{~cm}^{2}$ (Fig. 4(b)). The CIGS cell on this structure showed photocurrent losses over the wavelength range of $800-1100 \mathrm{~nm}$ (Fig. 4(c)) due to reflection losses at the ITO/air interface at the top cell, which was reduced using a $\mathrm{MgF}_{2}$ antireflection, leading to a PCE of $20.8 \%$. The stability of unencapsulated cells was observed by ageing the devices under ambient conditions for $500 \mathrm{~h}$ under 1 -sun continuous illumination while maintaining the cell at $30^{\circ} \mathrm{C}$. The performance was observed to drop to a value of $>88 \%$ from an initial PCE of $22 \%$. However, this loss was observed to be recoverable following storage of the cell in the dark for 12 hours. The high stability of the unencapsulated device under ambient conditions was attributed to use of $\mathrm{ZnO}$ and ITO which prevent moisture ingress ${ }^{81}$.

Despite the success in the above architecture developed by Han at al., ${ }^{80}$ one of the shortcomings was the requirement of a thick ITO layer which can result in parasitic absorption losses. To alleviate this shortcoming Jošt et al. ${ }^{79}$ developed a bilayer HTL (Fig. 4(d)) for the perovskite based on a conformal $\mathrm{NiO}_{\mathrm{x}}$ coating deposited using ALD (Fig. 4(e)), and PTAA. While $\mathrm{NiO}_{\mathrm{x}}$ deposited using ALD requires annealing at $300{ }^{\circ} \mathrm{C}$, this was avoided on the architecture reported as annealing at such high temperatures invariably results in interdiffusion at the CIGS/CdS interface. $2 \mathrm{~T}$ tandem devices were based on the $\mathrm{Cs}_{0.05}\left(\mathrm{FA}_{0.83} \mathrm{MA}_{0 .} 17-\right.$ ${ }_{0.95} \mathrm{~Pb}\left(\mathrm{I}_{0.83} \mathrm{Br}_{0.17}\right)_{3}$ composition reported by Saliba et al. ${ }^{7}$ Tandem devices based on the bilayer 
concept for the perovskite sub-cell showed a PCE of $21.6 \%$ with no hysteresis while devices that employed devices that used only PTAA or $\mathrm{s} \mathrm{NiO}_{\mathrm{x}}$ showed lower PCEs of $3.1 \%$ and $18.2 \%$ respectively (Fig. 4(f)). External Quantum Efficiency (EQE) measurements carried out indicated a current mismatch of $\sim 2 \mathrm{mAcm}^{-2}$ indicating room for further improvement. Additionally, a further $2.62 \mathrm{mAcm}^{-2} J_{s c}$ loss was identified due to reflection losses. Low parasitic absorption was observed between $400-1000 \mathrm{~nm}$ enabled by the highly transparent $n$-type contact. Parasitic absorption in the UV region dominated by absorption of $\mathrm{C}_{60}$ and IZO as well as absorption loss in CIGS near its band edge were identified as additional source of losses. In order to understand the losses in more detail, the authors fabricated single junction cells of CIGS consisting of a Ni/Al/Ni grid as the front contact which demonstrated a PCE of 16.3\%. The authors noted alkali postdeposition treatment and light trapping schemes for improving the $V_{o c}$ and $J_{s c}$ respectively. Furthermore, based on estimation of the he quasi Fermi level splitting (QFLS) through hyperspectral PL imaging the authors noted that a $\mathrm{V}_{\text {oc }}$ of $1.70 \mathrm{~V}$ should be possible on elimination of loss mechanisms.

More recently, Al-alshouri et al. ${ }^{24}$ reported the development of a new class of hole transport layers based on self-assembled monolayers (SAMs) for perovskites which enabled a stable, high performance for CIGS-LHP 2T tandem cells. The SAMs reported; V1036 (2-\{3,6bis[bis(4-methoxyphenyl)amino]-9H-carbazol-9-yl\}ethyl)phosphonic acid (V1036), MeO2PACz [2-(3,6-dimethoxy-9H-carbazol-9-yl)ethyl]phosphonic acid (MeO-2PACz) and [2(9H-carbazol-9-yl)ethyl]phosphonic acid (2PACz) were based on carbazole derivates that enable transportation of holes while the localization of electrons. Additionally, the phosphonic acid groups were incorporated to these SAM materials which enables a self-limiting adhesion process to ITO. The authors evaluated the above hole transport layers in perovskite/CIGS tandem PVs, using AZO/SAM (formed by dip coating) recombination junction. The resulting tandem devices showed an impressive certified PCE of $23.26 \%$ over an area of $1.03 \mathrm{~cm}^{2}$ which exceeded the PCE of $21.6 \%$ for perovskite/CIGS tandems incorporating the $\mathrm{NiO}_{\mathrm{x}} / \mathrm{PTAA}$ bilayer $^{79}$. Notably, the bottom cell alone demonstrated a PCE of $15-16 \%$ while the $V_{o c}$ was improved compared to the previous work from $1.59 \mathrm{~V}^{79}$ to $1.68 \mathrm{~V}$. However, the FF was reduced to $72 \%$ compared to $76 \%$ obtained for the $\mathrm{NiO}_{2} / \mathrm{PTAA}$ double layer.

The development of perovskite/CIGS tandems have also been expanded to the fabrication of flexible $2 \mathrm{~T}$ tandem architectures where the $\mathrm{MAPbI}_{3}$ perovskite sub-cell was processed on a CIGS cell that had been fabricated on a polyimide foil. ${ }^{82}$ A thin PTAA layer that was doped with $1 \mathrm{wt} . \%$ F4TCNQ was used as the hole transport layer for the perovskite sub-cell. Unlike 
the work reported by Jošt et al, ${ }^{79}$ the authors reported the formation of a conformal coating of PTAA on the somewhat rough, CIGS cell. A Ni-Al metal grid was also utilized on the AZO top transparent contact to enable better charge collection, while a $\mathrm{MgF}_{2}$ anti-reflection coating was incorporated to reduce reflectance losses. A steady state PCE of $13.2 \%$ was reported with very little $V_{o c}$ loss indicating the formation of a good recombination junction. However, the overall performance was limited by the sub-optimal photocurrent generation in the $\mathrm{MAPbI}_{3}$ layer due to its thickness of $<300 \mathrm{~nm}$ which does not enable all the incident photons above its $E_{G}$ to be absorbed. Additionally, a lower charge collection efficiency was observed for the LHP in the tandem configuration compared to its single junction variant indicating a collection loss. One possible source for this loss was attributed to the small grain size which is lower than the film thickness. Interestingly, despite the potential for such perovskite/CIGS flexible devices with improved performances, especially in light of recent developments in multi-cation perovskite absorbers, there has been very little work published so far in this regard.

Beyond the application of terrestrial applications, Lang et al. ${ }^{83}$ evaluated perovskite/CIGS tandem PVs for space-based energy harvesting (Fig. 4(g)). The resulting devices retained 85\% of its initial performance, even after irradiation under $68 \mathrm{MeV}$ protons with a cumulative dose of $\sim 10^{12}$ protons $/ \mathrm{cm}^{2}$ (Fig. 4(h) and (i))). The degradation in performance was attributed to increase in carrier recombination in the CIGS sub-cell and the $\mathrm{NiO}_{\mathrm{x}}$ layer used in the bilayer hole transport system used for the perovskite sub-cell. In comparison, the PCE of perovskite/silicon tandems were observed to decrease to $1 \%$ of its initial value under similar irradiation conditions. The high radiation stability of the perovskite is in agreement with their application as an emerging system for direct conversion radiation detectors ${ }^{84,85}$ and points towards a new field of application for these tandem devices. 
a

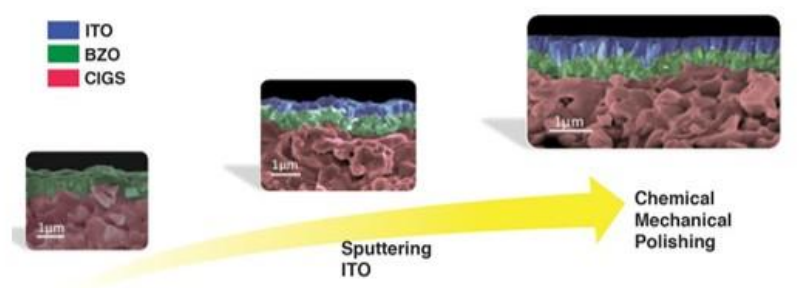

b

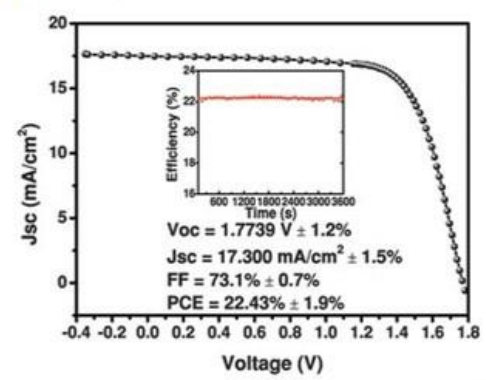

g

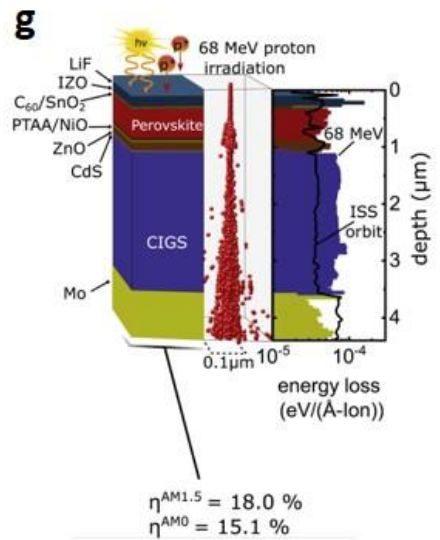

d

C

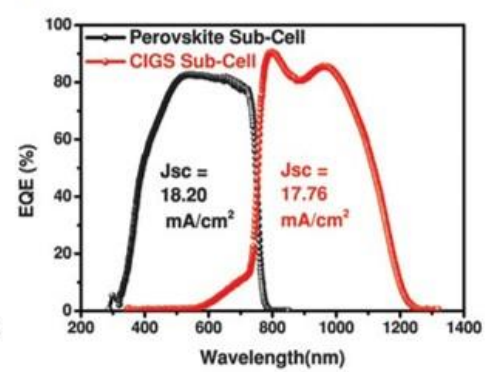

h

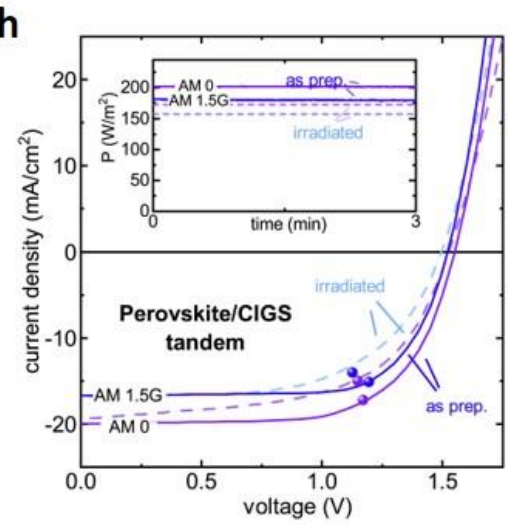

$\mathrm{Ni}$
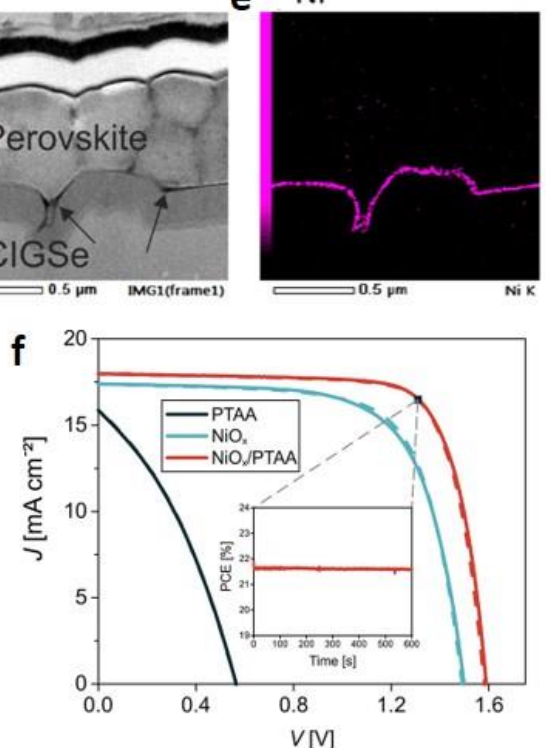

i

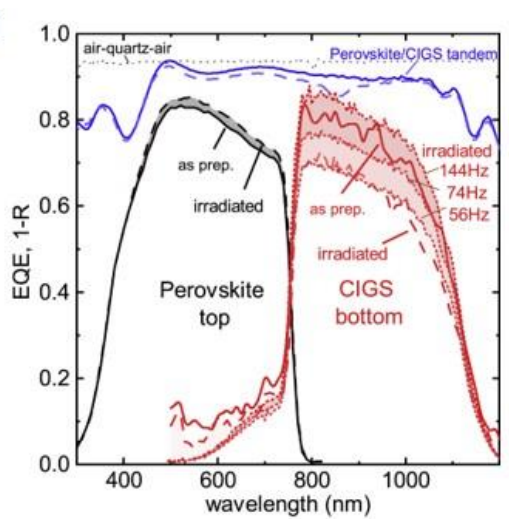

Fig. 4 (a) The chemical mechanical polishing (CMP) method used by Han et al ${ }^{80}$ to reduce the surface roughness of the CIGS sub-cell. (b) indicates the $J$ - $V$ characteristics of the perovskite/CIGS tandem formed where the CIGS sub-cell surface was smoothened using the CMP process and (c) the EQE spectra for each sub-cell for the above tandem device. The MPPT for the optimized device is shown on the inset for panel (b). From Ref. 80. Reprinted with permission from AAAS. (d) High-angle annular dark-field scanning transmission electron micrograph cross-section of the perovskite/CIGS tandem device reported by Jošt et al. ${ }^{79}$ The related EDX image for Ni indicating the conformal coating of $\mathrm{NiO}_{\mathrm{x}}$ on the CIGS sub-cell is given in (e) and (f) shows the tandem device performance for devices that utilized only PTAA, only $\mathrm{NiO}_{x}$ and $\mathrm{NiO}_{x} /$ PTAA bilayer. The MPPT for the optimized device is shown on the inset. Reprinted with permission from Ref. 79. Copyright (2019) American Chemical Society. (g) Schematic of the perovskite/CIGS tandem architecture evaluated for radiation stability by Lang et al. ${ }^{83}$ and the energy deposition profile for $68 \mathrm{MeV}$ protons for the same architecture. (h) $J-V$ characteristics for the above tandem device under AM1.5G and AM0 spectra, before and after proton irradiation. The MPPT tracking under both spectra before and after irradiation is shown in the inset. (i) The EQE spectra of the individual sub-cells before and after proton irradiation. The CIGS sub-cell is observed to have the highest lost in photocurrent. Reprinted from Ref. 83 under the Creative Commons CC-BY license. 
Table 2. Summary of performance characteristics for perovskite/CIGS tandem photovoltaics. SPO indicates stabilised power output.

\begin{tabular}{|c|c|c|c|c|c|c|}
\hline Year & Configuration & $V_{o c}(\mathrm{~V})$ & $\begin{array}{c}J_{s c} \\
\left(\mathrm{mAcm}^{-2}\right)\end{array}$ & $F F$ & $\begin{array}{c}\text { PCE (\%) } \\
(S P O(\%))\end{array}$ & Ref \\
\hline \multirow{2}{*}{2015} & $\begin{array}{c}\text { glass } / \mathrm{Si}_{3} \mathrm{~N}_{4} / \mathrm{Mo} / \mathrm{CIGS} / \mathrm{CdS} / \mathrm{ITO} / \mathrm{PEDOT}: \mathrm{PSS} / \mathrm{MAPb}(\mathrm{I}, \mathrm{Br})_{3} / \mathrm{PC}_{61} \mathrm{BM} / \\
\text { Al }\end{array}$ & 1.315 & 8.9 & 68.9 & $8(-)$ & \multirow[t]{2}{*}{78} \\
\hline & $\begin{array}{c}\text { glass } / \mathrm{Si}_{3} \mathrm{~N}_{4} / \mathrm{Mo} / \mathrm{CIGS} / \mathrm{CdS} / \mathrm{ITO} / \mathrm{PEDOT}: \mathrm{PSS} / \mathrm{MAPb}(\mathrm{I}, \mathrm{Br}) 3 / \\
\mathrm{PC}_{61} \mathrm{BM} / \mathrm{Ca}\end{array}$ & 1.45 & 12.7 & 56.6 & $10.9(-)$ & \\
\hline 2018 & $\begin{array}{c}\text { glass/Mo/CIGS/CdS/i-ZnO/BZO/ITO/PTAA/PVSK/ PC }{ }_{61} \mathrm{BM} / \mathrm{ZnO} \\
\mathrm{NP} / \mathrm{ITO} / \mathrm{MgF}_{2}\end{array}$ & 1.774 & 17.3 & 73.1 & 22.43 & 80 \\
\hline 2019 & $\begin{array}{c}\text { glass/Mo/ClGS/CdS/ZnO/NiO } / \mathrm{PTAA} / \\
\mathrm{Cs}_{0.05}\left(\mathrm{FA}_{0.83} \mathrm{MA}_{0.17}\right)_{0.95} \mathrm{~Pb}_{1.1}\left(\mathrm{l}_{0.83} \mathrm{Br}_{0.17}\right)_{3} / \mathrm{C}_{60} / \mathrm{SnO}_{2} / \mathrm{IZO} / \mathrm{LiF}\end{array}$ & 1.58 & 18 & 76 & $21.6(21.6)$ & 79 \\
\hline 2019 & $\begin{array}{c}\text { glass/Mo/CIGS/CdS/ZnO/SAM/ } \\
\mathrm{Cs}_{0.05}\left(\mathrm{FA}_{0.83} \mathrm{MA}_{0.17}\right)_{0.95} \mathrm{~Pb}\left(\mathrm{l}_{0.83} \mathrm{Br}_{0.17}\right)_{3} / \mathrm{C}_{60} / \mathrm{SnO}_{2} / \mathrm{IZO} / \mathrm{LiF}\end{array}$ & 1.68 & 19.17 & 71.9 & $\begin{array}{l}23.16 \\
(23.26)\end{array}$ & 24 \\
\hline 2020 & $\begin{array}{c}\text { glass/Mo/CIGS/CdS/ZnO/ } \mathrm{NiO}_{\times} / \mathrm{PTAA} / \\
\mathrm{Cs}_{0.05}\left(\mathrm{FA}_{0.83} \mathrm{MA}_{0.17}\right)_{0.95} \mathrm{~Pb}\left(\mathrm{I}_{0.83} \mathrm{Br}_{0.17}\right)_{3} / \mathrm{C}_{60} / \mathrm{SnO}_{2} / \mathrm{IZO} / \mathrm{LiF}\end{array}$ & 1.52 & 16.7 & 70.8 & $18(18)$ & 86 \\
\hline
\end{tabular}

\section{c) All perovskite tandem photovoltaics}

As mentioned previously, one of the key advantages of perovskite semiconductors is their bandgap tunability. While the development of wide $E_{G}$ has attracted a significant interest, there is now a growing activity in terms of developing narrow $E_{G}$ perovskites through the partial or complete replacement of $\mathrm{Pb}^{2+}$ with $\mathrm{Sn}^{2+}$. The slow development of this technology has been mainly due to the undesirable oxidation of $\mathrm{Sn}^{2+}$ to $\mathrm{Sn}^{4+}$, even when processed under glove box conditions. However, recent activities as discussed later-on have identified routes to mitigate this issue to some extent, enabling high performing single junction low band $E_{G}$ perovskite devices as well as all-perovskite tandem architectures to be developed, hinting the possibility for an all printed perovskite PV technology. In the discussion below, we highlight the key developments that have taken place in this area including devices which incorporate $\mathrm{Pb}$-only perovskite absorbers Related device performances are summarized in Table 3.

Due to the early development in $E_{G}$ tunability in lead-only PSCs, 2T tandem architectures incorporating $\mathrm{Pb}$-only perovskites were the first reported all-perovskite $2 \mathrm{~T}$ tandem architecture. For this, Heo et al. ${ }^{87}$ used a top cell made of $\operatorname{MAPbBr}_{3}\left(E_{G}=2.25 \mathrm{eV}\right)$ and a bottom cell made of $\mathrm{MAPbI}_{3}\left(E_{G}=1.55 \mathrm{eV}\right)$ where the tandem cell was fabricated by simply sandwiching the two substrates containing the top and bottom cells together by pressuring with a double clip and subsequent drying. Based on this simple methodology, they were able to fabricate a monolithic tandem with PCE of $10.8 \%$ and $V_{O C}$ of $1.95 \mathrm{~V}$. One of the biggest 
challenges faced in the fabrication of a $2 \mathrm{~T}$ tandem $\mathrm{PV}$ is the optimization of the charge recombination junction or the interconnecting layers (ICLs) between the top and bottom cells so as to a) avoid voltage losses, b) act as a barrier that prevents the dissolution of the bottom cell when depositing the top cell and c) minimise optical losses. In the above work by Heo et al. ${ }^{87}$ the clipping of cell prevented the dissolution of one cell. However, in terms of manufacturability and performance optimisation, it would be preferable for such an approach to be avoided. The first bottom-up fabricated 2T all-perovskite tandem PV was demonstrated by Jiang et al. ${ }^{88}$ where a solution processed charge recombination layer made of SpiroOMeTAD/ Poly(3,4-ethylenedioxythiophene)-poly(styrene sulfonate) (PEDOT:PSS)/Polyethyleneimine (PEI)/(PC $\left.{ }_{61} \mathrm{BM}\right)$ :PEI was used to serially bridge the top and bottom cells was used. By using these recombination layers and top and bottom cells made of $\mathrm{MAPbI}_{3}$, they were able to achieve a PCE of $7 \%$ and $\mathrm{V}_{\mathrm{OC}}$ of $1.89 \mathrm{~V}$, which was almost equal to the sum of $V_{O C}$ 's of the two sub cells.

Forgács et al. ${ }^{89}$ later reported a $2 \mathrm{~T}$ tandem architecture based on the double cation $\mathrm{Cs}_{0.15} \mathrm{FA}_{0.85} \mathrm{~Pb}\left(\mathrm{I}_{0.3} \mathrm{Br}_{0.7}\right)_{3}$ as the wide bandgap absorber (with $E_{G}=2 \mathrm{eV}$ ) and $\mathrm{MAPbI}_{3}$ as the low bandgap absorber $\left(E_{G}=1.55 \mathrm{eV}\right)$. In their work, N4,N4,N4",N4"-tetra([1,1'-biphenyl]-4yl)-[1,1':4',1"-terphenyl]-4,4"-diamine (TaTm), doped with 2,2'-(perfluoronaphthalene-2,6diylidene) dimalononitrile (F6-TCNNQ) and $\mathrm{C}_{60}$ doped with N1,N4-bis(tri-ptolylphosphoranylidene) benzene-1,4- diamine (PhIm) was used as the interconnecting layer (ICL). The resulting devices demonstrated a champion PCE of $18.1 \%$ with an impressive $V_{O C}$ of $2.1 \mathrm{~V}$, most likely due to improved optoelectronic characteristics in the dual cation $2 \mathrm{eV}$ wide $E_{G}$ cell used.

One of the major milestones in the field of all-perovskite 2T tandem architectures was reported by Eperon et al. ${ }^{90}$ where they combined a wide bandgap $\mathrm{FA}_{0.83} \mathrm{Cs}_{0.17} \mathrm{~Pb}\left(\mathrm{I}_{0.5} \mathrm{Br}_{0.5}\right)_{3}\left(E_{G}=1.8 \mathrm{eV}\right)$ with a narrow bandgap sub-cell consisting of the $\mathrm{Pb}-\mathrm{Sn}$ mixed perovskite system $\mathrm{FA}_{0.75} \mathrm{Cs}_{0.25} \mathrm{~Pb}_{0.5} \mathrm{Sn}_{0.5} \mathrm{I}_{3}\left(E_{G}=1.22 \mathrm{eV}\right)$ to form tandem architectures. The resulting monolithic devices fabricated also employed a recombination junction consisting of $\mathrm{SnO}_{2}$ and $\mathrm{ZTO}$ together with and sputtered indium tin oxide (ITO) which acted as a barrier, that protects the underlying perovskite from any solvent damage that occur during subsequent processing. The resulting $2 \mathrm{~T}$ tandem device demonstrated an impressive PCE of 17\% enabled by a high $V_{O C}>$ 1.65 V. The authors noted the impressive stability of the $\mathrm{Pb}-\mathrm{Sn}$ mixed composition reported here, where the device stability was identified to be on par with that of $\mathrm{Pb}$-only devices with no reduction in performance when held at maximum power-point (MPP) in an inert (nitrogen) 
environment for more than 18 hours. Following this, Leijten et al. ${ }^{91}$ reported a $2 \mathrm{~T}$ tandem architecture where a wide $E_{G} \quad \mathrm{Cs}_{0.4} \mathrm{FA}_{0.6} \mathrm{~Pb}\left(\mathrm{I}_{0.7} \mathrm{Br}_{0.3}\right)_{3}$ was combined with the $\mathrm{FA}_{0.75} \mathrm{Cs}_{0.25} \mathrm{~Pb}_{0.5} \mathrm{Sn}_{0.5} \mathrm{I}_{3}$ low $E_{G}$ absorber enabling a PCE of $19.1 \%$ to be achieved (Fig. 5(a) and (b)). The improvement in PCE was achieved through better current matching between the two sub-cells and the post deposition treatment of the narrow bandgap absorber with methylammonium chloride $(\mathrm{MACl})$ of the low bandgap absorber, which improved the perovskite crystallization and increased the grain size, ultimately leading to an increase in the $V_{O C}$ and fill $F F$.

Rajagopal et al. ${ }^{92}$ developed a tandem architecture based on $\mathrm{MAPb}{ }_{0.5} \mathrm{Sn}_{0.5} \mathrm{I}_{3}$ as the low bandgap absorber (with $E_{G}=1.2 \mathrm{eV}$ ) and $\mathrm{MA}_{0.9} \mathrm{Cs}_{0.1} \mathrm{~Pb}\left(\mathrm{I}_{0.6} \mathrm{Br}_{0.4}\right)_{3}$ as the wide bandgap absorber (with $\left.E_{G}=1.8 \mathrm{eV}\right)$. Among the key developments of this work involved a) the identification of indene-C60 bis-adduct as a more matching electron transport layer (ETL) for the $\mathrm{Pb}-\mathrm{Sn}$ mixed absorber and $b$ ) the development of an ICL based on Bis- $\mathrm{C}_{60} / \mathrm{ITO} / \mathrm{PEDOT}$ :PSS which enabled a high $V_{O C}$ of $1.98 \mathrm{~V}$ which is $80 \%$ of the value predicted by the Shockley-Queisser limit resulting in a PCE of $18.5 \%$.

The next notable improvement in $2 \mathrm{~T}$ all perovskite tandem solar cells was reported by Zhao et al. ${ }^{93}$ In their work, they utilised a composition of $\left(\mathrm{FASnI}_{3}\right)_{0.6}\left(\mathrm{MAPI}_{3-3 x} \mathrm{Cl}_{3 x}\right)_{0.4}$ for the low bandgap $\left(E_{G}=1.25 \mathrm{eV}\right)$. The incorporation of chloride ions, similar to Leijten et al. ${ }^{91}$ resulted in an increase in the grain size which is compatible with the film thickness of $\sim 750 \mathrm{~nm}$, as well as a reduction in the trap density. This low bandgap cell when combined with a wider bandgap absorber based on the $\left.\mathrm{FA}_{0.8} \mathrm{Cs}_{0.2} \mathrm{~Pb}_{\left(\mathrm{I}_{0.7}\right.} \mathrm{Br}_{0.3}\right)_{3}$ composition $\left(E_{B G}=1.75 \mathrm{eV}\right)$ through a $\mathrm{Ag}(1$ $\mathrm{nm}) / \mathrm{MoO}_{3}(3 \mathrm{~nm}) / \mathrm{ITO}(120 \mathrm{~nm})$ ICL led to the first demonstration of a PCE exceeding $20 \%$ (20.6\%) for all-perovskite 2T tandem architectures (Fig. 5(c)). These cells also demonstrated an impressive stability with $80 \%$ of its initial PCE being maintained after 80 hours of continuous illumination under AM1.5G conditions in air without encapsulation while the cells retained $94 \%$ of its initial PCE after 45 days of storage in ambient air (Fig. 5(d)).

Subsequent to this, there have been several rapid developments within a short span that has enabled further improvements in $2 \mathrm{~T}$ tandem architectures consisting of a wide bandgap $\mathrm{Pb}$ only cell in combination with a narrow bandgap $\mathrm{Pb}-\mathrm{Sn}$ mixed sub-cell. Among the developments made include processing optimisation for thicker $\mathrm{Pb}-\mathrm{Sn}$ mixed perovskite sub-cells and reduction of background carrier density. For example, Tong et al. ${ }^{94}$ reported the incorporation of guanidinium thiocyanate into the $\left(\mathrm{FASnI}_{3}\right)_{0.6}\left(\mathrm{MAPbI}_{3}\right)_{0.4}$ which enabled a significant 
improvement in the carrier lifetimes to $>1 \mu \mathrm{s}$ and also the reduction of the background carrier concentration by and order of magnitude, enabling the fabrication of thick absorber layers for increased light harvesting, especially in the near-infrared portion. This low bandgap cell when coupled with an $E_{G}=1.63 \mathrm{eV}$ wideband gap sub-cell with a composition of $\mathrm{Cs}_{0.05} \mathrm{FA}_{0.80} \mathrm{MA}_{0.15} \mathrm{PbI}_{2.55} \mathrm{Br}_{0.45}$ enabled a champion PCE of $18 \%$. By changing the wide bandgap absorber to a perovskite with $E_{G}=1.75 \mathrm{eV}$, a significantly improved PCE of $23.4 \%$ was obtained while more than $88 \%$ of the initial PCE was maintained under continuous AM1.5G illumination for 100 hours. These devices demonstrated an impressive FF exceeding $80 \%$ as well as a $V_{O C}$ of $1.942 \mathrm{~V}$.

While the above activities enabled PCE improvements in all-perovskite tandem devices, the oxidation of $\mathrm{Sn}^{2+}$ (the preferred oxidation state for PSCs) to $\mathrm{Sn}^{4+}$ remained a challenge with approaches such the inclusion of $\mathrm{SnF}_{2}$, use of appropriate anti-solvent washing and annealing temperatures ${ }^{11}$ being utilised to mitigate this issue. Recently, Lin et al. ${ }^{12}$ outlined a comproportionation process where Sn powder is added to the precursor mix enabling the reduction of $\mathrm{Sn}^{4+}$ to $\mathrm{Sn}^{2+}$ thereby minimising the detrimental impact of $\mathrm{Sn}^{2+}$ oxidation. Based on this method, a single junction PSC based on the $\mathrm{FA}_{0.7} \mathrm{MA}_{0.3} \mathrm{~Pb}_{0.5} \mathrm{Sn}_{0.5} \mathrm{I}_{3}$ absorber achieved a PCE of $21 \%$ PCE while combining this with a wide bandgap $\mathrm{Cs}_{0.2} \mathrm{FA}_{0.8} \mathrm{PbI}_{1.8} \mathrm{Br}_{1.2}$ absorber to form monolithic 2T tandem solar cell (Fig. 5(e)) resulted in a certified PCE of $24.8 \%$ for an aperture area of $0.073 \mathrm{~cm}^{2}$ (Fig. 5(f)) and $22.3 \%$ for an aperture area of $1.03 \mathrm{~cm}^{2}$. These are the highest reported for a $2 \mathrm{~T}$ all perovskite tandem solar cell as of present. These devices also demonstrated an impressive stability where $90 \%$ of its initial performance was maintained after 463 hours of operation (Fig. 5 (g)).

Perhaps one of the first demonstrations on fabrication of all perovskite tandem solar cells fabricated on flexible substrates was reported by Palmstrom et al. ${ }^{95}$ In their work ALD was used to grow the recombination layers of the monolithic tandem in order to reduce shunting and damage caused to the underlying layers due to solvents used in subsequent processing of the tandem cell. Hence, an ALD grown aluminium doped zinc Oxide (AZO) layer was grown on top of $\mathrm{C}_{60}$ using an ultra-thin $(1 \mathrm{~nm})$ nucleation layer in the form of poly(ethylenimine) ethoxylated (PEIE). However, they also discovered that a thin layer of transparent conductive oxide (TCO) is required to prevent $F F$ losses due to damage caused to the AZO layer by acidic PEDOT:PSS. 2T tandem architectures were fabricated on a flexible IZO coated polyethylene napthalate (PEN) substrate in the configuration of PEN/Sputtered IZO/Poly-TPD/PFN/ $\mathrm{FA}_{0.6} \mathrm{Cs}_{0.3} \mathrm{DMA}_{0.1} \mathrm{PbI}_{2.4} \mathrm{Br}_{0.6} / \mathrm{LiF} / \mathrm{C}_{60} / \mathrm{PEIE} / \mathrm{AZO} / \mathrm{IZO} / \mathrm{PEDOTT}: \mathrm{PSS} / \mathrm{FA}_{0.75} \mathrm{Cs}_{0.25} \mathrm{Sn}_{0.5} \mathrm{~Pb}_{0.5} \mathrm{I}_{3} /$ 
$\mathrm{C}_{60} / \mathrm{BCP} / \mathrm{Au}$ which resulted in a PCE of $21.3 \%$ (with $23.1 \%$ on a glass substrate) with a $V_{O C}$ of $1.82 \mathrm{~V}$ and a $F F$ of $75 \%$. The devices also maintained more than $95 \%$ of its initial performance after 100 bend cycles (bend radius of $1.5 \mathrm{~cm}$ ). Furthermore, no degradation was observed when continuously illuminated under AM1.5G for 13 hours as well as when stored in the dark at $85^{\circ} \mathrm{C}$ for $50 \mathrm{~h}$.

In terms of other developments with regards to appropriate ICL layers, Chang et al. ${ }^{86}$ developed an ICL based on a cross-linkable p-doped PTAA layer and PCBM. As the cross-linking agent, 1,2-bis[4-(azidomethyl)phenyl]- 1,2-diphenylethene (TPE-MN3) was employed while molybdenum tris-[1-(trifluoroethanoyl)-2-(trifluoro- methyl)ethane-1,2-dithiolene] $\left(\mathrm{Mo}(\mathrm{tfdCOCF})_{3}\right.$ was incorporated as the p-type dopant. The incorporation of TPE-MN3 enabled cross linking of PTAA under UV irradiation, resulting in a dense blocking layer that has better solvent-resistance, thereby protecting the underlying perovskite absorber when processing the top perovskite absorber. The devices based on a regular architecture (as opposed to the inverted architecture widely used for all perovskite $2 \mathrm{~T}$ tandem structures) which combines $\mathrm{MAPbI}_{3}$ as the wide bandgap absorber and $\mathrm{MAPb}_{0.75} \mathrm{Sn}_{0.25} \mathrm{I}_{3}$ as the low bandgap absorber resulted in a champion PCE of $18.69 \%$, with a stabilized PCE of $18.92 \%$. Most notably, the $V_{O C}$ of the tandem architecture $(1.79 \mathrm{~V})$ was exceptionally close to the sum of the $V_{O C} s$ of individual sub-cells $(1.80 \mathrm{~V})$ indicating the effectiveness of the ICL developed.

Going beyond the widely explored 2T-2J concept, McMeekin et al. ${ }^{96}$ demonstrated a 2T-3J (triple junction) architecture based on 3 perovskite light absorption layers, namely; $\mathrm{FA}_{0.83} \mathrm{Cs}_{0.17} \mathrm{~Pb}\left(\mathrm{I}_{0.3} \mathrm{Br}_{0.7}\right)_{3}\left(E_{G}=1.94 \mathrm{eV}\right)$ in the top cell, $\mathrm{MAPbI}_{3}\left(E_{G}=1.57 \mathrm{eV}\right)$ in the middle cell and $\mathrm{MAPb}_{0.75} \mathrm{Sn}_{0.25} \mathrm{I}_{3}\left(E_{G}=1.34 \mathrm{eV}\right)$ in the bottom. While optical modelling showed that the cell had a potential of achieving a PCE of around $26.7 \%$ and a corresponding $V_{O C}$ of 3.16 $\mathrm{V}$, the fabricated device only showed a PCE of $6.7 \%$ and a $V_{O C}$ of $2.7 \mathrm{~V}$. Despite being significantly lower than the anticipated values, it can be envisioned that significant improvements in performance as being possible following the optimisation of interconnecting layers to reduce parasitic absorptions etc. This work so far remains the only reported work for 2T-3J all-perovskite tandem devices. 
a

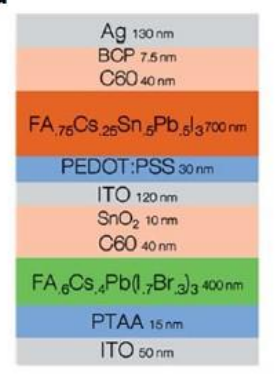

C

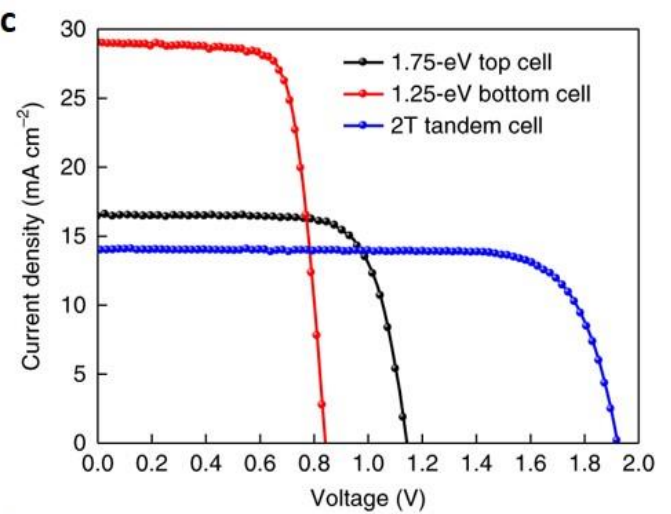

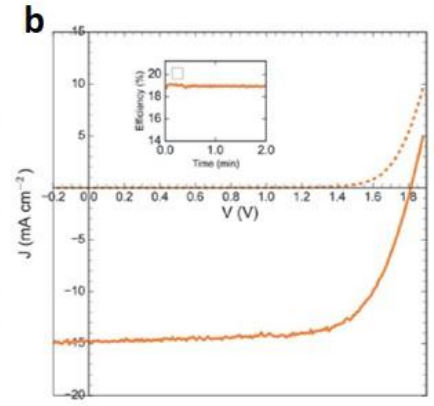

d 2

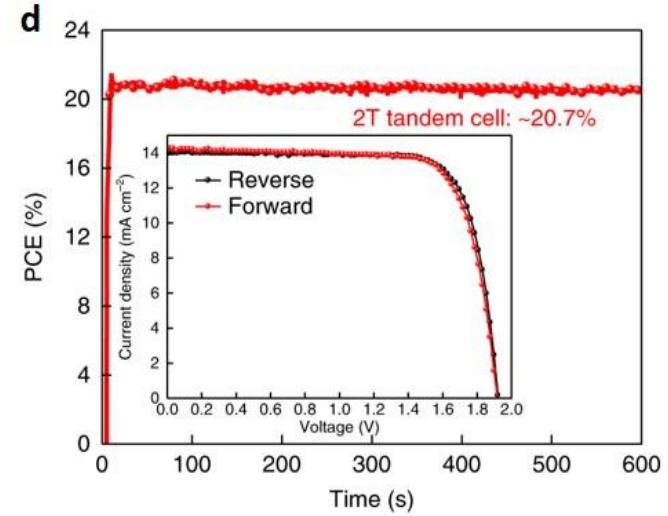

e
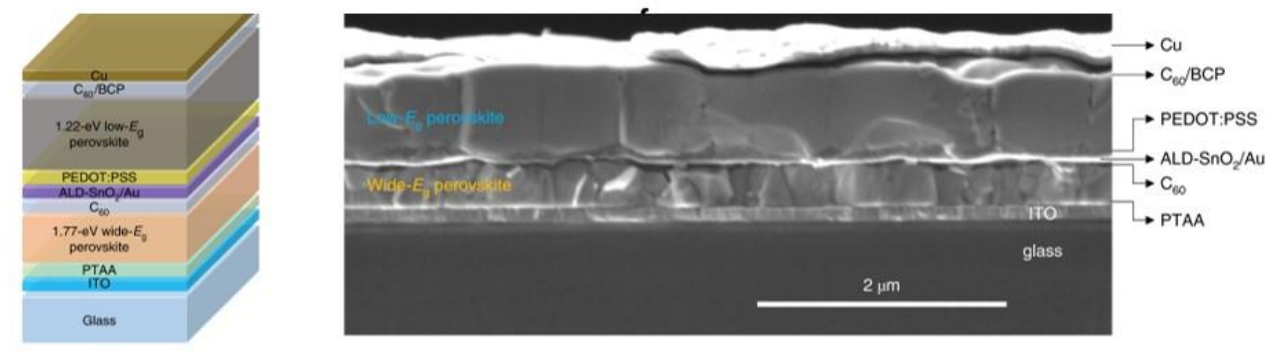

f

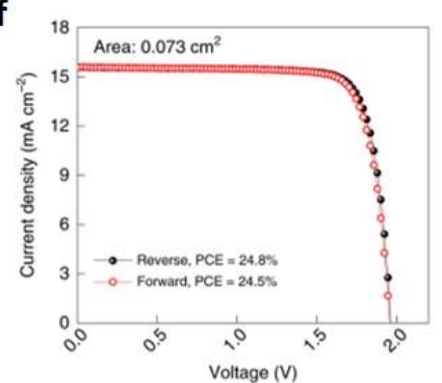

g

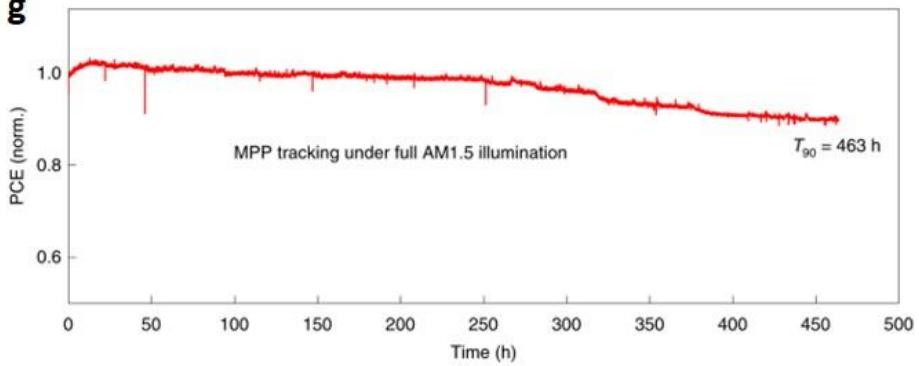

Fig. 5 (a) Schematic of the cross-sectional scanning electron micrograph of the device concept used by Leijten et al. ${ }^{91}$ in their all perovskite $2 \mathrm{~T}$ tandem architecture. The $J-V$ characteristic of this tandem devices is given in (b). Reproduced from Ref. 91 with permission from The Royal Society of Chemistry. (c) The $J-V$ characteristics of the wide bandgap, narrow bandgap single junction PSCs and the resulting tandem device incorporating $\mathrm{MACl}$ and (d) the maximum power point tracking of the same as reported by Zhao et al. ${ }^{93}$ Reproduced from Ref. 93 with permission from Springer Nature. (e) The schematic and cross sectional scanning electron micrograph of all perovskite $2 \mathrm{~T}$ tandem device reported by Lin et al. ${ }^{12}$ where the use of $\mathrm{Sn}$ powder to reduce the detrimental effect of oxidation of $\mathrm{Sn}^{2+}$ resulted in a PCE of $24.8 \%$ as indicated by (f) the $J-V$ characteristics. (g) The maximum power tracking carried out for 463 $\mathrm{h}$ for this device. Reproduced from Ref. 12 with permission from Springer Nature. 
Table 3. Summary of performance characteristics for all perovskite tandem photovoltaics. SPO indicates stabilised power output.

\begin{tabular}{|c|c|c|c|c|c|c|}
\hline Year & Configuration & $\begin{array}{l}V_{o c} \\
\text { (V) }\end{array}$ & $\begin{array}{c}J_{s c} \\
\left(\mathrm{mAcm}{ }^{-2}\right)\end{array}$ & $\boldsymbol{F F}$ & $\begin{array}{l}\text { PCE (\%) } \\
\text { (SPO(\%)) }\end{array}$ & Ref \\
\hline \multirow{2}{*}{2015} & Glass/FTO/c-TiO $2 / \mathrm{MAPbBr}_{3} / \mathrm{P} 3 \mathrm{HT} / \mathrm{PCBM} / \mathrm{MAPbl}_{3} / \mathrm{PEDOTT}: \mathrm{PSS} / \mathrm{ITO}$ & 1.95 & 8.4 & 66 & $10.8(-)$ & \multirow{2}{*}{87} \\
\hline & Glass/FTO/c- $\mathrm{TiO}_{2} / \mathrm{MAPbBr}_{3} / \mathrm{PTAA} / \mathrm{PCBM} / \mathrm{MAPbl}_{3} / \mathrm{PEDOTT}: \mathrm{PSS} / \mathrm{ITO}$ & 2.25 & 8.3 & 56 & $10.4(-)$ & \\
\hline 2016 & $\begin{array}{l}\text { Glass/FTO/c-TiO } / \mathrm{mp} \mathrm{TiO}_{2} / \mathrm{MAPbl}_{3} / \mathrm{Spiro}-\mathrm{OMeTAD} / \mathrm{PEDOT}: \\
\mathrm{PSS} / \mathrm{PEI} / \mathrm{PCBM}: \mathrm{PEI} / \mathrm{MAPbl}_{3} / \text { Spiro-OMeTAD/hc-PEDOT:PSS }\end{array}$ & 1.89 & 6.61 & 56 & $7(-)$ & 88 \\
\hline 2016 & $\begin{array}{l}\text { Glass/ITO/NiO/FA }{ }_{0.83} \mathrm{Cs}_{0.17} \mathrm{~Pb}\left(\mathrm{I}_{0.5} \mathrm{Br}_{0.5}\right)_{3} / \mathrm{ZTO} / \mathrm{SnO}_{2} / \mathrm{PCBM} / \mathrm{ITO} / \mathrm{PEDO} \\
\mathrm{T}: \mathrm{PSS} / \mathrm{FA}_{0.75} \mathrm{Cs}_{0.25} \mathrm{Sn}_{0.5} \mathrm{~Pb}_{0.5} \mathrm{I}_{3} /\left(\mathrm{C}_{60} / \mathrm{BCP}\right) / \mathrm{Ag}\end{array}$ & 1.66 & 14.5 & 70 & $16.9(14.8)$ & 90 \\
\hline 2016 & $\begin{array}{l}\mathrm{ITO} / \mathrm{TiO}_{2} / \mathrm{IPH} / \mathrm{Cs}_{0.15} \mathrm{FA}_{0.85} \mathrm{~Pb}\left(\mathrm{I}_{0.3} \mathrm{Br}_{0.7}\right)_{3} / \mathrm{TaTm} / \mathrm{TaTm}: \mathrm{F} 6- \\
\mathrm{TCNNQ} / \mathrm{C}_{60}: \mathrm{Phlm} / \mathrm{C}_{60} / \mathrm{MAPbl}_{3} / \mathrm{TaTmTaTm}_{\mathrm{F} 6-\mathrm{TCNNO} / \mathrm{Ag}}\end{array}$ & 2.29 & 9.83 & 80.3 & $18.1(14.5)$ & 89 \\
\hline 2017 & $\begin{array}{l}\text { Glass/ITO/NiO/MA }{ }_{0.9} \mathrm{Cs}_{0.1} \mathrm{~Pb}\left(\mathrm{I}_{0.6} \mathrm{Br}_{0.4}\right)_{3} / \mathrm{C}_{60} / \mathrm{Bis}-\mathrm{C}_{60} / \mathrm{Sputtered} \\
\text { ITO/PEDOT:PSS/ MAPb } 0.5 \mathrm{Sn}_{0.5} \mathrm{I}_{3} / \mathrm{IC}_{60} \mathrm{BA} / \mathrm{Bis}-\mathrm{C}_{60} / \mathrm{Ag}\end{array}$ & 1.98 & 12.7 & 73 & $18.4(18.5)$ & 92 \\
\hline 2018 & $\begin{array}{l}\text { Glass/ITO/PTAA/FA }{ }_{0.6} \mathrm{Cs}_{0.4} \mathrm{~Pb}\left(\mathrm{Br}_{0.3} \mathrm{I}_{0.7}\right)_{3} / \mathrm{C}_{60} / \mathrm{SnO}_{2} / \text { sputtered } \\
\text { ITO/PEDOT:PSS/FA } 0 .\left.{ }_{0.75} \mathrm{Cs}_{0.25} \mathrm{Sn}_{0.5} \mathrm{~Pb}_{0.5}\right|_{3} / \mathrm{C}_{60} / \mathrm{BCP} / \mathrm{Ag}\end{array}$ & 1.81 & 14.8 & 70 & $19.1(19.1)$ & 91 \\
\hline 2018 & $\begin{array}{l}\text { Glass/ITO/TiO } 2 / \mathrm{C}_{60} / \mathrm{MAPbl}_{3} / \mathrm{TaTm} / \mathrm{TaTm}: \mathrm{F6}- \\
\mathrm{TCNNO} \mathrm{C}_{60}: \mathrm{PhIm} / \mathrm{C}_{60} / \mathrm{MAPbl}_{3} / \mathrm{TaTm} / \mathrm{TaTm}: \mathrm{F6} \text {-TCNNQ} / \mathrm{Au}\end{array}$ & 2.3 & 9.84 & 79.58 & $18.02(-)$ & 97 \\
\hline 2018 & $\begin{array}{l}\text { Glass/ITO/NiO/FA }{ }_{0.83} \mathrm{Cs}_{0.17} \mathrm{~Pb}\left(\mathrm{Br}_{0.5} \mathrm{l}_{0.5}\right) 3 / \mathrm{FSIP} / \mathrm{C}_{60} / \mathrm{BCP} / \mathrm{Cu} / \mathrm{Au} / \mathrm{PEDOT} \\
\text { :PSS/FA } 0.5 \mathrm{MA}_{0.5} \mathrm{~Pb}_{0.5} \mathrm{Sn}_{0.5} \mathrm{I}_{3} / \text { polystyrene/C }{ }_{60} / \mathrm{BCP} / \mathrm{Ag}\end{array}$ & 1.72 & 12.8 & 73 & 16.07 (16.1) & 98 \\
\hline 2018 & $\begin{array}{l}\text { Glass/ITO/PTAA/FA }{ }_{0.6} \mathrm{Cs}_{0.4} \mathrm{~Pb}\left(\mathrm{Br}_{0.3} \mathrm{I}_{0.7}\right)_{3} / \mathrm{C}_{60} / \mathrm{BCP} / \mathrm{Ag} / \mathrm{MoO} / \text { sputtere } \\
\text { d ITO/PEDOT:PSS/FA }{ }_{0.75} \mathrm{Cs}_{0.25} \mathrm{Sn}_{0.5} \mathrm{~Pb}_{0.5} \mathrm{I}_{3}: \mathrm{Cl} / \mathrm{C}_{60} / \mathrm{BCP} / \mathrm{Ag}\end{array}$ & 1.92 & 14 & 78.1 & $21(20.7)$ & 93 \\
\hline \multirow[b]{2}{*}{2019} & $\begin{array}{l}\text { Glass/FTO/SnO } 2 / \mathrm{PC}_{61} \mathrm{BM} / \mathrm{FA}_{0.83} \mathrm{Cs}_{0.17} \mathrm{~Pb}\left(\mathrm{I}_{0.3} \mathrm{Br}_{0.7}\right)_{3} / \text { Spiro- } \\
\text { OMeTAD/PEDOT:PSS/ITO NPs/ } \mathrm{PC}_{61} \mathrm{BM} / \mathrm{MAPbl} 3 / \text { Spiro- } \\
\text { OMeTAD/Ag }\end{array}$ & 2.18 & 11.5 & 63 & $15.2(15.2)$ & \multirow[b]{2}{*}{96} \\
\hline & $\begin{array}{l}\text { Glass/FTO/SnO2/PC }{ }_{61} \mathrm{BM} / \mathrm{FA}_{0.83} \mathrm{Cs}_{0.17} \mathrm{~Pb}\left(\mathrm{I}_{0.3} \mathrm{Br}_{0.7}\right)_{3} / \mathrm{Spiro}^{-} \\
\text {OMeTAD/PEDOT:PSS/ITO NPs/PC }{ }_{61} \mathrm{BM} / \mathrm{MAPbl}_{3} / \text { Spiro- } \\
\text { OMeTAD/PEDOT:PSS/ITO NPs/ } \mathrm{PC}_{61} \mathrm{BM} / \mathrm{MAPb}_{0.75} \mathrm{Sn}_{0.25} \mathrm{I}_{3} / \text { Spiro- } \\
\text { (TFSI)2/Ag }\end{array}$ & 2.7 & 8.3 & 43 & $6.7(6.4)$ & \\
\hline 2019 & $\begin{array}{l}\text { Glass/ITO/PTAA/Cs }{ }_{0.05} \mathrm{FA}_{0.8} \mathrm{MA}_{0.15} \mathrm{Pbl}_{2.55} \mathrm{Br}_{45} / \mathrm{C} 60 / \mathrm{SnO} 2 / \mathrm{ZTO} / \mathrm{Sputte} \\
\text { red IZO/PEDOT:PSS/GuaSCN-modified }\left(\mathrm{FASnl}_{3}\right)_{0.6}\left(\mathrm{MAPbl}_{3}\right)_{0.4} / \\
\mathrm{C}_{60} / \mathrm{BCP} / \mathrm{Ag}\end{array}$ & 1.94 & 15.01 & 80.31 & $23.4(23.1)$ & 94 \\
\hline \multirow{2}{*}{2019} & $\begin{array}{l}\text { Glass/ITO/Poly-TPD/PFN/FA }{ }_{0.6} \mathrm{Cs}_{0.3} \mathrm{DMA}_{0.1} \mathrm{Pbl}_{2.4} \mathrm{Br}_{0.6} \\
\text { /LiF/C } 60 \text { /PEIE/AZO/IZO/PEDOTT:PSS/FA }\left.0.75 \mathrm{Cs}_{0.25} \mathrm{Sn}_{0.5} \mathrm{~Pb}_{0.5}\right|_{3} / \\
\mathrm{C}_{60} / \mathrm{BCP} / \mathrm{Au}\end{array}$ & 1.88 & 16 & 77 & $23.1(23)$ & \multirow{2}{*}{95} \\
\hline & $\begin{array}{l}\text { PEN/Sputtered IZO/PolyTPD/PFN/FA } 0.6 \mathrm{Cs}_{0.3} \mathrm{DMA}_{0.1} \mathrm{Pbl}_{2.4} \mathrm{Br}_{0.6} \\
\text { /LiF/C60/PEIE/AZO/IZO/PEDOTT:PSS/FA }\left.0.75 \mathrm{Cs}_{0.25} \mathrm{Sn}_{0.5} \mathrm{~Pb}_{0.5}\right|_{3} / \\
\mathrm{C}_{60} / \mathrm{BCP} / \mathrm{Au}\end{array}$ & 1.82 & 15.6 & 75 & $21.3(21.3)$ & \\
\hline 2019 & 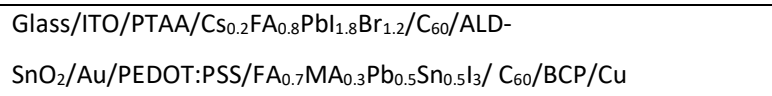 & 1.96 & 15.6 & 81 & $24.8(24.5)$ & 12 \\
\hline 2019 & $\begin{array}{l}\text { Glass/ITO/TiO } / \mathrm{PC}_{61} \mathrm{BM} / \mathrm{MAPb}_{3} / \mathrm{p} \text {-doped crosslinked PTAA/HMB- } \\
\text { doped } \mathrm{PC}_{61} \mathrm{BM} / \mathrm{MASn}_{0.25} \mathrm{~Pb}_{0.75} \mathrm{l} / \mathrm{p} \text {-doped crosslinked PTAA/Ag }\end{array}$ & 1.79 & 13.36 & 78.18 & 18.69 (18.92) & 99 \\
\hline
\end{tabular}




\section{d) Perovskite/organic tandem photovoltaics}

Organic BHJ PVs is perhaps one of the earliest PV technologies to adopt printing technologies. Despite this, perovskite-organic bulk heterojunction (BHJ) tandem devices are a relatively less well explored concept compared to the more widely investigated perovskite incorporated tandem architectures which employ either $\mathrm{Si}$, copper indium gallium selenide or even a perovskite as the low bandgap absorber. While initial tandem device concepts were based on combining two BHJ absorbers, the field was somewhat restricted in terms of the possible performance due to Voltage losses as high as $0.6 \mathrm{~V}^{100,101}$ and the lack of efficient infrared absorbers, recent developments in the field ${ }^{102,103}$ has resulted in the development of high performing single junction architectures with absorption up to $\sim 1000 \mathrm{~nm}^{104,105}$ while the Voltage losses have now been significantly reduced ${ }^{101,106}$. This has led to significant improvements in single junction device efficiencies which now exceed $16 \% .{ }^{107,108}$ As a result, there is now growing interest towards the formation of tandem architectures by combining organic BHJs with perovskites as discussed below (A summary of reported device performances are given in Table 4).

In terms of perovskite/organic BHJ $2 \mathrm{~T}$ tandem architecture, the first work in this regard was reported by Chen et al. ${ }^{109}$ In their work, the authors used $\mathrm{MAPbI}_{3}$ as the wide $E_{G}$ absorber while a BHJ consisting of PBSeDTEG8 $\left(E_{G}=1.28 \mathrm{eV}\right)$ as the donor and $\mathrm{PC}_{61} \mathrm{BM}$ as the acceptor was used as the narrow $E_{G}$ absorber. For the perovskite absorber, the authors reported the use of an additive assisted anti-solvent deposition method which enabled the formation of smooth pin-hole free absorber layers which resulted in a PCE of $9.1 \%$ for single junction PSCs. The use of the PBSeDTEG8 block copolymer-based donor was found to be beneficial in enabling better thermal stability for the BHJ absorber. Furthermore, this absorber did not necessitate the use of 1,8 diiodooctane (DIO), a commonly used additive in high performing organic BHJ devices, which can also result in poor shelf-life. ${ }^{110}$ The single junction organic BHJ sub-cell resulted in a PCE of $7 \%$. Compared to the conventional $2 \mathrm{~T}$ tandem architectures where the incident light first passes through the wide $E_{G}$ absorber, this work employed an architecture where the light first passes through the narrow $E_{G}$ BHJ absorber, a concept previously reported $^{111}$ for all organic BHJ tandem architectures. However, it is noted that such a device architecture is likely to result in undesirable absorption from the narrow $E_{G}$ and result in suboptimal performance. By employing an ICL consisting of poly[(9,9-bis $\left(3^{\prime}-(\mathrm{N}, \mathrm{N}-\right.$ dimethylamino)propyl)-2,7-fluorene)-alt-2,7-(9,9-dioctylfluorene)] (PFN)/PEDOT:PSS (high 
conductivity, PH1000)/PEDOT:PSS (low conductivity, PVP AI 4083), the authors successfully demonstrated a $2 \mathrm{~T}$ tandem device with a PCE of $10.2 \%$.

Following this, Liu et al. reported ${ }^{112}$ the development of a $2 \mathrm{~T}$ perovskite-organic tandem device where the efforts were focused on the development of an ICL based on the stack of poly [ $(9,9-$ bis(3'-(N,N-dimethylamino)propyl)-2,7-fluorene)-alt-2,7-(9,9-dioctylfluorene)] (PFN)/Al or Ag doped $\mathrm{MoO}_{3}$ (step-layer)/ $\mathrm{MoO}_{3}$. The authors noted an improvement in the $V_{O C}$ upon the incorporation of the step-layer. For example, when doped with $\mathrm{Al}$, the $V_{O C}$ was improved from $1.38 \mathrm{~V}$ to $1.45 \mathrm{~V}$ while this was further improved to $1.55 \mathrm{~V}$ upon using $\mathrm{Ag}$ as the dopant under optimized doping conditions. Furthermore, the use of dopants was also reported to result in the elimination of an $S$-shaped $J-V$ characteristic for the tandem device which is indicative of a more balanced charge transport through the device. Following a $2 \mathrm{~T}$ tandem device architecture incorporating $\mathrm{MAPbI}_{3-x} \mathrm{Cl}_{x}$ as the wide bandgap absorber and poly\{2,6'-4,8-di(5ethylhexylthienyl)benzo[1,2-b;3,4-b]dithiophene-alt-5,5'-dibutyloctyl-3,6-bis(5-thiophen-2yl)pyrrolo[3,4-c]pyrrole-1,4-dione (PBDTT-DPP): [6,6]-Phenyl C71 butyric acid methyl ester $\left(\mathrm{PC}_{71} \mathrm{BM}\right)$ as the narrower bandgap absorber, a PCE of $8.62 \%$ was achieved based on further optimization of the individual layers. In the above, the removal of $S$-shaped $J$ - $V$ characteristics following the inclusion of $\mathrm{Ag}$ as a dopant indicates the need for careful optimization of individual layers as well as the recombination junction to achieved balanced currents from individual sub-cell.

A significantly improved PCE of $16 \%$ for perovskite-BHJ $2 \mathrm{~T}$ tandems was subsequently reported by Liu, et al. ${ }^{113}$ In this work, the authors used $\mathrm{MAPbI}_{3}$ absorber processed using the acetate route $^{114}$ on a heated substrate temperature and a Poly([2,6'-4,8-di(5ethylhexylthienyl)benzo[1,2-b;3,3-b]dithiophene] $\{3$-fluoro-2[(2-

ethylhexyl)carbonyl]thieno[3,4-b]thiophenediyl\}) (referred to as PCE10 or PTB7-Th or PBDTTT-EFT or PBDTT-FTTE): PC $_{71}$ BM as the BHJ based absorber (Fig. 6(a)-(c)). We note several key developments that enabled the high PCE for this 2T tandem architecture. Firstly, an ICL based on tris(sulfobetaine)-substituted fulleropyrrolidine $\left(\mathrm{C}_{60}-\mathrm{SB}\right) / \mathrm{ultra}$-thin $\mathrm{Ag} / \mathrm{MoO}_{3}$ was used. The $\mathrm{C}_{60}$-SB layer processed using 2,2,2-trifluoroethanol as the solvent does not dissolve the underlying layers in the perovskite sub-cell and in combination with the ultrathin $\mathrm{Ag}$ and $\mathrm{MoO}_{3}$ layers, acts as a barrier against solvent induced dissolution of the perovskite subcell when processing the BHJ sub-cell. Additionally, based on Kelvin Probe Force Microscopy (KPFM) analysis, a favourable potential gradient was identified enabling electron extraction from the perovskite sub-cell into the $\mathrm{C}_{60}$-SB layer and the extraction of holes from the $\mathrm{BHJ}$ sub-cell into the $\mathrm{MoO}_{3}$ layer. While the PCE10:PC ${ }_{71} \mathrm{BM}$ sub-cell utilized DIO, the detrimental 
impact of this additive ${ }^{110}$ was eliminated through vacuum based removal of DIO in the BHJ layer. Finally, the thickness of the perovskite absorber was tuned in the range of $70-160 \mathrm{~nm}$ (significantly lower than that used for single junctions' PSCs) while maintaining a constant thickness of $100 \mathrm{~nm}$ for the PCE10:PC ${ }_{71} \mathrm{BM}$ layer enabling an improvement in $V_{O C}$ and $J_{S C}$ to be achieved.

Zeng et al. ${ }^{115}$ utilized the concept of an all inorganic perovskite absorber coupled with a BHJ to form a $2 \mathrm{~T}$ tandem device. In their work, the $\mathrm{CsPbI}_{2} \mathrm{Br}$ perovskite sub-cell was coupled with the high performing ternary BHJ system of PTB7-Th: 2,2'-[[4,4,11,11-tetrakis(4-hexylphenyl)4,11-dihydrothieno[2',3':4,5] thieno[2,3-

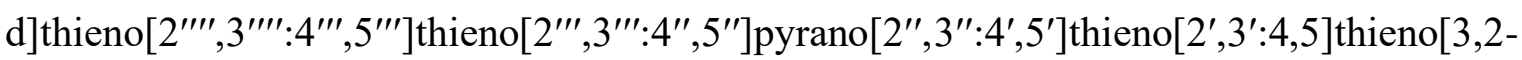
b]pyran-2,9-diyl]bis[methylidyne(5,6-difluoro) (or COi8DFIC):PC ${ }_{71} \mathrm{BM}$, a BHJ system used to demonstrate the highest all-organic $2 \mathrm{~T}$ tandem architecture reported so far $^{37}$. Using an ICL of $\mathrm{MoO}_{3} / \mathrm{Au} / \mathrm{ZnO}$, a PCE of $15.04 \%$ was reported with the overall performance being limited due to low current in the perovskite sub-cell. However, considering recent developments for the all-inorganic perovskite single junction devices ${ }^{6,116,117}$, further improvements in the above tandem architectures can be anticipated.

Compared to the above device architectures where an ICL layer is incorporated in forming a $2 \mathrm{~T}$ tandem architecture, there have also been reports on an "integrated" concept where the ICL layer is eliminated (Fig 6(d)). Not only does this enable complementary absorption to be incorporated during the design, this also eliminates the need for complicated processing for the deposition of an ICL, thereby simplifying the overall stack. Although this device architecture is perhaps not a tandem configuration as per the conventional usage of the term, we nevertheless discuss important developments in this area as it presents an opportunity to enhance the spectral response and perhaps improve tandem architectures based on $\mathrm{Pb}$-only compositions.

The first reported work in this regard was by Liu et al. ${ }^{118}$ where a small molecule organic BHJ based on DOR3T-TBDT: $\mathrm{PC}_{71} \mathrm{BM}$ was spin coated on an $\mathrm{MAPbI}_{3-x} \mathrm{Cl}_{x}$ perovskite absorber. Compared to semiconducting polymers, small molecule systems have been identified as an alternate that minimises performance variations due to factors such as the broad distribution in molecular weight as prevalent in semiconducting polymers. ${ }^{119,120}$ The device developed Liu et al. ${ }^{118}$ resulted in an overall device PCE of $14.3 \%$ (Fig 6(e)). As the absorption of the BHJ used overlaps with the perovskite absorber thereby making it difficult to identify the exact influence of the above architecture, the authors utilised a low bandgap BHJ architecture based on 
PBDTT-SeDPP (the selenised form of PBDTT-DPP): $\mathrm{PC}_{71} \mathrm{BM}$ as the $\mathrm{BHJ}$ which also demonstrated a PCE of $12 \%$ (Fig. 6(f)). In the above architecture, the authors attributed the observed performance as being due to the donor phase in the BHJ acting as a hole transport layer for perovskite while the perovskite acts as an electron accepting system for the charges generated in the BHJ. The charge generation within the BHJ was identified to be important in terms of the overall device performance as a lower PCE was observed when only the donor polymer was used.

Following this, Kim et al. ${ }^{121}$ reported a perovskite and organic ternary BHJ based integrated device with a PCE of $16.36 \%$ as compared to $14.7 \%$ efficient perovskite cells without a BHJ. The ternary BHJ was based on a blend consisting of the low bandgap polymer DT-PDPP2TTT(TT) as the donor and poly\{[N,N'-bis(2-octyldodecyl)-naphthalene-1,4,5,8bis(dicarboximide)-2,6-diyl]-alt-5,5'-(2,2'-bithiophene) $\}(\mathrm{N} 2200)$ as well as $\mathrm{PC}_{71} \mathrm{BM}$ as the acceptors. The authors also fabricated flexible integrated devices, taking advantage of the low temperature processing steps involved in this study, resulting in a champion PCE of $12 \%$.

Cheng et al. ${ }^{122}$ utilised a small molecule BHJ architecture with a $\left(\mathrm{FAPbI}_{3}\right)_{0.85}\left(\mathrm{MAPbBr}_{3}\right)_{0.15}$ perovskite absorber. The authors evaluated several small molecule systems were designed based on the acceptor-donor-acceptor (A-D-A) concept where the phenoxazine flanked benzo[1,2b:4,5b']-dithiophene backbone was used for all molecules, but capped with different electron-withdrawing units; N-ethylrhodanine (for the molecule M1), N-(2ethylhexyl)pyridinium ( for the molecule M3), and (2-(3-cyano- 5, 5-dimethylfuran-2 $(5 \mathrm{H})$ ylidene)-malononitrile (for the molecule M4) which enabled the adjustment of the energy levels. While PSCs were tested through incorporation of the above small molecules as the HTL, an increase in the $J_{S C}$ was observed when $\mathrm{PC}_{71} \mathrm{BM}$ was incorporated to the organic material to form a BHJ. A champion PCE of $17.3 \%$ in reverse (average PCE of $16.2 \%$ ) was achieved for the M3:PC $71 \mathrm{BM}$ BHJ incorporated device.

K. Gao et al. ${ }^{105}$ reported the performance of integrated devices with $\mathrm{MAPbI}_{3}$ as the perovskite and porphyrin donor based bulk heterojunction layer consisting of 5,15-bis(2,5-bis((2ethylhexyl)thino)-3,6-dithienyl-2-yl-2,5-dihydro-pyrrolo[3,4-c]pyrrole-1,4-dione-5'-ylethynyl)-10,20-bis(5-(2-ethylhexyl) thienyl)porphyrin zinc(II) (DPPZnP-TSEH): PC ${ }_{61} \mathrm{BM}$. As a result of the low bandgap of the organic donor, the authors were able to extend the absorption range of the perovskite and BHJ integrated stack up to the $900 \mathrm{~nm}$ which enabled a higher short circuit current density $\left(J_{S C}\right.$ ) (of $23.32 \mathrm{mAcm}^{-2}$ ) to be achieved in comparison to the above discussed work as well as the perovskite only reference device $\left(J_{S C}\right.$ of $\left.21.37 \mathrm{mAcm}^{-2}\right)$, which 
in turn enabled a PCE of $19.02 \%$. Similar to the above Guo et al. reported ${ }^{123}$ the use of an organic BHJ blend based on PBDTTT-E-T (PTB7): 2,2'-((2Z,2'Z)-((5,5'-(4,4,9,9-tetrakis(4hexylphenyl)-4,9-dihydro-s-indaceno[1,2-b:5,6-b']dithiophene-2,7-diyl)bis(4-((2-ethylhexyl)oxy)thiophene-5,2-diyl))bis(methanylylidene))bis(3-oxo-2,3-dihydro-1H-indene-2,1diylidene))dimalononitrile which enabled an extended absorption up to $930 \mathrm{~nm}$ and an external quantum efficiency of $50 \%$ in the near-infrared range. This $\mathrm{BHJ}$ in combination with $\mathrm{MAPbI}_{3}$ resulted in a high $J_{S C}$ of $24.77 \mathrm{mAcm}^{-2}$, although the PCE was $14.57 \%$ (lower than the perovskite only device) due to a low FF. More recently, a ternary BHJ consisting of two donors: Y6 and S1 together with PCBM to enable absorption up to $980 \mathrm{~nm}$ (Fig 6(g) and (h)) $)^{124}$ was coupled with a triple cation perovskite CsFAMA resulting in a champion PCE of $20.61 \%$, mainly due to the high $J_{S C}$ of $28 \mathrm{mAcm}^{-2}$ as a result of the extension of the absorption (Fig 6(i)). Both of these reports indicate the possibility of the concept of spectral enhancement in $\mathrm{Pb}$-only perovskite $\mathrm{PVs}$ by incorporation of newly emerging NIR absorbing organic semiconductors. 
a

b

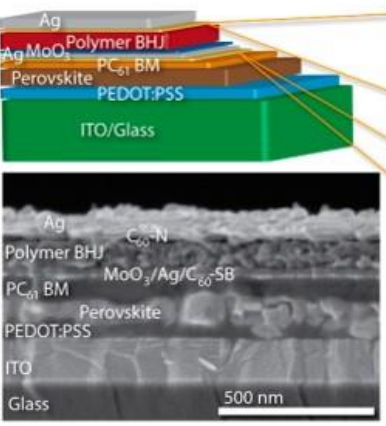

d

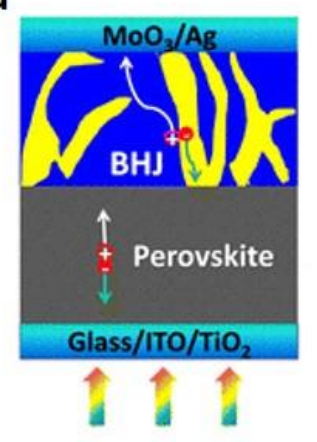

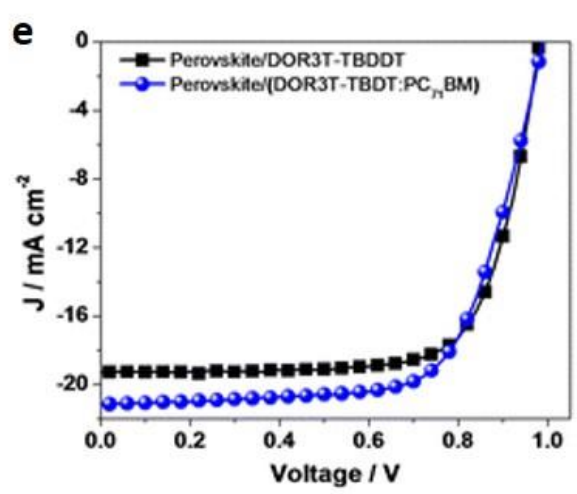

h

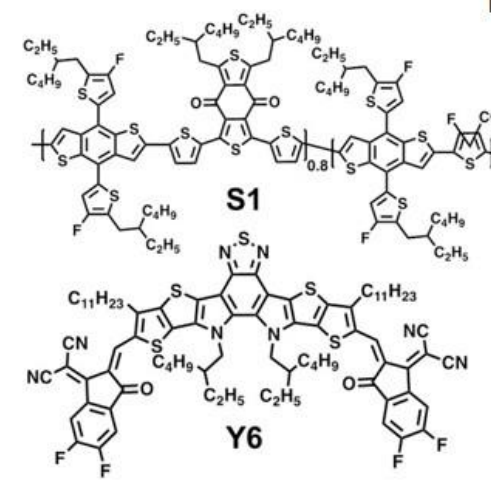

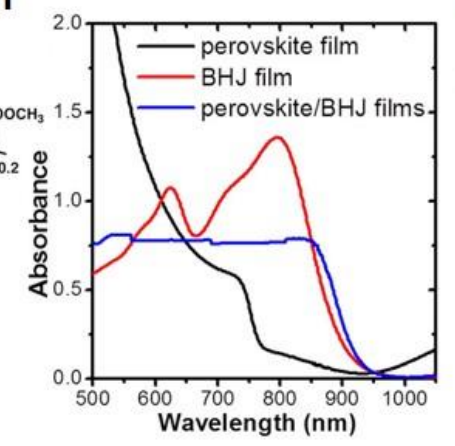
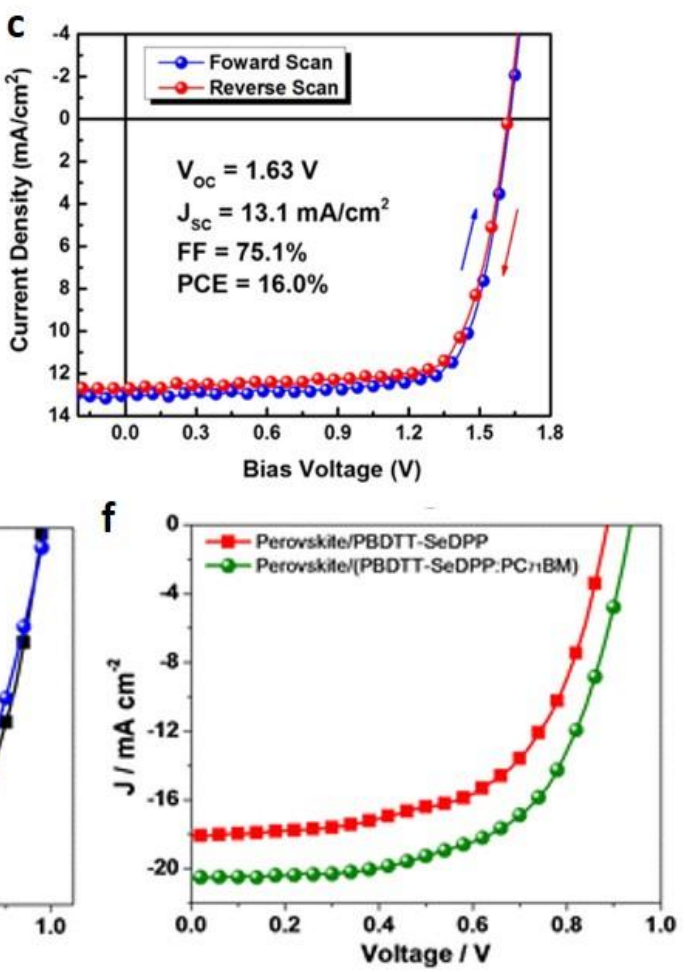

i

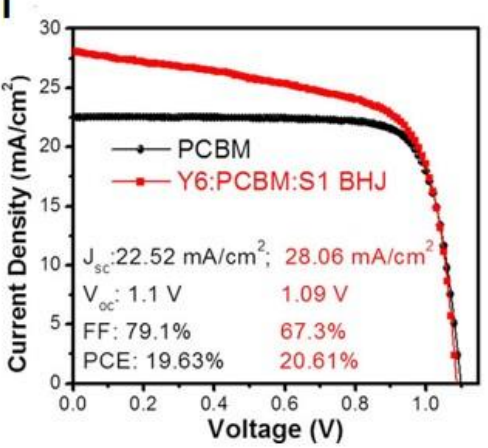

Fig. 6 (a) Schematic and (b) cross-section scanning electron micrograph of the perovskite-organic 2T tandem reported by Liu et al. ${ }^{113}$ resulting in a PCE of $16 \%$. The insets show the $\mathrm{C}_{60}$ based interfacial layer materials used. (c) The $J-V$ characteristics for the best performing device for the above report. Reprinted with permission from Ref. 113. Copyright (2016) American Chemical Society. (d) Schematic indicating the charge generation and extraction process in a perovskite-organic integrated solar cell. ${ }^{118}$ The first reported devices in this work by Liu et al. ${ }^{118}$ where (e) DOR3T-TBDT:PC ${ }_{71} \mathrm{BM}$ and (f) PBDTT-SeDPP:PC ${ }_{71} \mathrm{BM}$ BHJ layers were used. Reprinted with permission from Ref. 118. Copyright (2015) American Chemical Society. (g) The donor semiconductors used by Chen et al. ${ }^{124}$ to (h) enhance the spectral response of perovskite-organic integrated devices and the resulting $J$ - $V$ curves. Reprinted with permission from Ref. 124. Copyright (2019) American Chemical Society. 
Table 4. Summary of performance characteristics for perovskite/organic tandem photovoltaics. SPO indicates stabilised power output. *indicates values related to the integrated device concept.

\begin{tabular}{|c|c|c|c|c|c|c|}
\hline Year & Configuration & $V_{o c}(\mathrm{~V})$ & $\begin{array}{c}J_{s c} \\
\left(\mathrm{mAcm}^{-2}\right)\end{array}$ & $\boldsymbol{F F}$ & $\begin{array}{l}\text { PCE (\%) } \\
\text { (SPO(\%)) }\end{array}$ & Ref \\
\hline 2015 & $\begin{array}{l}\text { Glass/ITO/PEDOT:PSS/PBSeDTEGS8:PCBM/PFN/TiO } / \text { PEDOT:PSS } \\
\text { PH500/PEDOT:PSS 4083/MAPbI3/PC } 61 \text { BM/PFN/AI }\end{array}$ & 1.52 & 10.05 & 67 & $10.2(-)$ & 109 \\
\hline 2015 & Glass/ITO/TiO $/ \mathrm{MAPbl}_{(3-x)} \mathrm{Cl}_{x} / \mathrm{DOR} 3 \mathrm{TBDT}: \mathrm{PC}_{71} \mathrm{BM} / \mathrm{MoO}_{3} / \mathrm{Ag}^{*}$ & 0.98 & 19.3 & 72.9 & $13.8(-)$ & 118 \\
\hline 2016 & $\begin{array}{l}\text { Glass/ITO/PEDOT:PSS/PVSK/PC }{ }_{71} \mathrm{BM} / \mathrm{PFN} / \text { Step } \\
\text { layer/MoO } 3 \text { /PBDTT-DPP/PCBM/Ca/Al }\end{array}$ & 1.58 & 8.02 & 68 & $8.62(-)$ & 112 \\
\hline 2016 & $\begin{array}{l}\text { Glass/ITO/PEDOT:PSS/Perovskite/PC }{ }_{61} \mathrm{BM} / \mathrm{MoO}_{3} / \mathrm{Ag} / \mathrm{C} 60- \\
\text { SB/Polymer BHJ/C } 60-\mathrm{N} / \mathrm{Ag}\end{array}$ & 1.62 & 12.9 & 76.1 & $15.9(-)$ & 113 \\
\hline 2016 & $\begin{array}{l}\text { Glass/ITO/PEDOT:PSS/VO } / \text { Perovskite/PDPP2T:PC }{ }_{71} \text { BM:N2200/ } \\
\text { N-Doped TiO } / \text { Al* }^{*}\end{array}$ & 1.06 & 20.04 & 77 & $16.36(-)$ & 121 \\
\hline 2016 & Glass/FTO/TiO $2 /\left(\mathrm{FAPb}_{3}\right)_{0.85}\left(\mathrm{MAPbBr}_{3}\right)_{0.15} / \mathrm{M3}: \mathrm{PC}_{71} \mathrm{BM} / \mathrm{V}_{2} \mathrm{O}_{5} / \mathrm{Au}^{*}$ & 1.095 & 22.2 & 71.5 & $17.3(-)$ & 122 \\
\hline 2017 & Glass/ITO/SnO $2 / \mathrm{C}_{60} / \mathrm{MAPb}_{3} / \mathrm{DPPEZnP-TSEH} / \mathrm{PCBM} / \mathrm{MoO} / \mathrm{Ag}^{*}$ & 1.03 & 23.32 & 78 & $19.02(18.9)$ & 105 \\
\hline 2018 & Glass/FTO/TiO2/MAPbl 3 /PBDTT-E-T:IEICO/MoO3/Ag* & 0.993 & 24.08 & 60.97 & $14.57(-)$ & 123 \\
\hline 2019 & $\begin{array}{l}\text { Glass/ITO/SnO } / \mathrm{CSSPl}_{2} \mathrm{Br} / \mathrm{PTAA} / \mathrm{MoO}_{3} / \mathrm{Au} / \mathrm{ZnO} / \mathrm{PTB} 7- \\
\text { Th:COi8DFIC:PC } \\
{ }_{71} \mathrm{BM} / \mathrm{MoO} / \mathrm{Ag}\end{array}$ & 1.71 & 11.98 & 73.4 & $15.04(-)$ & 115 \\
\hline 2019 & $\begin{array}{c}\left.\text { Glass/ITO/PTAA//(FAPb| })_{3}\right)_{0.85}\left(\mathrm{MAPbBr}_{3}\right)_{0.15} / \mathrm{Y} 6: \mathrm{PC}_{71} \mathrm{BM}: \mathrm{S} 1 / \mathrm{ZrAcac} \\
/ \mathrm{Ag}^{*}\end{array}$ & 1.1 & 22.75 & 78.4 & $19.62(-)$ & 124 \\
\hline
\end{tabular}

\section{b) Other Perovskite based tandem concepts}

Beyond the above-mentioned solution processed tandem architectures, there have also been other concepts reported that are not as widely investigated as those discussed above. For example, Karani et al. ${ }^{125}$ investigated theoretically as well as experimentally the potential of coupling a $\mathrm{MAPbI}_{3}$ perovskite absorber together with lead sulfide $(\mathrm{PbS})$ colloidal quantum dots (CQDs) as the low bandgap absorber. They identified the possibility of achieving a PCE of $43 \%$ with a CQD absorber with $E_{G}=1 \mathrm{eV}$ if radiative coupling between the two sub-cells are considered while a maximum PCE of $37 \%$ was identified to be possible with a CQD absorber with $E_{G}=0.8 \mathrm{eV}$. They further fabricated a tandem architecture consisting of PbS CQDs with $E_{G}=1.03 \mathrm{eV}$ in combination with an $\mathrm{MoO}_{3} /(\mathrm{Au}$ or $\mathrm{Ag})$ tunnel junction between the two subcells. However, a rather low PCE of $1.01 \%$ was reported.

An alternative to the use of $3 \mathrm{D}$ perovskite absorbers, processed based on the previously discussed routes, involve the use of perovskite quantum dots. While the initial performances of these quantum dots remained low (i.e. $<10 \%$ ), developments on modification of quantum dot-quantum dot junctions ${ }^{126}$ and ligand exchange for compositional stability ${ }^{127}$ has enabled PCEs in excess of $16 \%$ for perovskite CQD PVs. Furthermore, the dimensionalities of such 
CQDs also enables the formation of more stable inorganic perovskite absorbers to be fabricated $^{128}$ in comparison to the conventional synthesis routes reported where rapid degradation of the inorganic absorber is often observed. In this regard, Christians et al. ${ }^{129}$ investigated the potential of utilizing $\mathrm{CsPbI}_{3} \mathrm{CQDs}$ for tandem architectures. However, a demonstration of perovskite CQDs have so far not been reported and remains an interesting area for future developments.

\section{Approaches to manufacturability}

\subsection{Limitations of spin coated processing}

Historically, spin coating has remained the preferred method for fabrication of small area, lab scale, solution processed photovoltaic technologies where substrate sizes typically do not exceed $2.5 \mathrm{~cm} \times 2.5 \mathrm{~cm}$. Indeed, in all the work discussed above, the fabrication of the perovskite absorber layer has relied on spin coating. Spin coating can be carried out via static or, dynamic dispensing where the ink is deposited on the substrate followed by the spin process in the former, whereas the ink is dispensed on an already spinning substrate in the latter. The resulting centrifugal forces results in a thin wet film. In situations where $<100 \mathrm{~nm}$ thick films are required, this often results in relatively dry films. On the other hand, during the fabrication of thicker films, the spin coating process often results in a semi-dry film which is often dried under thermal annealing to form the desired micro or nanostructure. ${ }^{130}$
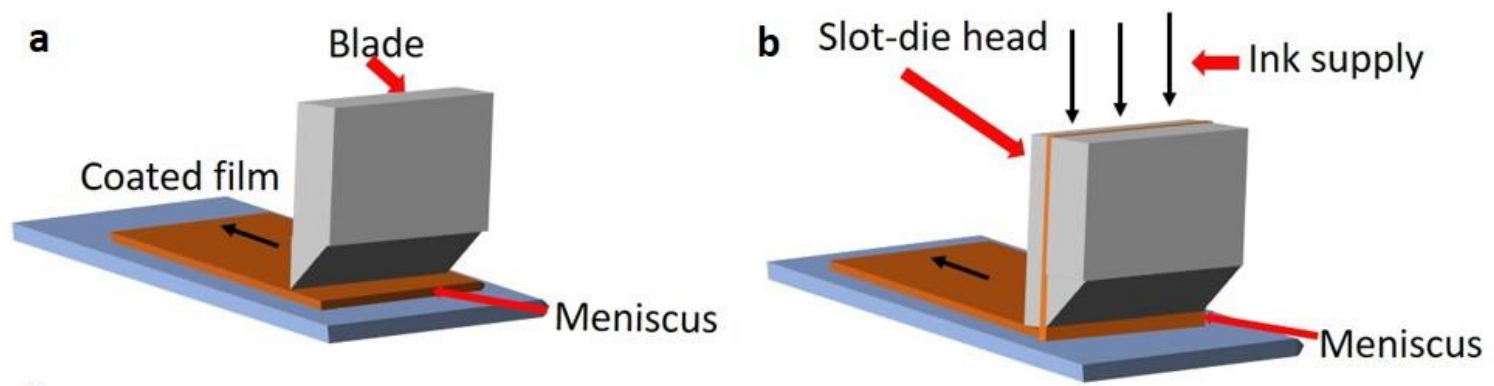

C
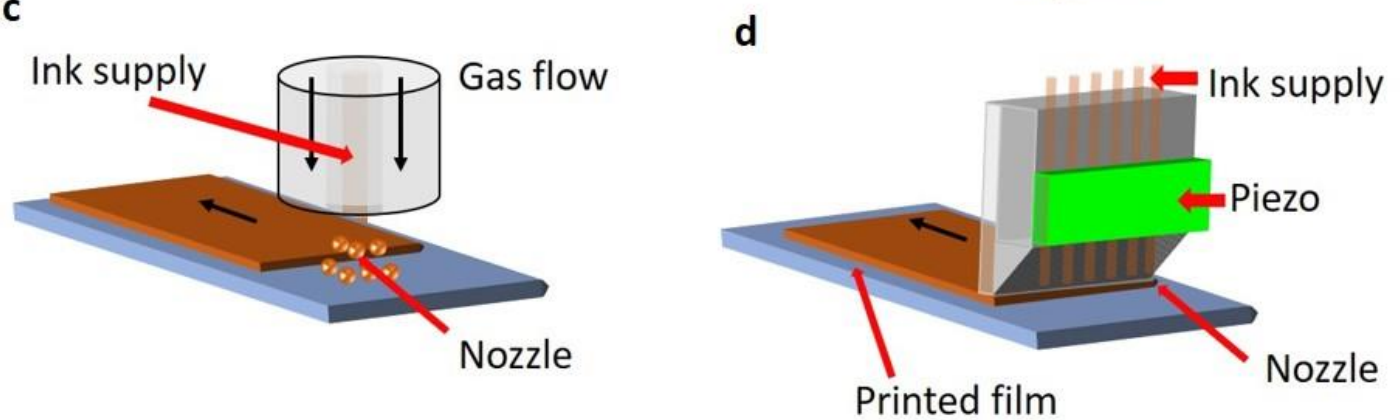

Fig. 7 Schematic illustrating (a) blade coating, (b) slot-die coating, (c) spray coating and (d) ink jet printing processes that are used for R2R and S2S fabrication of solution processed PVs. 
For perovskites, spin coating has been the widely adopted methodology in terms of fabricating high-performing devices. In terms of single cation systems such as $\mathrm{MAPbI}_{3}$, this often involves the careful control of the precursor composition (e.g.: the acetate route) $)^{114,131}$ and the ambient conditions (e.g.: the chloride route) $)^{4,132}$ which enables formulations that in principle can be adopted for scale-up coating techniques. However, in terms of the overall compositional space enabled by perovskites, the anti-solvent route ${ }^{133}$ which enables a uniform nucleation and crystallization has been the more widely preferred methodology for perovskite fabrication. While the anti-solvent route was first implemented for $\mathrm{MAPbI}_{3}{ }^{133}$ to enable the fabrication of pin-hole free absorber layers, this was adopted early-on for the multi-cation ${ }^{7}$ systems which have demonstrated better stability, higher efficiency, and a larger processing window in glove box environments.

In industry (and specially the microelectronics industry), spin coating is somewhat implemented over wafer scales where wafer diameters approach 12". However, this often leads to a large wastage in terms of the solutions/inks used which is not attractive in terms of developing low-cost photovoltaic technologies. Furthermore, spin coating is somewhat restrictive in its throughput as it does not enable a high production rate that is targeted for low cost photovoltaic technologies. We do note however that there have been instances where the spin coating process has been used for the fabrication of lab scale modules with areas of $\sim 100$ $\mathrm{cm}^{2}{ }^{134}$ Alternative technologies that enable the coating of perovskites and indeed, solution processed tandems include blade coating, slot die coating, spray coating and ink jet printing (Fig 7).

With regards to scaling up and manufacturability, Galagan et al. ${ }^{135}$ highlighted the following key points which should be addressed to enable manufacturability of perovskites on a R2R or S2S system:

1) Solvent choice enabling control of viscosity, boiling point, toxicity, price.

2) Controlled crystallization enabling pin-hole free films.

3) Uniformity of layer properties.

4) Performance.

In achieving the above key goals, one of the critical points which require careful attention is the development of appropriate crystallization routes that can be implemented on a R2R or S2S system that will facilitate the formation of pinhole-free films. 


\subsection{Enabling compact pinhole free films}

As indicated above, in the scaling up of perovskite coating process, one of the key challenges lies in the fabrication of a dense, pin hole free film. In this regard, the most attractive starting point in terms of forming a dense film is through the modification of the precursor composition. For example, while precursors consisting of $\mathrm{PbI}_{2}$ and MAI is perhaps the most widely used for fabrication of $\mathrm{MAPbI}_{3}$, replacing $\mathrm{PbI}_{2}$ with $\mathrm{Pb}(\mathrm{Ac})_{2}$ (lead acetate under the acetate route) has enabled compact-pin hole free perovskite solar cells to be formed ${ }^{114}$. Similarly, replacing $\mathrm{PbI}_{2}$ entirely with $\mathrm{PbCl}_{2}{ }^{4}$ in combination with appropriate control of ambient humidty ${ }^{132}$, or incorporating it with $\mathrm{Pb}(\mathrm{Ac})_{2}{ }^{131}$ also enables the formation of compact films.

An alternate route to enabling heterogenous nucleation in perovskites involves the deposition of the "semi-wet" perovskite film in a bath of the antisolvent ${ }^{136}$ that is typically dripped during the anti-solvent based spin coating method. However, it has been highlighted that the processing window that enables the incorporation of the above is fairly limited in the conventionally used DMF: DMSO solvent mixtures. This led Yang et al. ${ }^{136}$ to modify the original solvents used in the perovskite precursor to incorporate 1-methyl-2-pyrrolidone (NMP) which slowed down the drying dynamics enabling an anti-solvent bath to be used to enable heterogenous nucleation and crystallization to proceed.

From an overall scaling point-of-view, it would still be attractive to eliminate the need for an anti-solvent step. One potential route towards achieving this is through coating of the material on a heated substrate. ${ }^{137,138}$ Additionally, the use of acetates or chlorides highlighted above, the incorporation of additives into the precursor is an attractive route towards enabling compact films. This has already enabled the demonstration of modules incorporating additives ${ }^{139}$ such as didodecyldimethylammonium bromide, polyethylene glycol sorbitan monostearate, sodium dodecyl sulphate. Additionally, gas quenching methodology ${ }^{136,140}$ which was first implemented for spin coating methods in place of anti-solvent treatment is a route that enables the homogenous nucleation during R2R or S2S coating of perovskites. In this process, the blowing of a gas (often $\mathrm{N}_{2}$ ) results in speeding up of the (precursor) solvent evapouration that leads to in rapid saturation and precipitation of nucleation species which enables the formation of a dense pin-hole free film. This technique has already been adapted in R2R and S2S coating techniques for perovskite where the use of an air-knife ${ }^{141}$ facilitates the desired saturation, precipitation and crystallisation to take place, enabling dense films. 


\subsection{Large area coating methods}

In terms of high throughput $\mathrm{R} 2 \mathrm{R}$ and $\mathrm{S} 2 \mathrm{~S}$ manufacturing, we now outline some of the most promising routes. A summary of advantages and disadvantages of each technique ae also indicated in Table 5. We note that the details given above are not exhaustive and the readers are referred to more detailed reviews discussing individual techniques and the references therein. ${ }^{142-147}$

Table 5 Comparison of advantages and disadvantages of the large area coating techniques discussed in this review.

\begin{tabular}{|c|c|c|}
\hline Technique & Advantages & Disadvantages \\
\hline Blade coating & $\begin{array}{l}\text { - Can be used for both lab scale optimization and } \\
\text { industrial manufacturing. } \\
\text { - Significant reduction in ink used compared to spin } \\
\text { coating as well as slot die coating. }\end{array}$ & $\begin{array}{l}\text { - More appropriate for S2S printing as opposed to } \\
\text { R2R printing. }\end{array}$ \\
\hline Slot-die coating & $\begin{array}{l}\text { - Appropriate for high throughput manufacturing } \\
\text { on a R2R system. } \\
\text { - Can also be used for pilot scale optimization } \\
\text { studies for S2S printing. } \\
\text { - Better yield and reproducibility compared to blade } \\
\text { coating. }\end{array}$ & $\begin{array}{l}\text { Not suited for optimization of inks due to high } \\
\text { usage for a single print. }\end{array}$ \\
\hline Spray coating & $\begin{array}{l}\text { - Can be used for both lab scale optimization and } \\
\text { industrial manufacturing. }\end{array}$ & $\begin{array}{l}\text { - Careful optimization of ink required to avoid } \\
\text { clogging of spray head. } \\
\text { - Low throughput compared to blade coating and } \\
\text { slot-die coating. }\end{array}$ \\
\hline Inkjet printing & $\begin{array}{l}\text { - Can be used for both lab scale optimization and } \\
\text { industrial manufacturing. } \\
\text { - Better control in terms of feature sizes enabling } \\
\text { the removal of additional laser scribing steps for } \\
\text { material removal. }\end{array}$ & $\begin{array}{l}\text { - Clogging of print head can cause disruptions } \\
\text { requiring careful optimization of ink and } \\
\text { appropriate maintenance of head. } \\
\text { - Low throughput compared to blade coating and slot } \\
\text { die coating. }\end{array}$ \\
\hline
\end{tabular}

\section{a) Blade coating}

Blade coating has been a relatively widely used technique in S2S coating manufacturing. In simple terms, this technique involves the use of a blade for the spreading of the ink on the substrate (Fig. 8(a)). Appropriate control of the speed of the blade, the substrate-blade gap, the concentration and viscosity of the ink enables the formation of a wet film, that is subsequently dried to form the final film. This not only results in a very low ink usage, but also enables the fabrication of lab scale devices as well as large scale modules, enabling scalability in terms of the ink composition and drying methodologies used. While difficulty in patterning can be 
pointed out as a potential disadvantage for this technique, this is less likely to be relevant for printed solar cells where laser scribing processes are used for the patterning required which often is in the millimeter length scales.

Blade coating has been a widely used technique in organic photovoltaics in terms of developing small area devices ${ }^{148}$ as well as for demonstrating scaling up of printed photovoltaics ${ }^{29,149}$. However, as discussed previously, appropriate modifications need to be implemented either to the precursor, or the coating process to enable the formation of a compact film.

Among the methodologies utilized for obtaining a compact absorber layer based on perovskites, through blade coating has involved the use of substrate heating as means of both solvent removal as well as initiation of perovskite crystallisation. For example, Wu et al ${ }^{150}$ reported a module efficiency of $\sim 11 \%$ achieved through blade coating of a precursor mixture consisting of MAI and $\mathrm{PbI}_{2}$ in DMF on a heated substrate (temperature varied from $60-160^{\circ}$ C) which resulted in a PCE of $\sim 11 \%$. This work was subsequently modified by Peng et al. ${ }^{151}$ where the solvent used in the precursor was modified to a DMF:DMSO solvent mix and through the incorporation of excess MAI which enabled the formation of a more optimized absorber resulting in an average PCE of $10.16 \%$ (champion PCE of 10.92\%) for an aperture area of $0.09 \mathrm{~cm}^{2}$.

With regards to the impact of the substrate temperature on the formation of perovskites during blade coating, Zhong et al. ${ }^{152}$ reported insights on the crystallisation dynamics of perovskites under different substrate temperatures based on in-situ grazing incidence wide-angle X-ray scattering (GIWAXS) studies (Fig. 8(a)-(d)). For a precursor solution consisting of MAI and $\mathrm{PbI}_{2}$ in DMF, they observed the formation of a highly disordered and heavily solvated film for periods exceeding $200 \mathrm{~s}$ when the precursor is blade coated at room temperature. Increasing the substrate temperature resulted in a faster transition from the highly disordered and solvated film condition to a more ordered condition. For example, at $80^{\circ} \mathrm{C}$, this transition was observed to take place at $\sim 13 \mathrm{~s}$. When the temperature was further increased, the time for this transition was even further reduced (e.g. to $\sim 2.4 \mathrm{~s}$ at $135^{\circ} \mathrm{C}$ ). The resulting device performances also demonstrated a strong correlation to the transition from the highly disordered state to a more ordered state where the PCE increased with increasing substrate temperature.

Li et al. ${ }^{153}$ utilised a combination of solvents in the precursor and investigated the impact of the blade coating temperature on the conversion of the precursors in forming the final perovskite absorber layer. For a solvent mixture of DMSO: gamma Butyrolactone (GBL), 
studies on the film formation based on GIWAXS when blade coated at room temperature was observed to follow a similar route to that of spin coated samples without an anti-solvent. However, due to the slow solvent drying process, the resulting film formation also proceeded at longer time scales which is not an attractive feature in terms of high-throughput manufacturing. However, when the blade coating temperature was increased to $150^{\circ} \mathrm{C}$, a direct transition from the disordered sol-gel phase to the crystalline phase was observed, enabling higher film quality. Optimization of the above conditions enabled a champion PCE in excess of $18 \%$ for devices with an active area of $0.09 \mathrm{~cm}^{2}$ while a PCE of $17.06 \%$ was observed for 1 $\mathrm{cm}^{2}$ cells. In addition to the above, the blade coating speed has a significant impact on the formation of compact films. For example He et al. ${ }^{154}$ reported high efficiencies of $19.81 \%$ for $\left(\mathrm{FAPbI}_{3}\right)_{0.85}\left(\mathrm{MAPbBr}_{3}\right)_{0.15}$ over active areas of $0.1 \mathrm{~cm}^{2}$ and $18.02 \mathrm{~cm}^{2}$ for aperture areas of $0.98 \mathrm{~cm}^{2}$ by employing a slow coating speed in combination with high boiling point solvents. However, the use of slow coating speeds is less preferable in terms of high production rates. At higher blade coating speeds ( $>20 \mathrm{mms}^{-1}$ ), Deng et al. ${ }^{139}$ noted the need for a surfactant that would minimize microscale fluid flows that results in the formation of islands (Fig. 8(e)). In their work surfactants such as didodecyldimethylammonium bromide, polyethylene glycol sorbitan monostearate, sodium dodecyl sulphate were incorporated into the $\mathrm{MAPbI}_{3}$ perovskite precursor which enabled the formation of a dense film at high coating speeds of $50 \mathrm{mms}^{-1}$. This enabled PCEs of $20.3 \%$ for small area cells $\left(0.075 \mathrm{~cm}^{2}\right)$ and $14.6 \%$ for a module with an aperture area of $57.2 \mathrm{~cm}^{2}$ (Fig. 8(f) and (g)). It should be noted that in the case of forming a dense perovskite film, the hydrophilic/hydrophobic nature of the underlying layer also plays a critical role. For example, modification of PEDOT:PSS used as an HTL in blade coated devices by incorporating poly(4-styrenesulfonic acid) into the mixture was reported to enable scalable coating of $\mathrm{MAPbI}_{3}$ based on using $\mathrm{PbCl}_{2}$ as the $\mathrm{Pb}^{2+}$ source, resulting in an average PCE of $8.29 \%$ and a champion PCE of $10.15 \%$. It is noted that in the case of the above, the authors utilized DIO in perovskite precursors as well as a high coating speed between $2.5-10 \mathrm{cms}^{-1}$, although substrate heating was not used.

Beyond the more widely adopted approaches discussed above, we note that increasing the processing window (Fig. 8(h)) to enable anti-solvent bath deposition as a means of uniform crystallization has been reported for blade coated samples. For example, Yang et al. ${ }^{136}$ utilised a solvent mix of DMF and NMP which enabled the blade coating of perovskite precursors consisting of $\mathrm{MAI}, \mathrm{PbI}_{2}$ and $\mathrm{PbCl}_{2}$ followed by dipping in a bath of diethyl ether. This enabled stabilized efficiencies $>19 \%$ for $0.12 \mathrm{~cm}^{2}$ cells while a PCE of $>17 \%$ was achieved for $1.2 \mathrm{~cm}^{2}$ 
cells. The technique was further extended to a small area module with an active area of 11.09 $\mathrm{cm}^{2}$ which resulted in a PCE of $13.3 \%$ (Fig. 8(i) and (j)). We note that somewhat of a similar approach was adopted by Eperon et al.${ }^{90}$ in fabricating the low band gap $\mathrm{Pb}-\mathrm{Sn}$ mixed absorber, although the film was fabricated through spin coating. However, careful control as well as optimization of the humidity and temperature is important depending on the precursor used (e.g. $\mathrm{PbCl}_{2}$ in the perovskite precursor mix) as has been demonstrated for spin coated ${ }^{132}$ as well as blade coated ${ }^{155}$ PSCs.
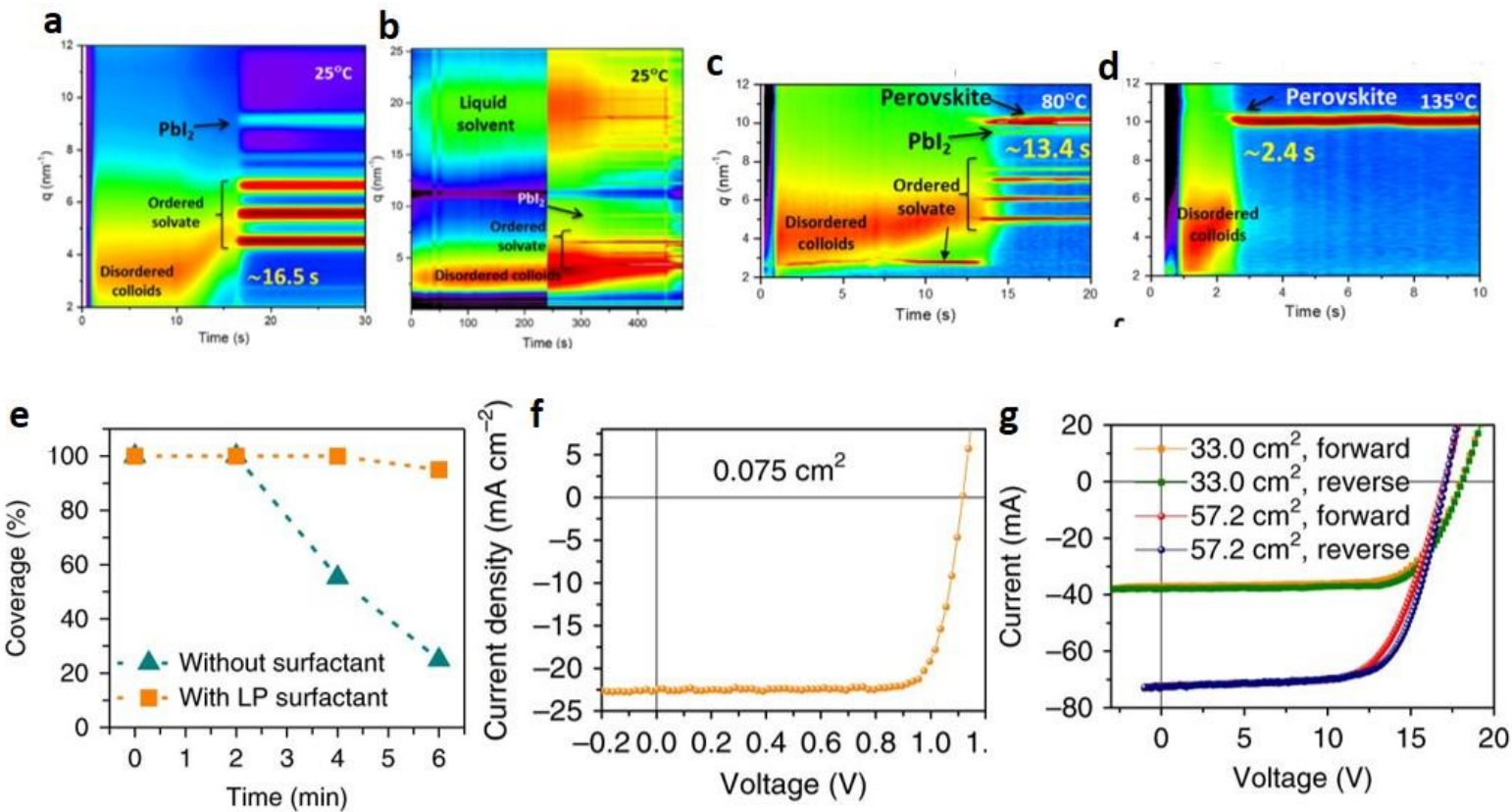

h

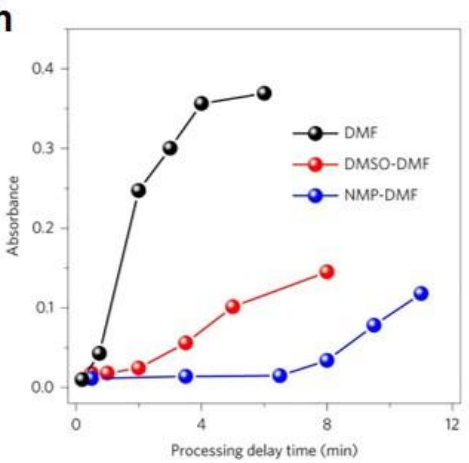

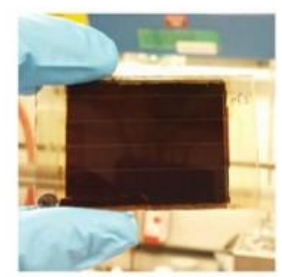

j

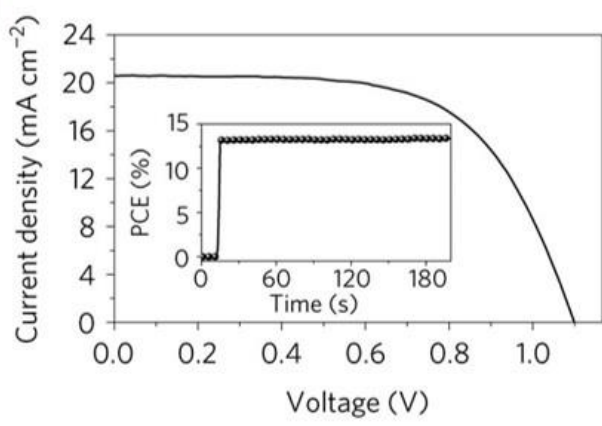

Fig. 8 Time dependent GIWAXS scans of (a) spin coated, and blade coated perovskite layers where the substrate was held at (b) $25^{\circ} \mathrm{C}$ (c) $80^{\circ} \mathrm{C}$ and (d) $135^{\circ} \mathrm{C}$ as reported by Zhong et al. ${ }^{152}$ Reprinted with permission from Ref. 152. Copyright (2018) American Chemical Society. (e) The influence of surfactants on the surface coverage of blade coated perovskites and the resulting (f) small area device and (g) module performance as reported by Deng et al. ${ }^{139}$ Reproduced from Ref. 139 with permission from Springer Nature. (h) The influence of solvent composition on the processing window which enables anti-solvent bath treatment of films coated using scalable techniques resulting in (i) smooth, compact films. (j) The resulting $J-V$ characteristics for a film with an active area of $1.2 \mathrm{~cm}^{2}$ which enables a PCE $>17 \% .{ }^{136}$ Reproduced from Ref. 136 with permission from Springer Nature. 


\section{b) Slot-die coating}

Slot-die coating can be considered as being somewhat similar to the blade coating method discussed above, with the exception of a continuous ink flow which enables R2R coating as opposed to S2S coating (only). A reservoir containing the ink is fed to the slot-die head which is applied to the substrates through a thin slit (shim) (Fig. 7(b)). The ink viscosity, precursor concentration $^{156}$, relative speed between the blade and the substrate is used to control the thickness of the final film while a heated bed is often preferred to enable uniform drying on a macroscopic scale. Slot die coating is a technique that has been widely adopted in the field of organic photovoltaic development activities focusing on high throughput R2R manufacturing ${ }^{157-159}$.

As per the case of blade coating of perovskites, precursor solutions can be coated at either room temperature or on substrates held at elevated temperatures, while an air knife can be used in order to control the crystallization during the coating process (Fig. 9(a)), enabling R2R fabrication on flexible substrates (Fig. 9(b)). Furthermore, this technique is compatible with either the single-step (where all the components of the perovskite are mixed in a single precursor) or the two-step (where the lead precursors and the organohalide precursors are prepared in separate solvents and are sequentially coated) process. For example, Qin et al. ${ }^{160}$ utilized a two-step process involving the slot die coating of $\mathrm{PbI}_{2}$ in $\mathrm{DMF}$ at temperatures between $25-30^{\circ} \mathrm{C}$ followed by dipping the coated substrate in a bath of MAI. The work resulted in PCEs of $11.7 \%$ and $14.75 \%$ over active areas of $0.1 \mathrm{~cm}^{2}$ for devices with slot die coated Spiro-OMeTAD and 2,2',7,7'-tetrakis(N,N-di-p-methoxyphenyl)amine-9,9'bifluorenylidene (Bifluo-OMeTAD) respectively.

In comparison to the 2-step approach, the single step coating is perhaps more favoured, especially in terms of potentially reducing the processing time on a R2R manufacturing process. For example, Cotella et al. ${ }^{141}$ adopted a single step coating process for a perovskite based on MAI and $\mathrm{PbCl}_{2}$ in DMF. The precursor was coated on preheated substrates held at 20,65 or $90^{\circ} \mathrm{C}$ which were achieved by placing the substrate in an oven for $30 \mathrm{~min}$ prior to coating. The optimum coverage was observed following preheating at $65^{\circ} \mathrm{C}$ while combining this with a cold air knife has enabled the formation of a smoother film. Devices optimized in this manner resulted an average PCE of 7\% and a champion PCE of 9.2\% for an aperture area of $0.0625 \mathrm{~cm}^{2}$. A similar approach was reported by Ciro et al. ${ }^{161}$ who reported the fabrication of flexible perovskite solar cells through coating of a precursor mix similar to that used by Cotella et al. ${ }^{141}$ on a heated ITO/polyethylene terephthalate (PET) substrate. The formation of a compact perovskite film was observed to depend on both the substrate temperature as well as 
the precursor concentration; an increased concentration at low temperatures results in the reduction of pinhole formation while increasing the temperature at all concentrations studied enabled the formation of compact films. Following further optimization for the $\mathrm{PC}_{61} \mathrm{BM}$ coating (used as the electron transport layer) thickness, a champion PCE of $2.91 \%$ was achieved.

Giacomo ${ }^{162}$ et al. used a modified precursor consisting of $\mathrm{PbCl}_{2}$ and $\mathrm{Pb}(\mathrm{Ac})_{2}$ as the lead sources and MAI in DMF for coating over 6" $\times$ 6" substrates (Fig. 9(c)-(e)). For devices with an active area of $0.09 \mathrm{~cm}^{2}$ tested with an aperture area of $0.04 \mathrm{~cm}^{2}$, an average PCE of $16.4 \%$ was achieved. Lee ${ }^{163}$ et al. utilized a similar precursor mix as that of Giacomo et al. ${ }^{162}$, but studied the influence of the ratio between the $\mathrm{Pb}^{2+}$ sources. A gas blowing method was implemented while the slot die coating was carried out under ambient temperature. The authors focused on the lower end of $\mathrm{PbCl}_{2}$ loading as the increase in $\mathrm{PbCl}_{2}$ results in longer annealing times. The incorporation of $\mathrm{PbCl}_{2}$ was noted to be beneficial in terms of increasing the perovskite grain sizes. In terms of devices, a champion PCE of $13.3 \%$ was reported for $\mathrm{Pb}(\mathrm{Ac})_{2}: \mathrm{PbCl}_{2}$ of 8:2. The use of both lead sources enabled pinhole free film formation as opposed to $\mathrm{Pb}(\mathrm{Ac})_{2}$ only. In order to demonstrate the possibility of scaling up, the authors investigated the performance of a module with an area of $10 \mathrm{~cm}^{2}$ which enabled a champion PCE of $8.3 \%$.

$\mathrm{Kim}^{164}$ et al. combined the gas blowing technique and substrate heating to improve slot die coated device performance. The absence of heating on the precursor consisting of MAI: $\mathrm{PbI}_{2}$ mix in DMF resulted in needle like structure formation with gas blowing only, while incorporation of substrate heating enabled more dense film formation. The authors also investigated the incorporation of additives DMSO, ammonium chloride $\left(\mathrm{NH}_{4} \mathrm{Cl}\right)$ and $\mathrm{N}$ cyclohexyl-2-pyrrolidone (CHP) where the latter two enabled better film quality for slot die coated films. The authors evaluated the use of P3HT and Bifluo-OMeTAD as HTLs in combination with different substrate heating temperatures for the perovskites where the best performance was observed for Bifluo-OMeTAD resulting in a champion PCE of $12.73 \%$. The latter aspect also indicates the importance of optimization of the transport layer materials to improve PCE for printed PSCs.

In terms of manufacturing, there is a strong need towards the elimination of toxic solvents such as DMF as highlighted by Galagan et al. ${ }^{135}$ In their work, a solvent mix consisting of DMSO and 2-butoxyethanol (2BE) was utilised where the latter solvent enabled better wetting of the precursor, formation of a uniform perovskite layer and acceleration of crystallization. When evaluated using precursors based on $\mathrm{MAI}$ and $\mathrm{PbI}_{2}$, needle-like structures were obtained when a slow heat up ramp was following the slot die coating process while a mixture of plate-like 
large crystals and some needle-like features were obtained when the temperature ramping rate was increased. To obtain better crystallization, the perovskite composition was changed to $\mathrm{Cs}_{0.15} \mathrm{FA}_{0.85} \mathrm{PbI}_{2.85} \mathrm{Br}_{0.15}$. Using the same solvent composition as above, plate-like structures were obtained under slow, as well as the fast temperature ramping rates (following the precursor coating) which enabled PCEs of $15.2 \%$ to be obtained for active areas of $0.09 \mathrm{~cm}^{2}$ on an ITO/PET substrate (Fig. 9(f) and (g)). When a similar device was fabricated using DMF as the solvent on glass using spin coating, a PCE of $15.8 \%$ was obtained while $13.5 \%$ was obtained for the DMSO:2BE solvent mix. This difference in performance between the spin coated samples and the slot die coated samples was attributed to the sheet resistance of the ITO used in terms of slot die coating where PET/ITO was used.

a
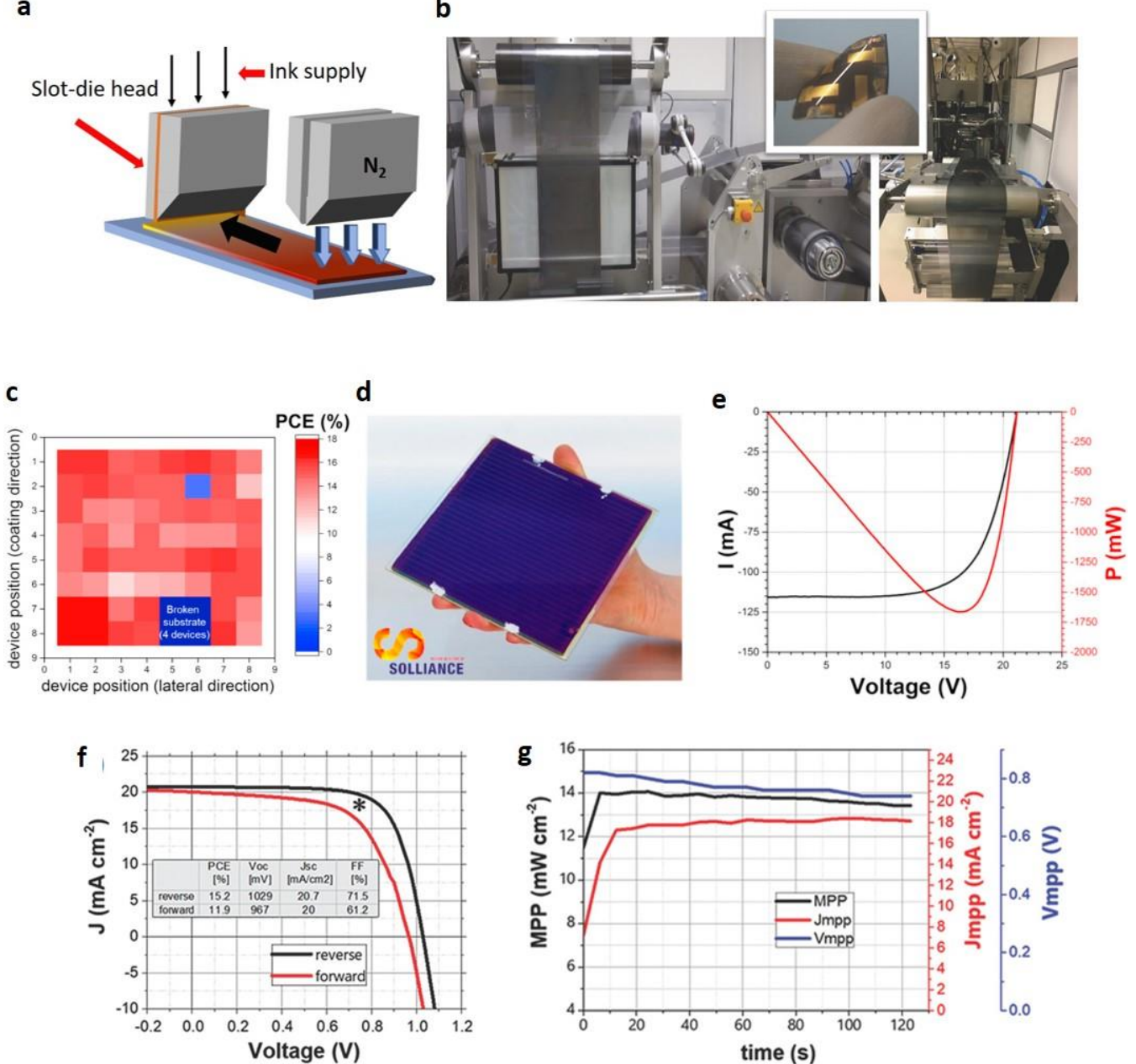

Fig. 9 (a) Schematic illustrating the air knife method employed during slot die coating of perovskites. (b) A R2R slot die coating system with a printed, flexible PSC shown on the inset. ${ }^{135}$ Reproduced from Ref. 135 with permission from Wiley-VCH. (c) PCE homogeneity mapping of slot die coated PSCs reported by Giacomo et al. ${ }^{162}$ over a $6 " \times 6$ " area and (d) a photograph of such a printed module. The resulting current-voltage and power curve are given in (e). Reproduced from Ref. 162 with permission from Elsevier B.V. (f) $J-V$ and (g) MPP, current density and voltage at MPP tracking for flexible PSCs printed using less toxic solvents as reported by Galagan et al. ${ }^{135}$ Reproduced from Ref. 135 with permission from Wiley-VCH. 


\section{c) Spray coating}

Spray coating is another technique that can be used for the scaling up of perovskite photovoltaic coatings for R2R or S2S fabrication. Under the spray coating method, a pressurized gas system or an ultrasound head is used to break down the precursor into droplets which are deposited on the substrate (Fig. 7(c))which can be either heated or at room temperature. ${ }^{165}$ The resulting semi-dry films can then be further processed either under vacuum ${ }^{166}$, in a solvent bath ${ }^{167}$ followed by thermal annealing ${ }^{168,169}$ to enable the formation of the final layer.

In terms of spray coated perovskite devices, one of the earliest reported work was by Barrows et al. ${ }^{169}$ who used ultrasonic spray coating to deposit $\mathrm{MAPbI}_{1-\mathrm{x}} \mathrm{Cl}_{\mathrm{x}}$. The coverage of the perovskite layer was observed to be dependent on the substrate temperature where $\sim 85 \pm 5 \%$ coverage was achieved at a substrate temperature of $75^{\circ} \mathrm{C}$. Furthermore, the authors reported that a lower post annealing processes required a long crystallization time while annealing temperatures above $110^{\circ} \mathrm{C}$ resulted in a de-wetting effect (Fig. 10(a)-(f)). An average thickness of $\sim 340 \mathrm{~nm}$ was observed to be ideal for the spray coated perovskite solar cell performance resulting in an average PCE of $7.8 \%$ and a champion PCE of $11.1 \%$. Das et al. ${ }^{170}$ reported the use of ultrasonic spray coating of precursors based on MAI and $\mathrm{PbCl}_{2}$ in $\mathrm{DMF}$, on glass and ITO/PET substrates. Substrate heating was employed to enable rapid drying of the films. The authors reported an optimum substrate temperature of $\sim 75^{\circ} \mathrm{C}$, similar to that reported by Barrows et al. Devices fabricated on glass substrates resulted in a champion PCE of $11.4 \pm$ $0.4 \%$. Following this, the authors translated the process to a flexible ITO/PET substrate where high density infrared pulses were used to cure the $\mathrm{TiO}_{2}$ layer which resulted in a significantly poor performance of $0.4 \%$.

Mohamad et al. ${ }^{168}$ demonstrated a spray coated perovskite solar cell based on $\mathrm{MAPbI}_{1-x} \mathrm{Cl}_{x}$ where the HTL and ETL (PEDOT:PSS and PCBM) were also spray coated resulting in an average PCE of $7.1 \%$ and champion PCE of $9.9 \%$ over an aperture area of $0.025 \mathrm{~cm}^{2}$ while cells where only the perovskite absorber was spray coated enabled an average PCE of $9.8 \%$ and a champion PCE of $11.1 \%$. Also, humidity was observed to have an impact on the performance where an increase in the humidity leading to a reduction of PCE.

Heo et al. ${ }^{171}$ developed a unique approach for spray coating of perovskite films by balancing out the outgoing solvent flux with the sprayed perovskite precursor enabling a longer spray coating window. MAI and $\mathrm{PbCl}_{2}$ were first reacted in IPA which were then purified and dissolved in a DMF/GBL solvent mix. Balancing of the DMF:GBL ratio was identified to be crucial in enabling the balancing of the solvent flux out with the spray coated precursor mix. 
This resulted in spray coated cells with a PCE of $18.03 \%$ over $0.16 \mathrm{~cm}^{2}$. They further demonstrated the possibility of fabricating a spray coated module with an active area of $40 \mathrm{~cm}^{2}$ resulting in a PCE of $15.5 \%$.

Bishop et al. ${ }^{142}$ modified the previously mentioned process reported by Mohamed et al. ${ }^{168}$ to enable spray coating of the compact $\mathrm{TiO}_{2}, \mathrm{mp}-\mathrm{TiO}_{2}$, the $\mathrm{MAPbI}_{1-x} \mathrm{Cl}_{x}$ absorber and spiroOMeTAD. Hydroiodic acid was used as an additive to enabled better solubility of $\mathrm{PbCl}_{2}$ in DMF while also promoting better surface coverage. The work enabled an average PCE of 9.2\% over a $4 \mathrm{~mm}^{2}$ pixel (aperture area of $0.0256 \mathrm{~cm}^{2}$ ) while cells with an active area of $1.51 \mathrm{~cm}^{2}$ enabled an average PCE of $6.59 \mathrm{~cm}^{2}$ (Fig. 10(f)-(h)).

An alternate route towards the fabrication of perovskite absorbers is based on the 2-step method. ${ }^{172,173}$ For example, Huang et al. ${ }^{173}$ developed a 2 -step spray coating process to fabricate $\mathrm{MAPbI}_{3}$ based solar cells. Initially, $\mathrm{PbI}_{2}$ in $\mathrm{DMF}$ was spray coated followed by spray coating of MAI in 2-proanol (IPA). The temperature was identified to be a key parameter as too-high temperature(s) did not enable the infiltration of the MAI into the dense $\mathrm{PbI}_{2}$ layer while a too-low temperature resulted in residual DMSO. The optimized coating process resulted in a PCE of $13.09 \%$ for a $1 \mathrm{~cm}^{2}$ pixel.

In comparison to the organic-inorganic hybrid perovskite spray coating reported as in the above work, Lau et al. ${ }^{174}$ developed spray coated all inorganic perovskite solar cells, an important composition in terms of forming thermally stable perovskites. ${ }^{116}$ In that work, a "semi" spray coated method was adopted where CsI was spray coated on a spin coated $\mathrm{PbBr}_{2}$ film enabling the formation of an all inorganic perovskite absorber. The substrate temperature was identified to have a crucial impact on the perovskite formation with substrates kept at room temperature enabling the desired perovskite phase while heating of the substrate to either $160^{\circ} \mathrm{C}$ or $350^{\circ} \mathrm{C}$ resulted in the formation of an undesirable CsI phase. A best PCE of 5.4\% was achieved for the room temperature spray coated samples while PCE $<3 \%$ was achieved for those prepared using heated substrates.

The use of spray coating also enabled the development of rapid compositional screening. For example, Tait et al. ${ }^{175}$ utilised concurrent spray coating of mixtures of $\mathrm{PbCl}_{2}: \mathrm{MAI}$ and $\mathrm{Pb}(\mathrm{Ac})_{2}$ : MAI in DMF on substrates held at a temperature of $40-60^{\circ} \mathrm{C}\left(40^{\circ} \mathrm{C}\right.$ being identified as the optimum). Based on the above method, the optimum $\mathrm{PbCl}_{2}: \mathrm{Pb}(\mathrm{Ac})_{2}$ ratio was identified to be 3:1 which facilitated low pinhole formation as well as good photovoltaic device performance resulting in a PCE of $13.7 \%$ for device areas of $0.13 \mathrm{~cm}^{2}$ and a PCE of $10.4 \%$ for module areas of $3.8 \mathrm{~cm}^{2}$. The authors also investigated concurrent spray coating of $\mathrm{PbCl}_{2}: \mathrm{MAI}$ and $\mathrm{PbBr}_{2}$ : 
$\mathrm{MABr}$ to enable bandgap tuning which resulted in a PCE of $6.8 \%$ for perovskite with an $E_{B G}$ of $1.8 \mathrm{eV}$. A more traditional approach towards compositional screening was reported by Chou et al. ${ }^{176}$ who reported the spray coating of $\mathrm{MA}_{1-x} \mathrm{FA}_{x} \mathrm{PbI}_{3}$ where $x=0,0.25,0.50,0.75 \& 1$ was investigated. The optimum performance was realized for $x=0.25$ which resulted in a champion PCE of $15.61 \%$ when the precursor was spray coated on a heated substrate kept at $70^{\circ} \mathrm{C}$. The work highlights the role of spray coating techniques as means of compositional optimization of perovskites, an area that is receiving significant attention in terms of utilizing machine learning approaches. ${ }^{177,178}$

Cai et al. ${ }^{179}$ utilised hot air blowing during the fabrication of spray coated cells. In their work, this methodology was reported to result in better reproducibility of $\mathrm{MAPbI}_{1-x} \mathrm{Cl}_{x}$ (in DMF) based PSCs resulting in a PCE of $13.5 \%$ (reverse scan) for an aperture area of $0.13 \mathrm{~cm}^{2}$ and $9.8 \%$ for an active area of $1 \mathrm{~cm}^{2}$.

With regards to the drying of the spray coated films, an alternate approach to the conventionally used thermal annealing process involves the vacuum drying of the spray coated samples that is followed by thermal annealing ${ }^{166}$, analogous to VASP reported by Bi et al. ${ }^{51}$ Based on this approach, Bishop et al. ${ }^{166}$ spray coated the triple cation perovskite; $\mathrm{Cs}_{0.05}\left[\left(\mathrm{FAPbI}_{3}\right)_{0.85}\left(\mathrm{MAPbBr}_{3}\right)_{0.15}\right]_{0.95}$ in a DMF:DMSO $=4: 1$ solvent mix onto a substrate held at $40^{\circ} \mathrm{C}$ followed by a vacuum drying and subsequent thermal annealing process which enabled a higher $V_{O C}$ compared to samples that have not undergone the vacuum drying process. The resulting devices showed an average PCE of $17.8 \%$ in the reverse direction with more spatially homogenous optoelectronic characteristics compared to non-vacuum dried films (Fig. 10(i)$(\mathrm{k}))$. 

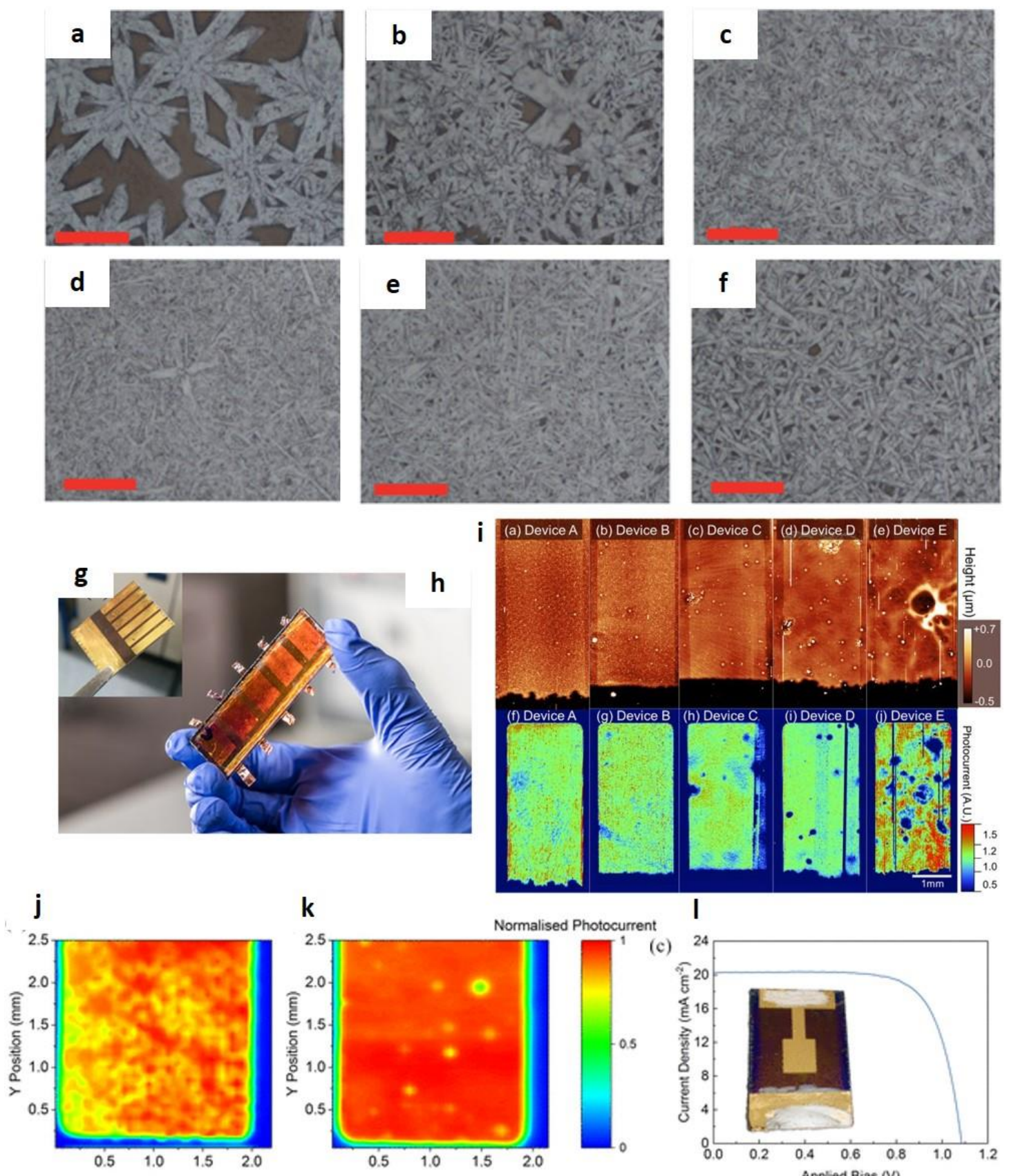

I

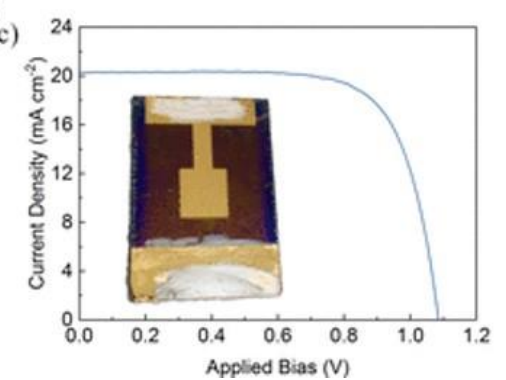

Fig. 10 Optical microscopy images of spray coated films on heated substrates held at (a) $28^{\circ} \mathrm{C}$, (b) $38^{\circ}$ $\mathrm{C}$, (c) $55^{\circ} \mathrm{C}$, (d) $75^{\circ} \mathrm{C}$, (e) $80^{\circ} \mathrm{C}$ and (f) $87^{\circ} \mathrm{C}$ indicating the importance of temperature control for compact perovskite absorber formation as reported by Barrows et al. ${ }^{169}$ The scale bar corresponds to 20 $\mu \mathrm{m}$. Reproduced from Ref. 169 with permission from The Royal Society of Chemistry. (g) Photographs of small area and (h) large area spray coated $\mathrm{MAPbI}_{3}$ solar cells reported by Bishop et al. ${ }^{142}$ where the compact and $\mathrm{mp}-\mathrm{TiO}_{2}$ were also spray coated in addition to the perovskite absorber. (i) The topographical (top row) and light beam induced current (LBIC) maps (bottom row) where in device A: all layers are spin coated, device $\mathrm{B}$ : only the $\mathrm{mp}-\mathrm{TiO}_{2}$ is spray coated, device $\mathrm{C}$ : only the perovskite absorber is spray coated, device $\mathrm{D}$ : both the $\mathrm{mp}-\mathrm{TiO}_{2}$ and the perovskite spray coated and device $\mathrm{E}$ : all of the above layers are spray coated. ${ }^{142}$ Reproduced from Ref. 142 under the Creative Commons CC BY License. LBIC maps of (j) non-VASP and (k) VASP processed, spray coated triple cation PSCs. Reported by Bishop et al. ${ }^{166}$ (l) Shows the $J$ - $V$ characteristics of a spray coated, VASP processed triple cation PSC. Reprinted with permission from Ref. 166. Copyright (2018) American Chemical Society. 


\section{d) Ink jet printing}

In terms of printed solar cells, ink jet printing is another attractive technology that bridges the gap between lab scale evaluation and manufacturing through R2R or S2S processes. In-fact, perovskite based solar cells fabricated through ink-jet printing (Fig. 7(d)) are already being evaluated as window facades. ${ }^{180}$ Ink jet printing and drop-on-demand printing ${ }^{146}$ (Fig. 11(a) and (b)). In continuous printing, the ink is forced through a nozzle where it results in a column of droplets due to the surface tension. The droplets then pass through a nozzle where a charge is imparted on it. The direction of printing is steered by deflection plates which steer the direction of the droplets. In the drop-on-demand printing method, a pressure pulse is generated in the head either through a piezoelectric transducer or through rapid heating of the ink which results in the formation of a bubble at the surface of a heater. The resulting pressure pulse drives the ink through the nozzle resulting in the refilling of the ink. It is noted here that ink jet printing has so far produced some of the best performing large area perovskite modules with the collaboration between Panasonic and Japan's New Energy and Industrial Technology Development Organization (NEDO) reporting ${ }^{25}$ a PCE of $16.09 \%$ for an aperture area of 802 $\mathrm{cm}^{2}$ (Fig 11(c)) while Saule Technologies, a company that is developing ink jet printed perovskite solar cells has tested a module on Skanska's Spark office in Warsaw ${ }^{181}$.

As in the case with many other manufacturing techniques, in inkjet printing of perovskites also, the substrate temperature plays a key role in terms of forming a compact perovskite film. For example, Li et al. ${ }^{182}$ demonstrated the inkjet printing of a perovskite layer consisting of MAI:PbI $2: \mathrm{MACl}=1-x: 1: x$ in GBL where substrate heating was implemented to enable rapid ramping of the temperature from $25^{\circ} \mathrm{C}$ to as high as $60^{\circ} \mathrm{C}$ within a couple of minutes which was identified to facilitate homogenous crystallization, similar to that of anti-solvent treatment ${ }^{8,11,12,133}$ and hot casting techniques ${ }^{137,138}$. A temperature of $50^{\circ} \mathrm{C}$ together with MAI:MACl ratio of 4: 6 (i.e. $x=0.6$ ) was identified as being the optimum condition to achieve the best performance of $12.3 \%$ where the $\mathrm{MACl}$ was identified to result in homogenous crystallization of the perovskite.

Mathies et al. ${ }^{183}$ utilised inkjet printing for the coating of $\mathrm{MAPbI}_{3}$ based on a solvent system consisting of DMSO and GBL which enabled slow solvent evapouration, and thereby resulting in the formation of smooth, thin films. Optimum performances were observed to be obtained following the incorporation of a vacuum annealing step over a duration of 2 or $5 \mathrm{~min}$, which resulted in the best performances of $\sim 4.5 \%$ and $4.3 \%$ for a single coating (i.e. perovskite thickness of $\sim 180 \mathrm{~nm}$ ). However, the performance was observed to decrease if the vacuum 
annealing was carried out for shorter or longer periods. Applying three coatings to enable a thickness of $\sim 480 \mathrm{~nm}$ in combination with vacuum annealing resulted in a higher PCE of $11.3 \%$ for a device area of $0.09 \mathrm{~cm}^{2}$ (Fig. 11(d)-(f)). Following this initial work on $\mathrm{MAPbI}_{3}{ }^{183}$, Mathies et al. reported ${ }^{184}$ the use of a triple cation perovskite, $\mathrm{C}_{0.10}\left(\mathrm{FA}_{0.83} \mathrm{MA}_{0.17}\right)_{0.90} \mathrm{~Pb}\left(\mathrm{I}_{0.83} \mathrm{Br}_{0.17}\right)_{3}$ in combination with the vacuum annealing process optimized at 2 min. The drop spacing was altered from $60 \mu \mathrm{m}$ to $25 \mu \mathrm{m}$ enabling the increase in thickness from $180 \mathrm{~nm}$ to $780 \mathrm{~nm}$. A champion PCE of 15.3\% (Fig 11(g)) was obtained for a thickness of $520 \mathrm{~nm}$. The triple cation printed devices also demonstrated an improved thermal stability compared to $\mathrm{MAPbI}_{3}$ with only $10 \%$ loss in PCE when kept at $80^{\circ} \mathrm{C}$ for $100 \mathrm{~min}$.

Liang et al. ${ }^{185}$ reported the printing of $\mathrm{MAPbI}_{3}$ precursors prepared in a DMSO: GBL mix to print perovskite films in combination with vacuum annealing. They achieved PCEs of $17.04 \%$ for $0.04 \mathrm{~cm}^{2}$ and $13.27 \%$ for $4 \mathrm{~cm}^{2}$. The improvements in performance was enabled by deposition of a $5 \mathrm{~nm}$ thick $\mathrm{C}_{60}$ layer on the $\mathrm{TiO}_{2} \mathrm{ETL}$ where the $\mathrm{C}_{60}$ coating enabled larger grains to be formed as well as an increased recombination resistance.

Gheno et al. ${ }^{186}$ evaluated the importance of the halide composition on methylammonium based perovskites in conjunction with the impact of printing on metal oxide films $\left(\mathrm{TiO}_{2}\right.$ compact or mesoporous films $\left(\mathrm{mp}-\mathrm{TiO}_{2}\right)$, or tungsten oxide $\left(\mathrm{WO}_{\mathrm{x}}\right)$ films). Four perovskite compositions were evaluated: $\mathrm{MAPbI}_{3}, \mathrm{MAPbI}_{3-x} \mathrm{Cl}_{x}, \mathrm{MAPbI}_{3-x} \mathrm{Cl}_{x}$ with $\mathrm{DIO}$ as an additive and $\mathrm{MAPbI}_{3-x} \mathrm{Br}_{x}$. ITO substrates stored in air enabled a more hydrophilic surface for printing of the $\mathrm{MAPbI}_{3-x} \mathrm{Cl}_{x}$ while $\mathrm{WO}_{\mathrm{x}}$ in nitrogen enables a similar outcome. This work enabled the identification of the importance of controlling the overall perovskite concentration such that the jetabillity is not impacted was identified, although it should be noted that it is likely that additives such as 5ammonium valeric acid iodide (5-AVAI) would also reduce the clogging of the printing head as reported by Hashmi et al. ${ }^{187}$ The influence on jettability is most likely due to presence of colloids in the perovskite precursors. ${ }^{188}$ The authors printed tungsten oxide $\left(\mathrm{WO}_{\mathrm{x}}\right)$ as an ETL/perovskite/Spiro-OMeTAD and evaluated solar cell performance. A champion PCE of $10.7 \%$ was achieved in reverse scan, although a large hysteresis was also observed.

Huckaba et al. ${ }^{189}$ reported inkjet printed PSCs where both the perovskite as well as the mp$\mathrm{TiO}_{2}$ were inkjet printed. In order to minimize the coffee-ring effect when drying, a solvent combination of $\mathrm{DMF} / \mathrm{DMSO} / \mathrm{GBL} / \mathrm{NMP}$ was used together with phosphatidylcholine as a surfactant. The perovskite composition followed a quadruple cation system based on: $\mathrm{Cs}_{0.10} \mathrm{Gu}_{0.05}\left(\mathrm{FA}_{0.83} \mathrm{MA}_{0.17}\right)_{0.85} \mathrm{PbI}_{2.63} \mathrm{Br}_{0.37}$. Contrary to the above conditions, the authors dipped 
the coated film in an anti-solvent bath of diethyl ether to enable homogenous crystallization. Decreasing the drop spacing during inkjet printing enabled the formation of a compact film as well as thicker film to be formed. A champion PCE of $14.1 \%$ was obtained with an average cell efficiency of $12.15 \%$ for devices with an area of $0.16 \mathrm{~cm}^{2}$ which was much higher than that obtained for inkjet printed $\mathrm{MAPbI}_{3}$ cells.

Hashmi et al. ${ }^{187}$ utilised inkjet printing towards fabrication of the perovskite absorber and the insulating $\mathrm{ZrO}_{2}$ spacer layer on a porous carbon layer to fabricate HTL free solar cells (Fig. 11(h)). The precursor used consisted of a mix of $\mathrm{MAPbI}_{3}$ and 5-AVAI mix which has previously been reported ${ }^{190}$ to result in one of the most stable device architectures. While 5AVAI enables slow crystallization, it also prevents the clogging of the inkjet head, enabling optimized devices with PCEs of $8.47 \%$ (in the reverse for an aperture area of $0.16 \mathrm{~cm}^{2}$ ) to be achieved. Initial investigations on the device stability where the cells were kept under illumination at $35^{\circ} \mathrm{C}$ for $1046 \mathrm{~h}$ showed very little decrease in performance. When stored in the dark for 3 weeks, the performance was observed to improve by $13 \%$ to a value of $9.53 \%$ for the champion cell (Fig. 11(i)). This work was later expanded ${ }^{191}$ to identify the stability of the cells under UV irradiation where the devices, when encapsulated with an epoxy showed no performance degradation under UV irradiation equivalent to 1.5 Sun illumination conditions over 1002 hours.

An interesting approach in terms of "colouring" of perovskite solar cells was reported by Schlisske et al. ${ }^{192}$ who incorporated ink jet printed luminescent down shifting layers (mixtures of Violet 570, Yellow 083, and Red 300 Lumogen-F series, BASF in polymethylmethacrylate) together with a solar cell consisting of ink-jet printed perovskite layer $\mathrm{Cs}_{0.10}\left(\mathrm{FA}_{0.83}\right.$ $\left.\mathrm{MA}_{0.17}\right)_{0.90} \mathrm{~Pb}\left(\mathrm{I}_{0.83} \mathrm{Br}_{0.17}\right)_{3}$. However, the PCE was observed to decrease from $11.5 \%$ to $9.4 \%$ following the incorporation of the down-shifting layers. Such an approach is likely to be attractive in terms of developing perovskites for building integrated PV where variation in colours is preferred for aesthetic purposes.

The use of inkjet printing has also been used rapid compositional screening of perovskites. For example, Bag et al. ${ }^{193}$ used in-situ mixing capabilities of multichannel ink-jet printers to explore the compositional space based performance of ink-jet printed perovskite solar cells where the CMYK (cyan magenta yellow black) channels consisted of $\mathrm{MA}^{+}, \mathrm{FA}^{+}$, water, water. By variation of the CMYK values, different MA:FA combinations was evaluated. The resulting printed devices indicated the best performance to be obtained from an MA:FA $=2: 1$ resulting 
in a champion device performance of $11.1 \%$. As noted previously for similar activities discussed under spray coating, inkjet printed compositional screening provides an avenue that support machine learning based perovskite composition optimization activities.

is based on 2 approaches: continuous printing
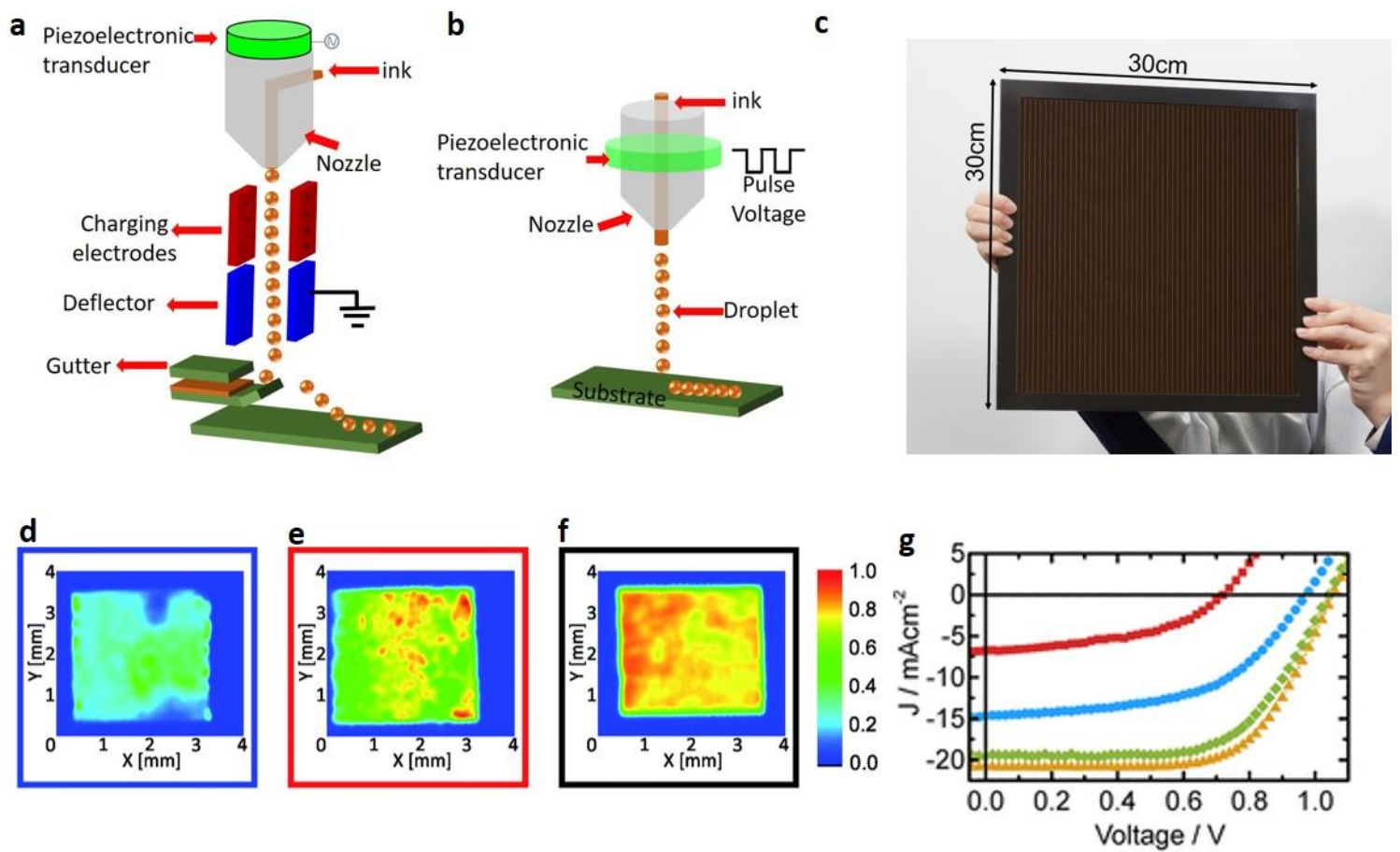

h

i
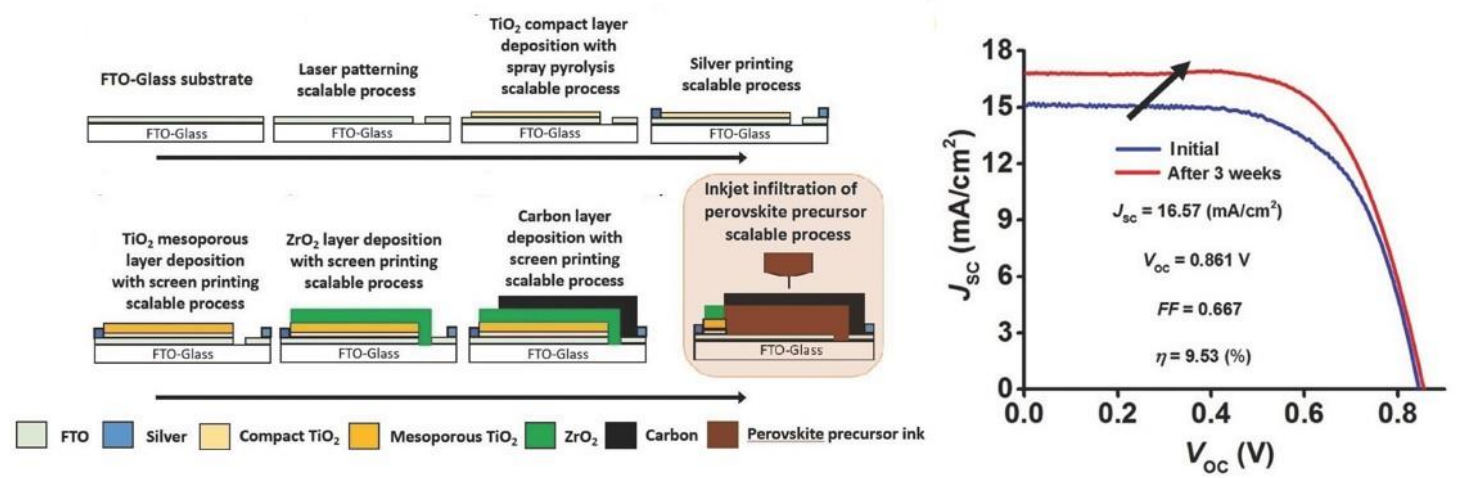

Fig. 11 Inkjet printing based on (a) continuous and (b) drop-on-demand technique. (Schematic based on ref $^{146}$ ). (c) Photograph of $30 \mathrm{~cm} \times 30 \mathrm{~cm}$ inkjet printed perovskite module by Panasonic. ${ }^{194}$ Photograph reproduced with permission from Panasonic. Light beam induced current mapping of inkjet printed (d) non-vacuum treated, (e) vacuum treated and (f) spin coated perovskite films reported by Mathies et al. ${ }^{183}$ Reproduced from Ref. 183 with permission from The Royal Society of Chemistry. (g) $J-V$ characteristics of inkjet printed triple cation perovskites of varying thickness (from $150 \mathrm{~nm}-750$ $\mathrm{nm}$ ) reported by Mathies et al. ${ }^{184}$ Reprinted with permission from Ref. 184. Copyright (2018) American Chemical Society. (h) Process steps followed by Hashmi et al. ${ }^{187}$ in fabricating inkjet infiltrated carbon porous contact based PSC and, (i) the improvement in performance of these devices following storage in the dark for 3 weeks. Reproduced from Ref. 187 with permission from Wiley-VCH. 


\section{Prospects and future directions}

One of the key issues in the development of perovskite absorbers has been its inherent instability under certain compositions. For example, $\mathrm{MAPbI}_{3}$, the fruit-fly of perovskite research has been identified to demonstrate inherent instability under elevated temperatures $\left(>85^{\circ} \mathrm{C}\right)$ conditionMAPbI${ }_{3}$ often requires annealing temperatures closer to $100^{\circ} \mathrm{C}$, there is the need towards screening for compositions which minimise or eliminate this risk.

As discussed in this review, one of the key attractions in the development of PSCs has been its bandgap tunability, which enables the formation of low bandgap absorbers based on $\mathrm{Pb}-\mathrm{Sn}$ mixed perovskites. However, the oxidation of $\mathrm{Sn}^{2+}$ (the preferred oxidation state for PSCs) to $\mathrm{Sn}^{4+}$ remains a key challenge, especially considering that it would be preferable to carry out the printing of low bandgap perovskites under ambient conditions, which accelerates the oxidation of $\mathrm{Sn}^{2+}$. In terms of minimising oxidation, A number of routes have been developed such as the inclusion of $\mathrm{SnF}_{2}{ }^{195}$, use of appropriate anti-solvent washing such as toluene (Fig. 12(a)) and annealing temperatures ${ }^{11}$ as well as the inclusion of tin $\operatorname{powder}^{12}$ (Fig. 12(b)) to the precursor mix. In terms of a R2R or S2S printing capability, we do not foresee any significant barrier towards utilising the above methodologies. However, more in-depth studies are required in this regard to ensure that stable, low bandgap absorbers can indeed be printed on high throughput manufacturing systems.

Another significant impediment towards the high throughput manufacturing of perovskite based tandem structures is the use of toxic solvents such as DMF, chlorobenzene (CB), dichlorobenzene (DCB) etc. ${ }^{7,10,12}$. For example, solvents such as DMF is noted for its harmful nature (when in contact with skin) ${ }^{196}$. Similar obstacles have been highlighted in the manufacturing of organic photovoltaics which use solvents such as CB or DCB in lab scale device optimization. This has in fact resulted in studies for the optimization of this technology based on green solvents ${ }^{197,198}$. With regards to perovskites, there have been demonstrations towards the development of precursors based on more environmentally friendly solvents. For example, Gardner et al. ${ }^{199}$ has discussed several environmentally friendly solvent combinations for the perovskite precursor while Galagan et al. ${ }^{135}$ have demonstrated slot die coated examples of perovskites where DMF has been eliminated. Noel et al. ${ }^{200}$ (Fig. 12(c))has also reported clean, low boiling point solvents that can enable the fabrication of perovskites in a manner that can be implemented on a manufacturing line. This approach was more recently reported ${ }^{201}$ to be utilised for the development of slot die coating in conjunction with an air knife for the 
fabrication of perovskites on ITO/PET which demonstrated a champion PCE of $14.7 \%$. However, there remains significant room for further improvement that will require future activities at lab scale processes to focus on the uptake of environmentally friendly manufacturing methodologies to ensure that the promise of perovskites as a printed PV technology is realised.

In terms of future applications beyond contribution to the grid, it is anticipated that perovskites will be integrated into building components with early developments already being reported. While a current limitation lies in terms of its aesthetics (i.e. colour of the module), the approach reported by Schlisske et al. ${ }^{192}$ is likely to enable this issue to be bypassed. Other than this, perovskite-based tandems are also likely to lead to space-based energy harvesting applications. The reported high radiation tolerance is likely to make this technology a favourable candidate. This could also be considered as a new application space for all-perovskite tandem solar cell applications where module degradation due to oxygen and moisture are of less concern. Additionally, the satisfactory performance of perovskites under concentrator applications ${ }^{202}$ can also lead to broadening the device configurations developed in this area.

s which can result in the conversion of $\mathrm{CH}_{3} \mathrm{NH}_{3} \mathrm{I}$ into $\mathrm{CH}_{3} \mathrm{I}$ and $\mathrm{NH}_{3}{ }^{8}$. As 
a

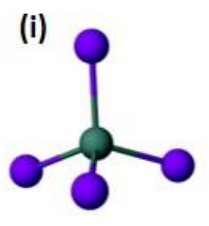

(ii)

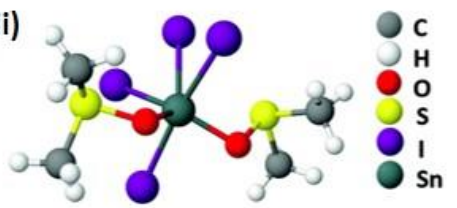

(iii)

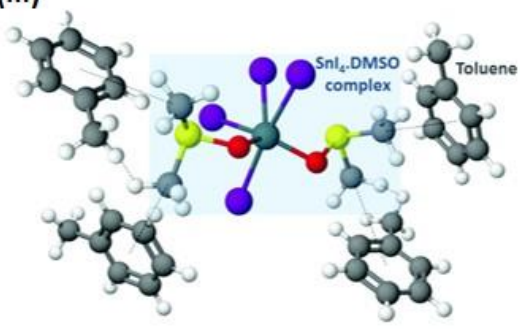

b

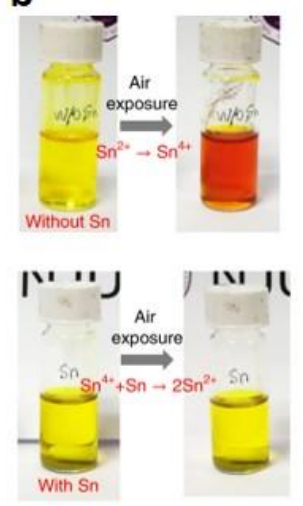

(iv)

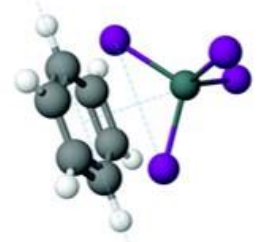

d (i)

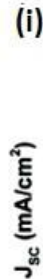

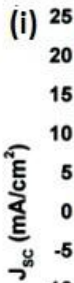

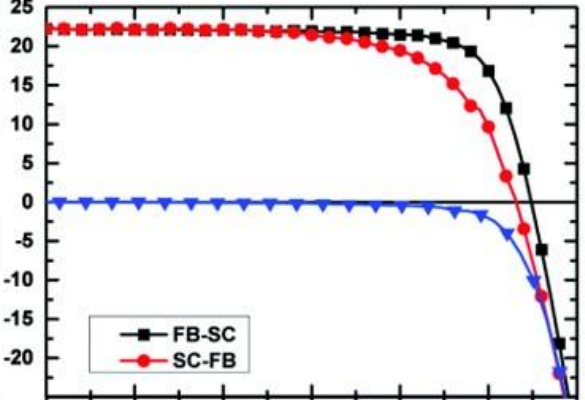

(ii)

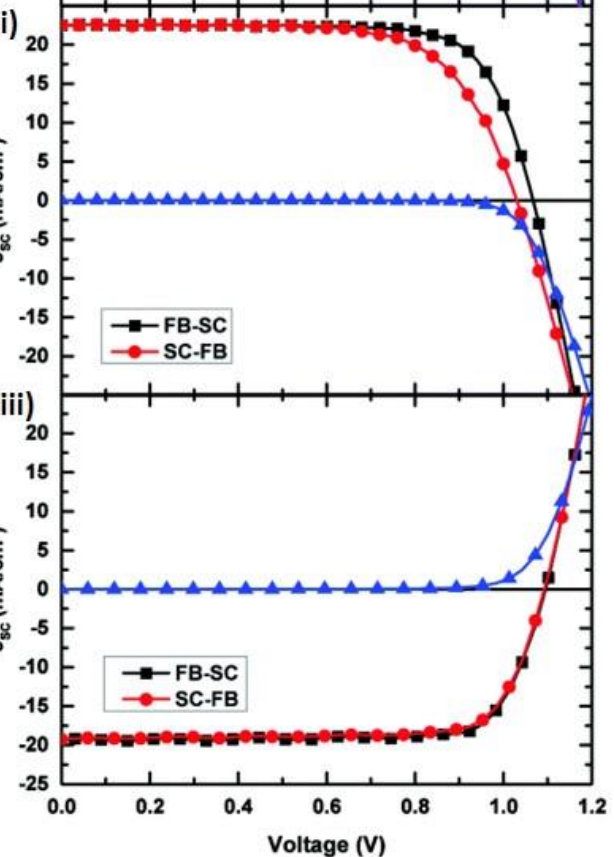

Fig. 12 (a) Solvent induced removal of $\mathrm{Sn}^{4+}$ where $\mathrm{SnI}_{4}$ (i) forms a complex with DMSO (ii). The resulting $\mathrm{SnI}_{4} \cdot$ (DMSO) interacts with non-polar toluene (iii). $\mathrm{SnI}_{4}$ can also interact with other non-polar aromatic molecules such as benzene. ${ }^{203}$ Reproduced from Ref. 203 with permission from The Royal Society of Chemistry. (b) photograph showing the oxidation of $\mathrm{Sn}^{2+}$ to $\mathrm{Sn}^{4+}$ in air and the reduction of $\mathrm{Sn}^{4+}$ to $\mathrm{Sn}^{2+}$ in the presence of Sn powder. ${ }^{12}$ Reproduced from Ref. 12 with permission from Springer Nature. (c) photograph of a highly specular $\mathrm{MAPbI}_{3}$ spin coated based on the method reported by Noel et al ${ }^{200}$ and the resulting (d) $J-V$ characteristics of the champion device prepared by (i) annealing at $100^{\circ} \mathrm{C}$ for 1 hour (regular architecture), (ii) degassed under vacuum overnight and (iii) annealed at $100^{\circ}$ $\mathrm{C}$ for 1 hour (inverted architecture). Reproduced from Ref. 200 with permission from The Royal Society of Chemistry.

\section{Conflict of Interest}

There are no conflicts of interest to declare. 


\section{Acknowledgements}

K. D. G. I. J. and S. M. S. gratefully acknowledges financial support from the Equality Foundation of Hong Kong. R. K. M. gratefully acknowledge support and the European Commission H2020 CORNET program (Grant ID: 760949). S. M. S. Acknowledges support from the University of Surrey Vice Chancellors Scholarship Scheme. The authors also acknowledge the assistance provided by Dr Mozhgan Yavari at the Advanced Technology Institute, University of Surrey in preparing this review.

\section{Notes}

Figures 1(a) and (b) have been reprinted with permission from Ref. 26. Copyright (2015) American Chemical Society. Further permissions related to the material excerpted should be directed to the American Chemical Society.

\section{References}

1 D. J. Nelson and M. Strano, Nat. Nanotechnol., 2006, 1, 96-97.

2 M. Kaltenbrunner, G. Adam, E. D. Głowacki, M. Drack, R. Schwödiauer, L. Leonat, D. H. Apaydin, H. Groiss, M. C. Scharber, M. S. White, N. S. Sariciftci and S. Bauer, Nat. Mater., 2015, 14, 1032-1039.

3 G. E. Eperon, V. M. Burlakov, A. Goriely and H. J. Snaith, ACS Nano, 2014, 8, 591598.

4 M. M. Lee, J. Teuscher, T. Miyasaka, T. N. Murakami and H. J. Snaith, Science, 2012, 338, 643-647.

5 L. Hong, J. Milic, P. Ahlawat, M. Mladenovic, D. J. Kubicki, F. Jahanbakhshi, D. Ren, M. Gelvez-Rueda, M. A. Ruiz-Preciado, A. Ummadisingu, Y. Liu, C. Tian, L. Pan, S. M. Zakeeruddin, A. Hagfeldt, F. C. Grozema, U. Rothlisberger, L. Emsley, H. Han and M. Grätzel, Angew. Chemie Int. Ed., 2020, 59, 4691-4697.

6 W. Xiang, Z. Wang, D. J. Kubicki, W. Tress, J. Luo, D. Prochowicz, S. Akin, L. Emsley, J. Zhou, G. Dietler, M. Grätzel and A. Hagfeldt, Joule, 2019, 3, 205-214.

7 M. Saliba, T. Matsui, J. Y. Seo, K. Domanski, J. P. Correa-Baena, M. K. Nazeeruddin, S. M. Zakeeruddin, W. Tress, A. Abate, A. Hagfeldt and M. Grätzel, Energy Environ. Sci., 2016, 9, 1989-1997. 
N. K. Noel, S. D. Stranks, A. Abate, C. Wehrenfennig, S. Guarnera, A. A.

Haghighirad, A. Sadhanala, G. E. Eperon, S. K. Pathak, M. B. Johnston, A. Petrozza, L. M. Herz and H. J. Snaith, Energy Environ. Sci., 2014, 7, 3061-3068.

10 K. D. G. I. Jayawardena, R. M. I. Bandara, M. Monti, E. Butler-Caddle, T. Pichler, H. Shiozawa, Z. Wang, S. Jenatsch, S. J. Hinder, M. G. Masteghin, M. Patel, H. M. Thirimanne, W. Zhang, R. A. Sporea, J. Lloyd-Hughes and S. R. P. Silva, J. Mater. Chem. A, 2020, 8, 693-705.

11 R. M. I. Bandara, K. D. G. I. Jayawardena, S. O. Adeyemo, S. J. Hinder, J. A. Smith, H. M. Thirimanne, N. C. Wong, F. M. Amin, B. G. Freestone, A. J. Parnell, D. G. Lidzey, H. J. Joyce, R. A. Sporea and S. R. P. Silva, J. Mater. Chem. C, 2019, 7, 8389-8397.

12 R. Lin, K. Xiao, Z. Qin, Q. Han, C. Zhang, M. Wei, M. I. Saidaminov, Y. Gao, J. Xu, M. Xiao, A. Li, J. Zhu, E. H. Sargent and H. Tan, Nat. Energy, 2019, 4, 864-873.

13 J. Xu, C. C. Boyd, Z. J. Yu, A. F. Palmstrom, D. J. Witter, B. W. Larson, R. M. France, J. Werner, S. P. Harvey, E. J. Wolf, W. Weigand, S. Manzoor, M. F. A. M. van Hest, J. J. Berry, J. M. Luther, Z. C. Holman and M. D. McGehee, Science (80-. )., 2020, 367, 1097-1104.

14 D. P. McMeekin, G. Sadoughi, W. Rehman, G. E. Eperon, M. Saliba, M. T. Hörantner, A. Haghighirad, N. Sakai, L. Korte, B. Rech, M. B. Johnston, L. M. Herz and H. J. Snaith, Science, 2016, 351, 151-155.

15 A. Kojima, K. Teshima, Y. Shirai and T. Miyasaka, J. Am. Chem. Soc., 2009, 131, $6050-6051$.

16 Best Research-Cell Efficiency Chart | Photovoltaic Research | NREL, https://www.nrel.gov/pv/cell-efficiency.html, (accessed 25 April 2020).

17 S. D. Stranks, G. E. Eperon, G. Grancini, C. Menelaou, M. J. P. Alcocer, T. Leijtens, L. M. Herz, A. Petrozza and H. J. Snaith, Science, 2013, 342, 341-344.

18 D. Meggiolaro, S. G. Motti, E. Mosconi, A. J. Barker, J. Ball, C. Andrea Riccardo Perini, F. Deschler, A. Petrozza and F. De Angelis, Energy Environ. Sci., 2018, 11, $702-713$. 
19 A. Miyata, A. Mitioglu, P. Plochocka, O. Portugall, J. T. W. Wang, S. D. Stranks, H. J. Snaith and R. J. Nicholas, Nat. Phys., 2015, 11, 582-587.

20 J. A. Christians, P. Schulz, J. S. Tinkham, T. H. Schloemer, S. P. Harvey, B. J. Tremolet De Villers, A. Sellinger, J. J. Berry and J. M. Luther, Nat. Energy, 2018, 3, $68-74$.

21 K. Gao, B. Xu, C. Hong, X. Shi, H. Liu, X. Li, L. Xie and A. K.-Y. Jen, Adv. Energy Mater., 2018, 8, 1800809.

22 O. D. Miller, E. Yablonovitch and S. R. Kurtz, IEEE J. Photovoltaics, 2012, 2, $303-$ 311.

23 M. Saliba, J. P. Correa-Baena, M. Grätzel, A. Hagfeldt and A. Abate, Angew. Chemie Int. Ed., 2018, 57, 2554-2569.

24 A. Al-Ashouri, A. Magomedov, M. Roß, M. Jošt, M. Talaikis, G. Chistiakova, T. Bertram, J. A. Márquez, E. Köhnen, E. Kasparavičius, S. Levcenco, L. Gil-Escrig, C. J. Hages, R. Schlatmann, B. Rech, T. Malinauskas, T. Unold, C. A. Kaufmann, L. Korte, G. Niaura, V. Getautis and S. Albrecht, Energy Environ. Sci., 2019, 12, 33563369.

25 Panasonic reaches $16.09 \%$ efficiency with perovskite solar module using inkjet-based coating, https://www.solarpowerworldonline.com/2020/02/panasonic-reaches-16-09efficiency-with-perovskite-solar-module-using-inkjet-based-coating/, (accessed 19 February 2020).

26 Saule Technologies - Inkjet-Printed Perovskite Solar Cells, https://sauletech.com/, (accessed 20 February 2020).

27 Swift Solar - Next generation lightweight and efficient solar technology, https://www.swiftsolar.com/, (accessed 20 February 2020).

28 T. Ameri, N. Li and C. J. Brabec, Energy Environ. Sci., 2013, 6, 2390-2413.

29 G. Dennler, M. C. Scharber, T. Ameri, P. Denk, K. Forberich, C. Waldauf and C. J. Brabec, Adv. Mater., 2008, 20, 579-583.

30 L. Protesescu, S. Yakunin, M. I. Bodnarchuk, F. Krieg, R. Caputo, C. H. Hendon, R. X. Yang, A. Walsh and M. V. Kovalenko, Nano Lett., 2015, 15, 3692-3696. 
31 L. C. Hirst and N. J. Ekins-Daukes, Prog. Photovoltaics Res. Appl., 2011, 19, 286293.

32 W. Shockley and H. J. Queisser, J. Appl. Phys., 1961, 32, 510-519.

33 R. T. Ross, J. Chem. Phys., 1967, 46, 4590-4593.

34 G. E. Eperon, M. T. Hörantner and H. J. Snaith, Nat. Rev. Chem., 2017, 1, 1-18.

35 M. T. Hörantner, T. Leijtens, M. E. Ziffer, G. E. Eperon, M. G. Christoforo, M. D. McGehee and H. J. Snaith, ACS Energy Lett., 2017, 2, 2506-2513.

36 P. Cheng, G. Li, X. Zhan and Y. Yang, Nat. Photonics, 2018, 12, 131-142.

37 L. Meng, Y. Zhang, X. Wan, C. Li, X. Zhang, Y. Wang, X. Ke, Z. Xiao, L. Ding, R. Xia, H. L. Yip, Y. Cao and Y. Chen, Science, 2018, 361, 1094-1098.

38 J. You, C. C. Chen, Z. Hong, K. Yoshimura, K. Ohya, R. Xu, S. Ye, J. Gao, G. Li and Y. Yang, Adv. Mater., 2013, 25, 3973-3978.

39 K. Yoshikawa, W. Yoshida, T. Irie, H. Kawasaki, K. Konishi, H. Ishibashi, T. Asatani, D. Adachi, M. Kanematsu, H. Uzu and K. Yamamoto, Sol. Energy Mater. Sol. Cells, $2017, \mathbf{1 7 3}, 37-42$.

40 J. H. Noh, S. H. Im, J. H. Heo, T. N. Mandal and S. Il Seok, Nano Lett., 2013, 13, 1764-1769.

41 J. Burschka, N. Pellet, S.-J. Moon, R. Humphry-Baker, P. Gao, M. K. Nazeeruddin and M. Grätzel, Nature, 2013, 499, 316-319.

42 Heterojunction, https://www.meyerburger.com/en/technologyproducts/photovoltaics/heterojunction-hjt/\#, (accessed 25 April 2020).

43 H. Shen, S. T. Omelchenko, D. A. Jacobs, S. Yalamanchili, Y. Wan, D. Yan, P. Phang, T. Duong, Y. Wu, Y. Yin, C. Samundsett, J. Peng, N. Wu, T. P. White, G. G. Andersson, N. S. Lewis and K. R. Catchpole, Sci. Adv., 2018, 4, eaau9711.

44 M. Taguchi, A. Yano, S. Tohoda, K. Matsuyama, Y. Nakamura, T. Nishiwaki, K. Fujita and E. Maruyama, IEEE J. Photovoltaics, 2014, 4, 96-99.

45 J. P. Mailoa, C. D. Bailie, E. C. Johlin, E. T. Hoke, A. J. Akey, W. H. Nguyen, M. D. McGehee and T. Buonassisi, Appl. Phys. Lett., 2015, 106, 121105. 
F. Sahli, J. Werner, B. A. Kamino, M. Bräuninger, R. Monnard, B. Paviet-Salomon, L. Barraud, L. Ding, J. J. Diaz Leon, D. Sacchetto, G. Cattaneo, M. Despeisse, M.

Boccard, S. Nicolay, Q. Jeangros, B. Niesen and C. Ballif, Nat. Mater., 2018, 17, 820826.

47 Y. Hou, E. Aydin, M. De Bastiani, C. Xiao, F. H. Isikgor, D.-J. Xue, B. Chen, H.

Chen, B. Bahrami, A. H. Chowdhury, A. Johnston, S.-W. Baek, Z. Huang, M. Wei, Y. Dong, J. Troughton, R. Jalmood, A. J. Mirabelli, T. G. Allen, E. Van Kerschaver, M. I. Saidaminov, D. Baran, Q. Qiao, K. Zhu, S. De Wolf and E. H. Sargent, Science, 2020, 367, 1135-1140.

48 J. Werner, A. Walter, E. Rucavado, S. J. Moon, D. Sacchetto, M. Rienaecker, R. Peibst, R. Brendel, X. Niquille, S. De Wolf, P. Löper, M. Morales-Masis, S. Nicolay, B. Niesen and C. Ballif, Appl. Phys. Lett., 2016, 109, 233902.

49 Y. Wu, D. Yan, J. Peng, T. Duong, Y. Wan, S. P. Phang, H. Shen, N. Wu, C. Barugkin, X. Fu, S. Surve, D. Grant, D. Walter, T. P. White, K. R. Catchpole and K. J. Weber, Energy Environ. Sci., 2017, 10, 2472-2479.

50 M. Saliba, T. Matsui, K. Domanski, J. Y. Seo, A. Ummadisingu, S. M. Zakeeruddin, J. P. Correa-Baena, W. R. Tress, A. Abate, A. Hagfeldt and M. Grätzel, Science, 2016, 354, 206-209.

51 X. Li, D. Bi, C. Yi, J. D. Décoppet, J. Luo, S. M. Zakeeruddin, A. Hagfeldt and M. Grätzel, Science, 2016, 353, 58-62.

52 J. Zheng, C. F. J. Lau, H. Mehrvarz, F. J. Ma, Y. Jiang, X. Deng, A. Soeriyadi, J. Kim, M. Zhang, L. Hu, X. Cui, D. S. Lee, J. Bing, Y. Cho, C. Chen, M. A. Green, S. Huang and A. W. Y. Ho-Baillie, Energy Environ. Sci., 2018, 11, 2432-2443.

53 J. Zheng, H. Mehrvarz, C. Liao, J. Bing, X. Cui, Y. Li, V. R. Goncąles, C. F. J. Lau, D. S. Lee, Y. Li, M. Zhang, J. Kim, Y. Cho, L. G. Caro, S. Tang, C. Chen, S. Huang and A. W. Y. Ho-Baillie, ACS Energy Lett., 2019, 4, 2623-2631.

54 G. Nogay, F. Sahli, J. Werner, R. Monnard, M. Boccard, M. Despeisse, F. J. Haug, Q. Jeangros, A. Ingenito and C. Ballif, ACS Energy Lett., 2019, 4, 844-845. C. U. Kim, J. C. Yu, E. D. Jung, I. Y. Choi, W. Park, H. Lee, I. Kim, D. K. Lee, K. K. Hong, M. H. Song and K. J. Choi, Nano Energy, 2019, 60, 213-221. 

Abate, J. Rappich, L. Korte, R. Schlatmann, M. K. Nazeeruddin, A. Hagfeldt, M. Grätzel and B. Rech, Energy Environ. Sci., 2016, 9, 81-88.

57 J. Werner, C. H. Weng, A. Walter, L. Fesquet, J. P. Seif, S. De Wolf, B. Niesen and C. Ballif, J. Phys. Chem. Lett., 2016, 7, 161-166.

58 J. Werner, L. Barraud, A. Walter, M. Bräuninger, F. Sahli, D. Sacchetto, N. Tétreault, B. Paviet-Salomon, S. J. Moon, C. Allebé, M. Despeisse, S. Nicolay, S. De Wolf, B. Niesen and C. Ballif, ACS Energy Lett., 2016, 1, 474-480.

59 S. Zhu, X. Yao, Q. Ren, C. C. Zheng, S. Li, Y. Tong, B. Shi, S. Guo, L. Fan, H. Ren, C. Wei, B. Li, Y. Ding, Q. Huang, Y. L. Li, Y. Zhao and X. Zhang, Nano Energy, 2018, 45, 280-286.

60 R. Fan, N. Zhou, L. Zhang, R. Yang, Y. Meng, L. Li, T. Guo, Y. Chen, Z. Xu, G. Zheng, Y. Huang, L. Li, L. Qin, X. Qiu, Q. Chen and H. Zhou, Sol. RRL, 2017, 1, 1700149.

61 Z. Qiu, Z. Xu, N. Li, N. Zhou, Y. Chen, X. Wan, J. Liu, N. Li, X. Hao, P. Bi, Q. Chen, B. Cao and H. Zhou, Nano Energy, 2018, 53, 798-807.

62 P. Holzhey, P. Yadav, S. H. Turren-Cruz, A. Ummadisingu, M. Grätzel, A. Hagfeldt and M. Saliba, Mater. Today, 2019, 29, 10-19.

63 K. A. Bush, A. F. Palmstrom, Z. J. Yu, M. Boccard, R. Cheacharoen, J. P. Mailoa, D. P. McMeekin, R. L. Z. Hoye, C. D. Bailie, T. Leijtens, I. M. Peters, M. C. Minichetti, N. Rolston, R. Prasanna, S. Sofia, D. Harwood, W. Ma, F. Moghadam, H. J. Snaith, T. Buonassisi, Z. C. Holman, S. F. Bent and M. D. McGehee, Nat. Energy, 2017, 2, 1-7. K. A. Bush, S. Manzoor, K. Frohna, Z. J. Yu, J. A. Raiford, A. F. Palmstrom, H. P. Wang, R. Prasanna, S. F. Bent, Z. C. Holman and M. D. McGehee, ACS Energy Lett., 2018, 3, 2173-2180.

65 F. Sahli, B. A. Kamino, J. Werner, M. Bräuninger, B. Paviet-salomon, L. Barraud, R. Monnard, J. P. Seif, A. Tomasi, Q. Jeangros, A. Hessler-wyser, S. De Wolf, M. Despeisse, S. Nicolay, B. Niesen and C. Ballif, Adv. Energy Mater., 2018, 8, 1701609. 66 E. Köhnen, M. Jošt, A. B. Morales-Vilches, P. Tockhorn, A. Al-Ashouri, B. Macco, L. Kegelmann, L. Korte, B. Rech, R. Schlatmann, B. Stannowski and S. Albrecht, 
Sustain. Energy Fuels, 2019, 3, 1995-2005.

67 Q. Ren, S. Li, S. Zhu, H. Ren, X. Yao, C. Wei, B. Yan, Y. Zhao and X. Zhang, Sol. Energy Mater. Sol. Cells, 2018, 185, 124-129.

68 L. Mazzarella, Y. H. Lin, S. Kirner, A. B. Morales-Vilches, L. Korte, S. Albrecht, E. Crossland, B. Stannowski, C. Case, H. J. Snaith and R. Schlatmann, Adv. Energy Mater., 2019, 9, 1-9.

69 M. Jošt, E. Köhnen, A. B. Morales-Vilches, B. Lipovšek, K. Jäger, B. Macco, A. A1Ashouri, J. Krč, L. Korte, B. Rech, R. Schlatmann, M. Topič, B. Stannowski and S. Albrecht, Energy Environ. Sci., 2018, 11, 3511-3523.

70 F. Hou, C. Han, O. Isabella, L. Yan, B. Shi, J. Chen, S. An, Z. Zhou, W. Huang, H. Ren, Q. Huang, G. Hou, X. Chen, Y. Li, Y. Ding, G. Wang, C. Wei, D. Zhang, M. Zeman, Y. Zhao and X. Zhang, Nano Energy, 2019, 56, 234-240.

71 S. Zhu, F. Hou, W. Huang, X. Yao, B. Shi, Q. Ren, J. Chen, L. Yan, S. An, Z. Zhou, H. Ren, C. Wei, Q. Huang, Y. Li, G. Hou, X. Chen, Y. Ding, G. Wang, B. Li, Y. Zhao and X. Zhang, Sol. RRL, 2018, 2, 1800176.

72 B. Chen, Z. Yu, K. Liu, X. Zheng, Y. Liu, J. Shi, D. Spronk, P. N. Rudd, Z. Holman and J. Huang, Joule, 2019, 3, 177-190.

73 M. Abdi-Jalebi, Z. Andaji-Garmaroudi, S. Cacovich, C. Stavrakas, B. Philippe, J. M. Richter, M. Alsari, E. P. Booker, E. M. Hutter, A. J. Pearson, S. Lilliu, T. J. Savenije, H. Rensmo, G. Divitini, C. Ducati, R. H. Friend and S. D. Stranks, Nature, 2018, 555, 497-501.

74 D. Kim, D. Kim, H. J. Jung, I. J. Park, B. W. Larson, S. P. Dunfield, C. Xiao, J. Kim, J. Tong, P. Boonmongkolras, S. G. Ji, F. Zhang and S. R. Pae, 2020, 3433, 1-12.

75 T. Feurer, P. Reinhard, E. Avancini, B. Bissig, J. Löckinger, P. Fuchs, R. Carron, T. P. Weiss, J. Perrenoud, S. Stutterheim, S. Buecheler and A. N. Tiwari, Prog.

Photovoltaics Res. Appl., 2017, 25, 645-667.

76 M. A. Green, E. D. Dunlop, J. Hohl-Ebinger, M. Yoshita, N. Kopidakis and A. W. Y. Ho-Baillie, Prog. Photovoltaics Res. Appl., 2020, 28, 3-15.

77 S. Seyrling, S. Calnan, S. Bücheler, J. Hüpkes, S. Wenger, D. Brémaud, H. Zogg and 
A. N. Tiwari, Thin Solid Films, 2009, 517, 2411-2414.

T. Todorov, T. Gershon, O. Gunawan, Y. S. Lee, C. Sturdevant, L.-Y. Chang and S. Guha, Adv. Energy Mater., 2015, 5, 1500799.

79 M. Jošt, T. Bertram, D. Koushik, J. A. Marquez, M. A. Verheijen, M. D. Heinemann, E. Köhnen, A. Al-Ashouri, S. Braunger, F. Lang, B. Rech, T. Unold, M. Creatore, I. Lauermann, C. A. Kaufmann, R. Schlatmann and S. Albrecht, ACS Energy Lett., 2019, 4, 583-590.

80 Q. Han, Y. T. Hsieh, L. Meng, J. L. Wu, P. Sun, E. P. Yao, S. Y. Chang, S. H. Bae, T. Kato, V. Bermudez and Y. Yang, Science, 2018, 361, 904-908.

81 K. A. Bush, C. D. Bailie, Y. Chen, A. R. Bowring, W. Wang, W. Ma, T. Leijtens, F. Moghadam and M. D. McGehee, Adv. Mater., 2016, 28, 3937-3943.

82 F. Fu, S. Nishiwaki, J. Werner, T. Feurer, S. Pisoni, Q. Jeangros, S. Buecheler, C. Ballif and A. N. Tiwari, Flexible perovskite/Cu(In, Ga)Se 2 monolithic tandem solar cells, arXiv.org, 2019, arXiv:1907.10330v1 [physics.app-ph].

83 F. Lang, M. Jošt, K. Frohna, E. Köhnen, A. Al-Ashouri, A. R. Bowman, T. Bertram, A. B. Morales-Vilches, D. Koushik, E. M. Tennyson, K. Galkowski, G. Landi, M. Creatore, B. Stannowski, C. A. Kaufmann, J. Bundesmann, J. Rappich, B. Rech, A. Denker, S. Albrecht, H.-C. Neitzert, N. H. Nickel and S. D. Stranks, Joule, 2020, 4, 116.

84 S. Shrestha, R. Fischer, G. J. Matt, P. Feldner, T. Michel, A. Osvet, I. Levchuk, B. Merle, S. Golkar, H. Chen, S. F. Tedde, O. Schmidt, R. Hock, M. Rührig, M. Göken, W. Heiss, G. Anton and C. J. Brabec, Nat. Photonics, 2017, 11, 436-440.

85 H. Tsai, F. Liu, S. Shrestha, K. Fernando, S. Tretiak, B. Scott, D. T. Vo, J. Strzalka and W. Nie, Sci. Adv., 2020, 6, eaay0815.

86 F. Lang, M. Jošt, J. Bundesmann, A. Denker, S. Albrecht, G. Landi, H. C. Neitzert, J. Rappich and N. H. Nickel, Energy Environ. Sci., 2019, 12, 1634-1647.

87 J. H. Heo and S. H. Im, Adv. Mater., 2016, 28, 5121-5125.

88 F. Jiang, T. Liu, B. Luo, J. Tong, F. Qin, S. Xiong, Z. Li and Y. Zhou, J. Mater. Chem. A, 2016, 4, 1208-1213. 
Ballif, M. Sessolo and H. J. Bolink, Adv. Energy Mater., 2017, 7, 1602121.

90 G. E. Eperon, T. Leijtens, K. A. Bush, R. Prasanna, T. Green, J. T. W. Wang, D. P. McMeekin, G. Volonakis, R. L. Milot, R. May, A. Palmstrom, D. J. Slotcavage, R. A. Belisle, J. B. Patel, E. S. Parrott, R. J. Sutton, W. Ma, F. Moghadam, B. Conings, A. Babayigit, H. G. Boyen, S. Bent, F. Giustino, L. M. Herz, M. B. Johnston, M. D. McGehee and H. J. Snaith, Science, 2016, 354, 861-865.

91 T. Leijtens, R. Prasanna, K. A. Bush, G. E. Eperon, J. A. Raiford, A. Gold-Parker, E. J. Wolf, S. A. Swifter, C. C. Boyd, H. P. Wang, M. F. Toney, S. F. Bent and M. D. McGehee, Sustain. Energy Fuels, 2018, 2, 2450-2459.

92 A. Rajagopal, Z. Yang, S. B. Jo, I. L. Braly, P. W. Liang, H. W. Hillhouse and A. K. Y. Jen, Adv. Mater., 2017, 29, 1702140.

93 D. Zhao, C. Chen, C. Wang, M. M. Junda, Z. Song, C. R. Grice, Y. Yu, C. Li, B. Subedi, N. J. Podraza, X. Zhao, G. Fang, R. G. Xiong, K. Zhu and Y. Yan, Nat. Energy, 2018, 3, 1093-1100.

94 J. Tong, Z. Song, D. H. Kim, X. Chen, C. Chen, A. F. Palmstrom, P. F. Ndione, M. O. Reese, S. P. Dunfield, O. G. Reid, J. Liu, F. Zhang, S. P. Harvey, Z. Li, S. T. Christensen, G. Teeter, D. Zhao, M. M. Al-Jassim, M. F. A. M. Van Hest, M. C. Beard, S. E. Shaheen, J. J. Berry, Y. Yan and K. Zhu, Science, 2019, 364, 475-479.

95 A. F. Palmstrom, G. E. Eperon, T. Leijtens, R. Prasanna, S. N. Habisreutinger, W. Nemeth, E. A. Gaulding, S. P. Dunfield, M. Reese, S. Nanayakkara, T. Moot, J. Werner, J. Liu, B. To, S. T. Christensen, M. D. McGehee, M. F. A. M. van Hest, J. M. Luther, J. J. Berry and D. T. Moore, Joule, 2019, 3, 2193-2204.

96 D. P. McMeekin, S. Mahesh, N. K. Noel, M. T. Klug, J. C. Lim, J. H. Warby, J. M. Ball, L. M. Herz, M. B. Johnston and H. J. Snaith, Joule, 2019, 3, 387-401.

97 J. Ávila, C. Momblona, P. Boix, M. Sessolo, M. Anaya, G. Lozano, K. Vandewal, H. Míguez and H. J. Bolink, Energy Environ. Sci., 2018, 11, 3292-3297.

98 C. Li, Z. S. Wang, H. L. Zhu, D. Zhang, J. Cheng, H. Lin, D. Ouyang and W. C. H. Choy, Adv. Energy Mater., 2018, 8, 1801954.

99 C. Y. Chang, B. C. Tsai, Y. C. Hsiao, M. Z. Lin and H. F. Meng, Nano Energy, 2019, 
$\mathbf{5 5}, 354-367$.

100 D. Veldman, S. C. J. Meskers and R. A. J. Janssen, Adv. Funct. Mater., 2009, 19, 1939-1948.

101 D. Baran, T. Kirchartz, S. Wheeler, S. Dimitrov, M. Abdelsamie, J. Gorman, R. S. Ashraf, S. Holliday, A. Wadsworth, N. Gasparini, P. Kaienburg, H. Yan, A. Amassian, C. J. Brabec, J. R. Durrant and I. McCulloch, Energy Environ. Sci., 2016, 9, 37833793.

102 N. Gasparini, S. H. K. Paleti, J. Bertrandie, G. Cai, G. Zhang, A. Wadsworth, xinhui lu, H.-L. Yip, I. McCulloch and D. Baran, ACS Energy Lett., , DOI:10.1021/acsenergylett.0c00604.

103 C. Duan, K. Gao, F. J. M. Colberts, F. Liu, S. C. J. Meskers, M. M. Wienk and R. A. J. Janssen, Adv. Energy Mater., 2017, 7, 1700519.

104 T. Liu, Z. Luo, Y. Chen, T. Yang, Y. Xiao, G. Zhang, R. Ma, X. Lu, C. Zhan, M. Zhang, C. Yang, Y. Li, J. Yao and H. Yan, Energy Environ. Sci., 2019, 12, 25292536.

105 K. Gao, Z. Zhu, B. Xu, S. B. Jo, Y. Kan, X. Peng and A. K. Y. Jen, Adv. Mater., 2017, 29, 1703980.

106 K. Gao, L. Xiao, Y. Kan, B. Yang, J. Peng, Y. Cao, F. Liu, T. P. Russell and X. Peng, J. Mater. Chem. C, 2016, 4, 3843-3850.

107 L. Zhu, M. Zhang, G. Zhou, T. Hao, J. Xu, J. Wang, C. Qiu, N. Prine, J. Ali, W. Feng, X. Gu, Z. Ma, Z. Tang, H. Zhu, L. Ying, Y. Zhang and F. Liu, Adv. Energy Mater., 2020, 1904234.

108 L. Liu, Y. Kan, K. Gao, J. Wang, M. Zhao, H. Chen, C. Zhao, T. Jiu, A. -Y. Jen and Y. Li, Adv. Mater., 2020, 32, 1907604.

109 C. C. Chen, S. H. Bae, W. H. Chang, Z. Hong, G. Li, Q. Chen, H. Zhou and Y. Yang, Mater. Horizons, 2015, 2, 203-211.

110 N. Y. Doumon, G. Wang, X. Qiu, A. J. Minnaard, R. C. Chiechi and L. J. A. Koster, Sci. Rep., 2019, 9, 1-14.

111 J. Y. Kim, K. Lee, N. E. Coates, D. Moses, T. Q. Nguyen, M. Dante and A. J. Heeger, 
Science (80-. )., 2007, 317, 222-225.

112 J. Liu, S. Lu, L. Zhu, X. Li and W. C. H. Choy, Nanoscale, 2016, 8, 3638-3646.

113 Y. Liu, L. A. Renna, M. Bag, Z. A. Page, P. Kim, J. Choi, T. Emrick, D. Venkataraman and T. P. Russell, ACS Appl. Mater. Interfaces, 2016, 8, 7070-7076.

114 W. Zhang, M. Saliba, D. T. Moore, S. K. Pathak, M. T. Hörantner, T. Stergiopoulos, S. D. Stranks, G. E. Eperon, J. A. Alexander-Webber, A. Abate, A. Sadhanala, S. Yao, Y. Chen, R. H. Friend, L. A. Estroff, U. Wiesner and H. J. Snaith, Nat. Commun., 2015, 6, $1-10$.

115 Q. Zeng, L. Liu, Z. Xiao, F. Liu, Y. Hua, Y. Yuan and L. Ding, Sci. Bull., 2019, 64, $885-887$.

116 J. Zhang, Z. Wang, A. Mishra, M. Yu, M. Shasti, W. Tress, D. J. Kubicki, C. E. Avalos, H. Lu, Y. Liu, B. I. Carlsen, A. Agarwalla, Z. Wang, W. Xiang, L. Emsley, Z. Zhang, M. Grätzel, W. Guo and A. Hagfeldt, Joule, 2020, 4, 222-234.

117 Y. Zheng, X. Yang, R. Su, P. Wu, Q. Gong and R. Zhu, Adv. Funct. Mater., 2020, 2000457.

118 Y. Liu, Z. Hong, Q. Chen, W. Chang, H. Zhou, T. Bin Song, E. Young, Y. Yang, J. You, G. Li and Y. Yang, Nano Lett., 2015, 15, 662-668.

119 Y. Sun, G. C. Welch, W. L. Leong, C. J. Takacs, G. C. Bazan and A. J. Heeger, Nat. Mater., 2012, 11, 44-48.

120 K. Gao, J. Miao, L. Xiao, W. Deng, Y. Kan, T. Liang, C. Wang, F. Huang, J. Peng, Y. Cao, F. Liu, T. P. Russell, H. Wu and X. Peng, Adv. Mater., 2016, 28, 4727-4733.

121 J. Kim, G. Kim, H. Back, J. Kong, I. W. Hwang, T. K. Kim, S. Kwon, J. H. Lee, J. Lee, K. Yu, C. L. Lee, H. Kang and K. Lee, Adv. Mater., 2016, 28, 3159-3165.

122 M. Cheng, C. Chen, K. Aitola, F. Zhang, Y. Hua, G. Boschloo, L. Kloo and L. Sun, Chem. Mater., 2016, 28, 8631-8639.

123 Q. Guo, H. Liu, Z. Shi, F. Wang, E. Zhou, X. Bian, B. Zhang, A. Alsaedi, T. Hayat and Z. Tan, Nanoscale, 2018, 10, 3245-3253.

124 W. Chen, H. Sun, Q. Hu, A. B. Djurišić, T. P. Russell, X. Guo and Z. He, ACS Energy Lett., 2019, 4, 2535-2536. 
125 A. Karani, L. Yang, S. Bai, M. H. Futscher, H. J. Snaith, B. Ehrler, N. C. Greenham and D. Di, ACS Energy Lett., 2018, 3, 869-874.

126 E. M. Sanehira, A. R. Marshall, J. A. Christians, S. P. Harvey, P. N. Ciesielski, L. M. Wheeler, P. Schulz, L. Y. Lin, M. C. Beard and J. M. Luther, Sci. Adv., 2017, 3, eaao4204.

127 M. Hao, Y. Bai, S. Zeiske, L. Ren, J. Liu, Y. Yuan, N. Zarrabi, N. Cheng, M.

Ghasemi, P. Chen, M. Lyu, D. He, J. H. Yun, Y. Du, Y. Wang, S. Ding, A. Armin, P. Meredith, G. Liu, H. M. Cheng and L. Wang, Nat. Energy, 2020, 5, 79-88.

128 A. Swarnkar, A. R. Marshall, E. M. Sanehira, B. D. Chernomordik, D. T. Moore, J. A. Christians, T. Chakrabarti and J. M. Luther, Science, 2016, 354, 92-95.

129 J. A. Christians, A. R. Marshall, Q. Zhao, P. Ndione, E. M. Sanehira and J. M. Luther, in 2018 IEEE 7th World Conference on Photovoltaic Energy Conversion, WCPEC 2018 - A Joint Conference of 45th IEEE PVSC, 28th PVSEC and 34th EU PVSEC, Institute of Electrical and Electronics Engineers Inc., 2018, pp. 81-84.

130 S. Lilliu, T. Agostinelli, E. Pires, M. Hampton, J. Nelson and J. E. MacDonald, Macromolecules, 2011, 44, 2725-2734.

131 Z. Liu, L. Krückemeier, B. Krogmeier, B. Klingebiel, J. A. Márquez, S. Levcenko, S. Öz, S. Mathur, U. Rau, T. Unold and T. Kirchartz, ACS Energy Lett., 2019, 4, 110 117.

132 H. M. Cronin, K. D. G. I. Jayawardena, Z. Stoeva, M. Shkunov and S. R. P. Silva, Nanotechnology, 2017, 28, 114004.

133 M. Xiao, F. Huang, W. Huang, Y. Dkhissi, Y. Zhu, J. Etheridge, A. Gray-Weale, U. Bach, Y. B. Cheng and L. Spiccia, Angew. Chemie - Int. Ed., 2014, 53, 9898-9903.

134 T. Bu, X. Liu, J. Li, W. Huang, Z. Wu, F. Huang, Y.-B. Cheng and J. Zhong, Sol. RRL, 2019, 4, 1900263.

135 Y. Galagan, F. Di Giacomo, H. Gorter, G. Kirchner, I. de Vries, R. Andriessen and P. Groen, Adv. Energy Mater., 2018, 8, 1801935.

136 M. Yang, Z. Li, M. O. Reese, O. G. Reid, D. H. Kim, S. Siol, T. R. Klein, Y. Yan, J. J. Berry, M. F. A. M. Van Hest and K. Zhu, Nat. Energy, 2017, 2, 1-9. 
137 W. Nie, H. Tsai, R. Asadpour, J. C. Blancon, A. J. Neukirch, G. Gupta, J. J. Crochet, M. Chhowalla, S. Tretiak, M. A. Alam, H. L. Wang and A. D. Mohite, Science, 2015, 347, 522-525.

138 H. Tsai, W. Nie, J. C. Blancon, C. C. Stoumpos, R. Asadpour, B. Harutyunyan, A. J. Neukirch, R. Verduzco, J. J. Crochet, S. Tretiak, L. Pedesseau, J. Even, M. A. Alam, G. Gupta, J. Lou, P. M. Ajayan, M. J. Bedzyk, M. G. Kanatzidis and A. D. Mohite, Nature, 2016, 536, 312-317.

139 Y. Deng, X. Zheng, Y. Bai, Q. Wang, J. Zhao and J. Huang, Nat. Energy, 2018, 3, $560-566$.

140 A. Babayigit, J. D’Haen, H. G. Boyen and B. Conings, Joule, 2018, 2, 1205-1209.

141 G. Cotella, J. Baker, D. Worsley, F. De Rossi, C. Pleydell-Pearce, M. Carnie and T. Watson, Sol. Energy Mater. Sol. Cells, 2017, 159, 362-369.

142 J. E. Bishop, D. K. Mohamad, M. Wong-Stringer, A. Smith and D. G. Lidzey, Sci. Rep., 2017, 7, 1-11.

143 Y. Galagan, J. Phys. Chem. Lett., 2018, 9, 4326-4335.

144 N.-G. Park and K. Zhu, Nat. Rev. Mater., 2020, 1-18.

145 D. H. Kim, J. B. Whitaker, Z. Li, M. F. A. M. van Hest and K. Zhu, Joule, 2018, 2, 1437-1451.

146 S. K. Karunakaran, G. M. Arumugam, W. Yang, S. Ge, S. N. Khan, X. Lin and G. Yang, J. Mater. Chem. A, 2019, 7, 13873-13902.

147 F. Mathies, E. J. W. List-Kratochvil and E. L. Unger, Energy Technol., 2019, 1900991.

148 B. S. S. Pokuri, J. Sit, O. Wodo, D. Baran, T. Ameri, C. J. Brabec, A. J. Moule and B. Ganapathysubramanian, Adv. Energy Mater., 2017, 7, 1701269.

149 K. Zhang, Z. Chen, A. Armin, S. Dong, R. Xia, H.-L. Yip, S. Shoaee, F. Huang and Y. Cao, Sol. RRL, 2018, 2, 1700169.

150 H. Wu, C. Zhang, K. Ding, L. Wang, Y. Gao and J. Yang, Org. Electron., 2017, 45, 302-307.

151 Y. Peng, Y. Cheng, C. Wang, C. Zhang, H. Xia, K. Huang, S. Tong, X. Hao and J. 
Yang, Org. Electron., 2018, 58, 153-158.

152 Y. Zhong, R. Munir, J. Li, M.-C. Tang, M. R. Niazi, D.-M. Smilgies, K. Zhao and A. Amassian, ACS Energy Lett., 2018, 3, 1078-1085.

153 J. Li, R. Munir, Y. Fan, T. Niu, Y. Liu, Y. Zhong, Z. Yang, Y. Tian, B. Liu, J. Sun, D. M. Smilgies, S. Thoroddsen, A. Amassian, K. Zhao and S. (Frank) Liu, Joule, 2018, 2, $1313-1330$.

154 M. He, B. Li, X. Cui, B. Jiang, Y. He, Y. Chen, D. O’Neil, P. Szymanski, M. A. EiSayed, J. Huang and Z. Lin, Nat. Commun., 2017, 8, 1-10.

155 Z. Yang, C. C. Chueh, F. Zuo, J. H. Kim, P. W. Liang and A. K. Y. Jen, Adv. Energy Mater., 2015, 5, 1500328.

156 J. B. Whitaker, D. H. Kim, B. W. Larson, F. Zhang, J. J. Berry, M. F. A. M. Van Hest and K. Zhu, Sustain. Energy Fuels, 2018, 2, 2442-2449.

157 D. I. Kutsarov, E. New, F. Bausi, A. Zoladek-Lemanczyk, F. A. Castro and S. R. P. Silva, Sol. Energy Mater. Sol. Cells, 2017, 161, 388-396.

158 M. Helgesen, J. E. Carlé and F. C. Krebs, Adv. Energy Mater., 2013, 3, 1664-1669.

159 A. Sandstrom, H. F. Dam, F. C. Krebs and L. Edman, Nat. Commun., 2012, 3, 1-5.

160 T. Qin, W. Huang, J. E. Kim, D. Vak, C. Forsyth, C. R. McNeill and Y. B. Cheng, Nano Energy, 2017, 31, 210-217.

161 J. Ciro, M. A. Mejía-Escobar and F. Jaramillo, Sol. Energy, 2017, 150, 570-576.

162 F. Di Giacomo, S. Shanmugam, H. Fledderus, B. J. Bruijnaers, W. J. H. Verhees, M. S. Dorenkamper, S. C. Veenstra, W. Qiu, R. Gehlhaar, T. Merckx, T. Aernouts, R. Andriessen and Y. Galagan, Sol. Energy Mater. Sol. Cells, 2018, 181, 53-59.

163 D. Lee, Y.-S. Jung, Y.-J. Heo, S. Lee, K. Hwang, Y.-J. Jeon, J.-E. Kim, J. Park, G. Y. Jung and D.-Y. Kim, ACS Appl. Mater. Interfaces, 2018, 10, 16133-16139.

164 J. E. Kim, Y. S. Jung, Y. J. Heo, K. Hwang, T. Qin, D. Y. Kim and D. Vak, Sol. Energy Mater. Sol. Cells, 2018, 179, 80-86.

165 J. E. Bishop, T. J. Routledge and D. G. Lidzey, J. Phys. Chem. Lett., 2018, 9, 19771984. 
166 J. E. Bishop, J. A. Smith, C. Greenland, V. Kumar, N. Vaenas, O. S. Game, T. J. Routledge, M. Wong-Stringer, C. Rodenburg and D. G. Lidzey, ACS Appl. Mater. Interfaces, 2018, 10, 39428-39434.

167 J. Su, H. Cai, J. Yang, X. Ye, R. Han, J. Ni, J. Li and J. Zhang, ACS Appl. Mater. Interfaces, , DOI:10.1021/acsami.9b17141.

168 D. K. Mohamad, J. Griffin, C. Bracher, A. T. Barrows and D. G. Lidzey, Adv. Energy Mater., 2016, 6, 1600994.

169 A. T. Barrows, A. J. Pearson, C. K. Kwak, A. D. F. Dunbar, A. R. Buckley and D. G. Lidzey, Energy Environ. Sci., 2014, 7, 2944-2950.

170 S. Das, B. Yang, G. Gu, P. C. Joshi, I. N. Ivanov, C. M. Rouleau, T. Aytug, D. B. Geohegan and K. Xiao, ACS Photonics, 2015, 2, 680-686.

171 J. H. Heo, M. H. Lee, M. H. Jang and S. H. Im, J. Mater. Chem. A, 2016, 4, 1763617642.

172 D. H. Lan, S. H. Hong, L. H. Chou, X. F. Wang and C. L. Liu, J. Power Sources, 2018, 390, 270-277.

173 H. Huang, J. Shi, L. Zhu, D. Li, Y. Luo and Q. Meng, Nano Energy, 2016, 27, 352358.

174 C. F. J. Lau, X. Deng, Q. Ma, J. Zheng, J. S. Yun, M. A. Green, S. Huang and A. W. Y. Ho-Baillie, ACS Energy Lett., 2016, 1, 573-577.

175 J. G. Tait, S. Manghooli, W. Qiu, L. Rakocevic, L. Kootstra, M. Jaysankar, C. A. Masse De La Huerta, U. W. Paetzold, R. Gehlhaar, D. Cheyns, P. Heremans and J. Poortmans, J. Mater. Chem. A, 2016, 4, 3792-3797.

176 Y. S. Chou, L. H. Chou, A. Z. Guo, X. F. Wang, I. Osaka, C. G. Wu and C. L. Liu, ACS Sustain. Chem. Eng., 2019, 7, 14217-14224.

177 M. Saliba, Adv. Energy Mater., 2019, 9, 1803754.

178 J. Li, B. Pradhan, S. Gaur and J. Thomas, Adv. Energy Mater., 2019, 9, 1901891.

179 J. Su, H. Cai, X. Ye, X. Zhou, J. Yang, D. Wang, J. Ni, J. Li and J. Zhang, ACS Appl. Mater. Interfaces, 2019, 11, 10689-10696. 
180 First building-integrated deployment shows perovskite solar's growing maturity | News | Chemistry World, https://www.chemistryworld.com/news/first-buildingintegrated-deployment-shows-perovskite-solars-growing-maturity/3009953.article, (accessed 22 February 2020).

181 Perovskite Solar Panel Tested On Skanska Building In Warsaw | CleanTechnica, https://cleantechnica.com/2019/01/08/perovskite-solar-panel-tested-on-sanskabuilding-in-warsaw/, (accessed 19 February 2020).

182 S. G. Li, K. J. Jiang, M. J. Su, X. P. Cui, J. H. Huang, Q. Q. Zhang, X. Q. Zhou, L. M. Yang and Y. L. Song, J. Mater. Chem. A, 2015, 3, 9092-9097.

183 F. Mathies, T. Abzieher, A. Hochstuhl, K. Glaser, A. Colsmann, U. W. Paetzold, G. Hernandez-Sosa, U. Lemmer and A. Quintilla, J. Mater. Chem. A, 2016, 4, 1920719213.

184 F. Mathies, H. Eggers, B. S. Richards, G. Hernandez-Sosa, U. Lemmer and U. W. Paetzold, ACS Appl. Energy Mater., 2018, 1, 1834-1839.

185 C. Liang, P. Li, H. Gu, Y. Zhang, F. Li, Y. Song, G. Shao, N. Mathews and G. Xing, Sol. RRL, 2018, 2, 1700217.

186 A. Gheno, Y. Huang, J. Bouclé, B. Ratier, A. Rolland, J. Even and S. Vedraine, Sol. $R R L, 2018,2,1800191$.

187 S. G. Hashmi, D. Martineau, X. Li, M. Ozkan, A. Tiihonen, M. I. Dar, T. Sarikka, S. M. Zakeeruddin, J. Paltakari, P. D. Lund and M. Grätzel, Adv. Mater. Technol., 2017, 2, 1600183.

188 D. P. McMeekin, Z. Wang, W. Rehman, F. Pulvirenti, J. B. Patel, N. K. Noel, M. B. Johnston, S. R. Marder, L. M. Herz and H. J. Snaith, Adv. Mater., 2017, 29, 1607039.

189 A. J. Huckaba, Y. Lee, R. Xia, S. Paek, V. C. Bassetto, E. Oveisi, A. Lesch, S. Kinge, P. J. Dyson, H. Girault and M. K. Nazeeruddin, Energy Technol., 2019, 7, 317-324.

190 G. Grancini, C. Roldán-Carmona, I. Zimmermann, E. Mosconi, X. Lee, D. Martineau, S. Narbey, F. Oswald, F. De Angelis, M. Graetzel and M. K. Nazeeruddin, Nat. Commun., 2017, 8, 1-8.

191 S. G. Hashmi, A. Tiihonen, D. Martineau, M. Ozkan, P. Vivo, K. Kaunisto, V. Ulla, S. 
M. Zakeeruddin and M. Grätzel, J. Mater. Chem. A, 2017, 5, 4797-4802.

192 S. Schlisske, F. Mathies, D. Busko, N. Strobel, T. Rödlmeier, B. S. Richards, U. Lemmer, U. W. Paetzold, G. Hernandez-Sosa and E. Klampaftis, ACS Appl. Energy Mater., 2019, 2, 764-769.

193 M. Bag, Z. Jiang, L. A. Renna, S. P. Jeong, V. M. Rotello and D. Venkataraman, Mater. Lett., 2016, 164, 472-475.

194 Japan's NEDO and Panasonic Achieve the World's Highest Conversion Efficiency of 16.09\% for Largest-area Perovskite Solar Cell Module | Headquarters News | Panasonic Newsroom Global, https://news.panasonic.com/global/press/data/2020/02/en200207-2/en200207-2.html, (accessed 1 March 2020).

195 S. Gupta, D. Cahen and G. Hodes, J. Phys. Chem. C, 2018, 122, 13926-13936.

196 MSDS - 227056, https://www.sigmaaldrich.com/MSDS/MSDS/DisplayMSDSPage.do?country=GB\&la nguage $=$ en $\&$ productNumber $=227056 \&$ brand $=$ SIAL\&PageToGoToURL $=$ https $\% 3 \mathrm{~A} \%$ 2F\%2Fwww.sigmaaldrich.com\%2Fcatalog\%2Fproduct\%2Fsial\%2F227056\%3Flang\% 3Den, (accessed 22 February 2020).

197 C. McDowell and G. C. Bazan, Curr. Opin. Green Sustain. Chem., 2017, 5, 49-54.

198 J. Zhao, Y. Li, G. Yang, K. Jiang, H. Lin, H. Ade, W. Ma and H. Yan, Nat. Energy, $2016,1,1-7$.

199 K. L. Gardner, J. G. Tait, T. Merckx, W. Qiu, U. W. Paetzold, L. Kootstra, M. Jaysankar, R. Gehlhaar, D. Cheyns, P. Heremans and J. Poortmans, Adv. Energy Mater., 2016, 6, 1600386.

200 N. K. Noel, S. N. Habisreutinger, B. Wenger, M. T. Klug, M. T. Hörantner, M. B. Johnston, R. J. Nicholas, D. T. Moore and H. J. Snaith, Energy Environ. Sci., 2017, 10, $145-152$.

201 D. Burkitt, R. Swartwout, J. McGettrick, P. Greenwood, D. Beynon, R. Brenes, V. Bulović and T. Watson, RSC Adv., 2019, 9, 37415-37423.

202 Z. Wang, Q. Lin, B. Wenger, M. G. Christoforo, Y. H. Lin, M. T. Klug, M. B. 
Johnston, L. M. Herz and H. J. Snaith, Nat. Energy, 2018, 3, 855-861.

203 R. M. I. Bandara, K. D. G. I. Jayawardena, S. O. Adeyemo, S. J. Hinder, J. A. Smith, H. M. Thirimanne, N. C. Wong, F. M. Amin, B. G. Freestone, A. J. Parnell, D. G. Lidzey, H. J. Joyce, R. A. Sporea and S. R. P. Silva, J. Mater. Chem. C, 2019, 7, 8389-8397. 